UNIVERSIDADE DE SÃO PAULO

ESCOLA DE EDUCAÇÃO FÍSICA E ESPORTE

AUMENTO DE COMPLEXIDADE NA APRENDIZAGEM MOTORA: EFEITOS DOS NÍVEIS DE ESTABILIZAÇÃO E DOS CANAIS DE DESEMPENHO

Luciano Basso

SÃO PAULO

2010 


\title{
AUMENTO DE COMPLEXIDADE NA APRENDIZAGEM MOTORA: EFEITOS DOS NÍVEIS DE ESTABILIZAÇÃO E DOS CANAIS DE DESEMPENHO
}

\author{
LUCIANO BASSO
}

Tese apresentada à Escola de Educação Física e Esporte da Universidade de São Paulo como requisito parcial para a obtenção do título de Doutor em Educação Física.

ORIENTADOR: Prof. Dr. GO TANI 


\section{AGRADECIMENTOS}

Ao meu orientador, Prof. Dr. Go Tani, por toda a dedicação e amizade e desafios cada vez mais complexos que me apresentou durante esses anos.

Ao meu orientador no exterior, Prof. Dr. José António Ribeiro Maia, por me permitir conhecer e viver os seus sonhos, pelo exemplo de pesquisador e ser humano. Por toda escrita azul a me disciplinar o pensamento.

Ao diretor da Faculdade de Desporto da Universidade do Porto, Prof. Dr. Jorge Olímpio Bento, pelo pronto auxílio.

Ao meu querido amigo e Prof. Dr. Antonio Prista, pelas palavras firmes nos momentos de dúvida, pelo exemplo de pensar e fazer, pela alegria com a nossa música brasileira.

Aos membros do Laboratório de Comportamento Motor, pelos embates e discussões, em especial: Andy, Suely, Umberto, Jorge, Cleverton, Flávio, Cinthya, Jaqueline, Serginho, Maria Teresa, Bruzi, Ulysses, Lúcio, Meico, Renata e Matheus.

À Profa. Dra. Maria Tereza Cattuzzo, pela amizade e auxilio na construção do equipamento, por meio do projeto PQI.

À Jane e Francisco por todo o carinho e acolhimento em Minas Gerais.

Aos amigos do Laboratório de Cineantropometria e Estatística Aplicada da Faculdade de Desporto da Universidade do Porto, Prof. Dr. André Seabra, Prof. Dr. Rui Garganta, Ramon, Rojapon, Diana, Renata, Israel, Sónia e Alcebíades.

Aos novos amigos Eugene Maguin e Art Kendall por toda atenção e suporte no mundo Python e SPSS.

Aos professores do Projeto Esporte Talento CEPEUSP.

Às diretorias do Colégio Lyceu Anglo de Muzambinho-MG, do Colégio Anglo de Pouso Alegre-MG, da Escola Estadual Presidente Arthur da Costa e Silva-MG e do Colégio Estadual João Sampaio-PR.

À Universidade de São Paulo, pela oportunidade.

À Universidade do Porto pela agradável receptividade à "moda portuguesa". 
À CAPES, pelo financiamento do estágio no exterior.

À todas crianças que participaram da pesquisa.

Aos funcionários da Escola de Educação Física e Esporte da USP, por fazer a escola viver com tanto carinho.

À Lynx Tecnologia Eletrônica Ltda, pelo desenvolvimento do equipamento, em especial ao Jaime Ono, pela sua competência.

À Inara, Chico, Caio e Pedro, por serem meu porto seguro, onde tudo começou e gosto de sempre de estar.

Aos padrinhos portugueses de Coimbra Manuel e Isabel, pelo carinho e espírito de vida.

À minha família, Sebastião, Vera, Fernando, Camila e Karina que apesar da distância, nunca deixaram de acompanhar as minhas conquistas e angústias.

À minha mais nova família, José Roberto, Maria de Loudes, Marcos, Nilva, Marcel e Karina.

À minha querida esposa, Micaela, por todo amor e vida.

À Deus.

A todos, muito obrigado! 


\section{SUMÁRIO}

Página

LISTA DE TABELAS ....................................................................iii

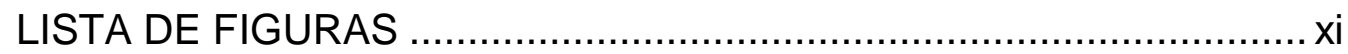

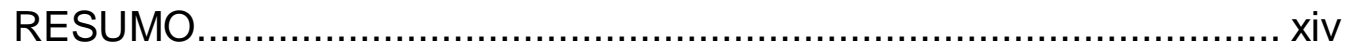

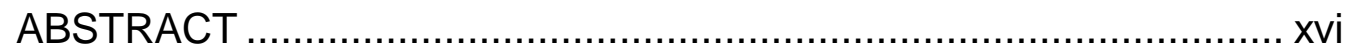

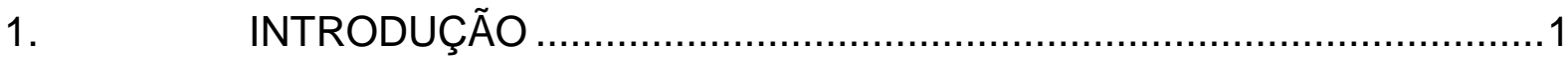

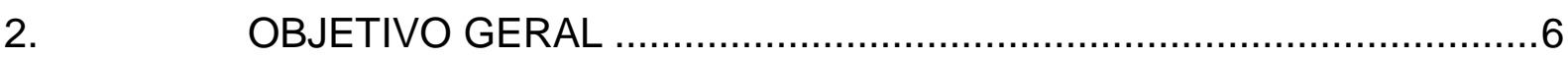

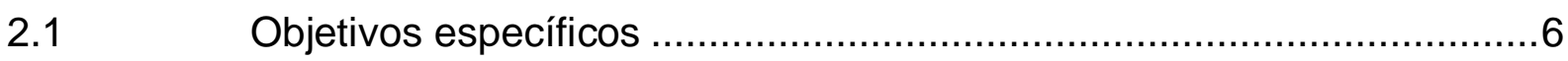

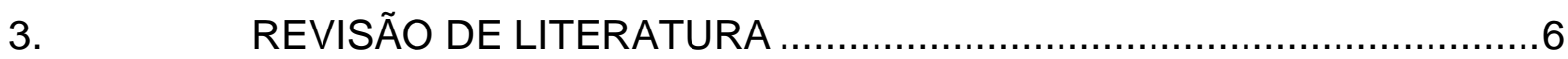

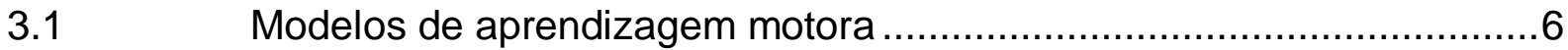

3.1.1 Aquisição de habilidades motoras orientada ao processo adaptativo ....9

3.1.2 Aumento de complexidade entre habilidades via modularização .........14

3.1.3 Notas sobre o processo de modularização integrado ao processo

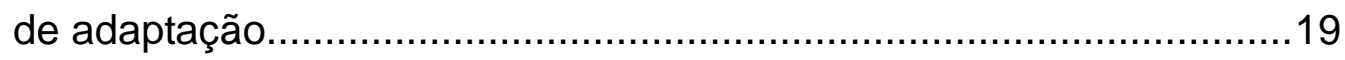

3.2 O estudo da estabilidade ao longo do tempo ....................................23

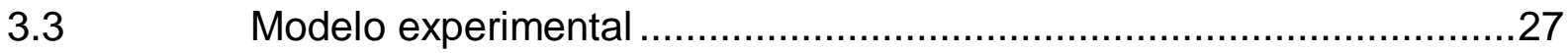

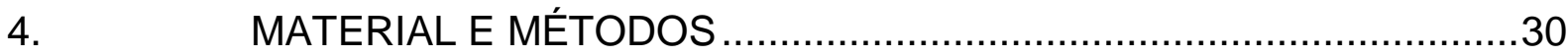

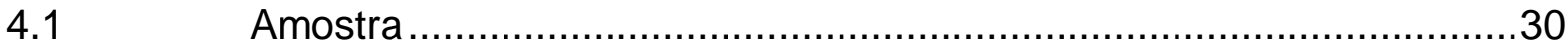

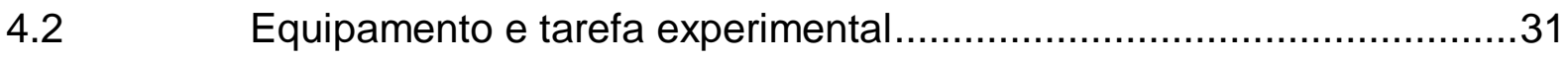

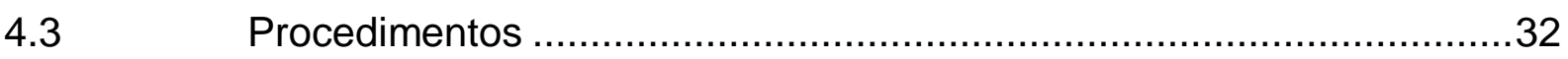

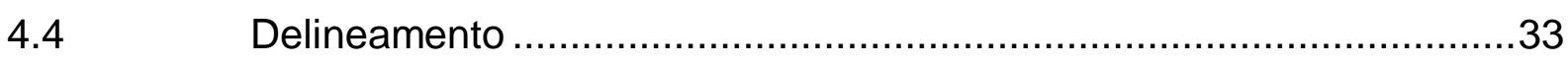

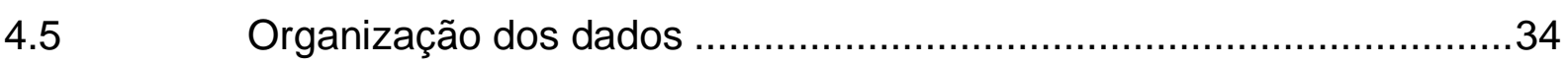

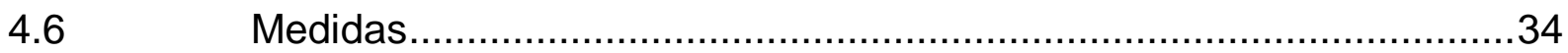

4.6.1 Proporção de ocorrência de cada tipo de resposta ...............................35

4.6.2 Desempenho Coletivo Máximo (DCM) ............................................36

4.6.3 Consistência do desempenho dos componentes (CDC) e da

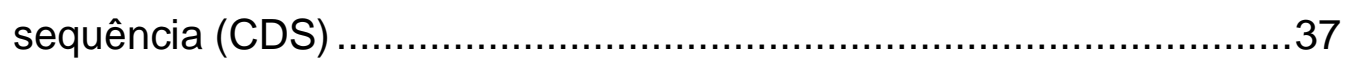

4.6.4 Tempo entre o estímulo e a resposta ..............................................38 
4.6.5 Quantidade de tentativas para o alcance dos critérios nas fases de

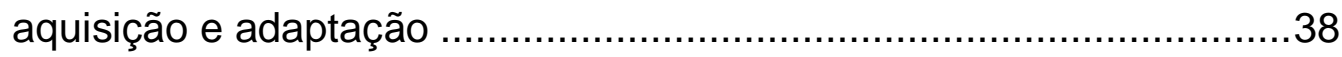

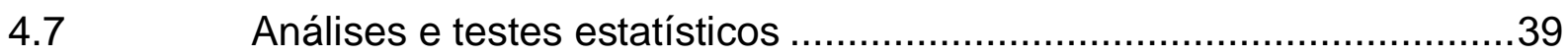

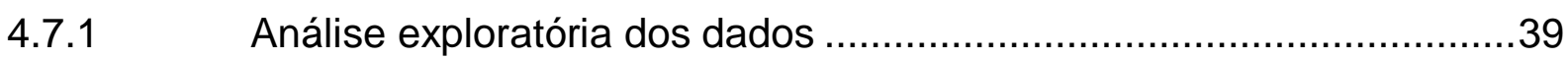

4.7.2 Análise relativa às questões da mudança normativa ...........................39

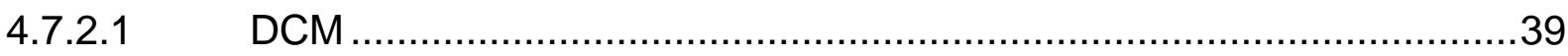

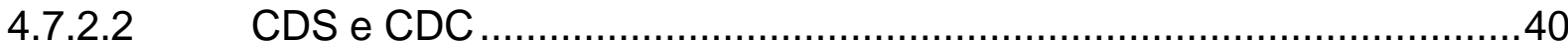

4.7.3 Análise da estabilidade interindividual na mudança intra-individual .....40

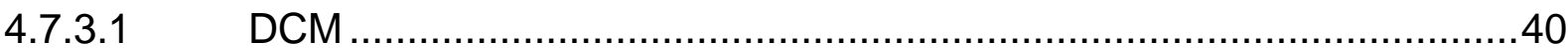

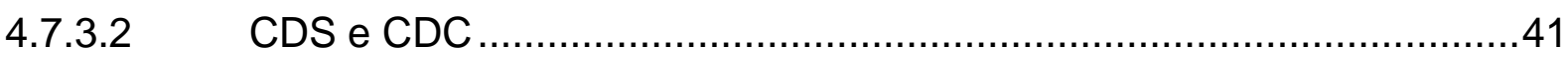

4.7.4 Análise da associação entre os níveis de estabilidade e comportamentos modais individuais e a formação de subgrupos .........42

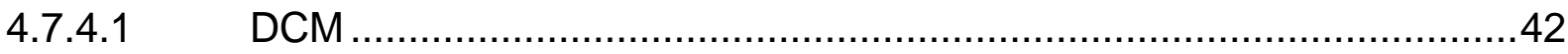

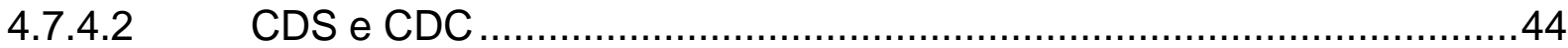

4.7.4.3 Formação dos subgrupos com comportamentos opostos para o DCM, a CDS e a CDC

4.7.5 Análise da manutenção da estrutura das respostas antecipatórias

na tarefa mais complexa

4.7.6 Tempo entre o estímulo e a resposta dos sujeitos que mantiveram a estrutura de respostas antecipatórias na fase de adaptação 46

4.7.7 Análise do efeito do nível de estabilização na probabilidade de ocorrência dos processos de modularização e adaptação .46

4.7.8 Análise da quantidade de tentativas para o alcance dos critérios na fase de aquisição e adaptação: efeito do nível de estabilização e processos envolvidos no aumento de complexidade da habilidade motora .50

4.7.9 Análise do tipo de resposta logo após a inserção do novo componente. .50

5.

RESULTADOS .51

5.1

Análise exploratória dos dados .51

5.2 Análise normativa .56 
5.2.2 Análise da mudança individual do DCM entre blocos adjacentes ........59

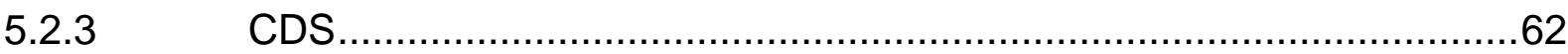

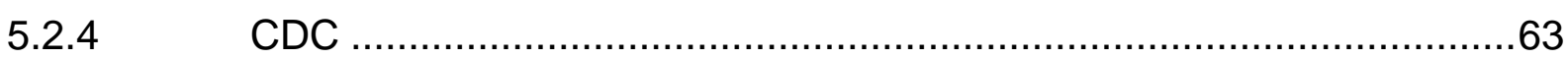

5.5 Análise da estabilidade interindividual na mudança intraindividual ......65

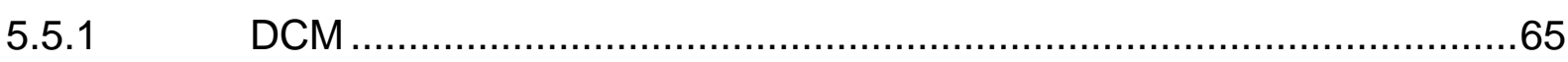

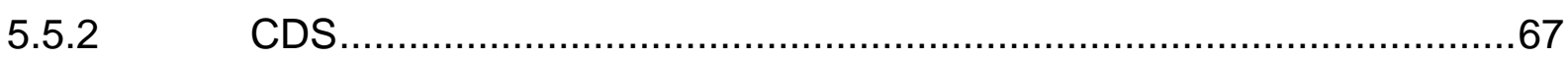

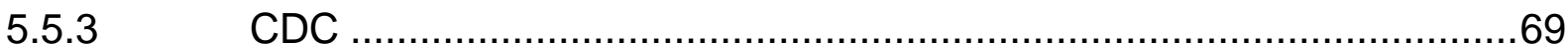

5.6 Análise da associação entre os níveis de estabilidade, comportamentos modais individuais e formação de subgrupos..........71

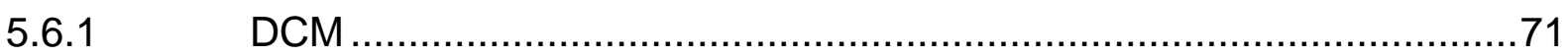

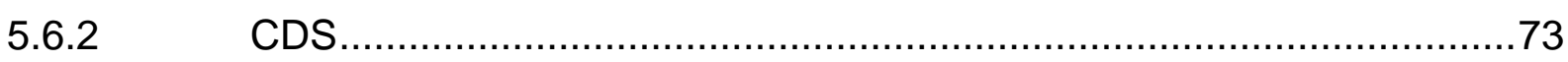

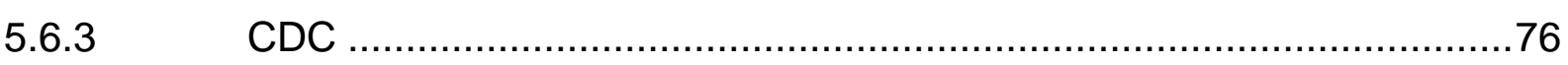

5.7 Formação dos subgrupos com comportamentos opostos para 0 DCM, a CDS e a CDC ........................................................... 78

5.8 Análise da frequência de respostas antecipatórias da sequência aprendida na fase de estabilização na tarefa mais complexa . .80

5.9 Análise do tempo entre o estímulo e a resposta dos sujeitos que mantiveram a estrutura de respostas antecipatórias na fase de adaptação

5.10 Análise dos efeitos da estabilização e canais de desempenho na probabilidade de ocorrência do processo de modularização e adaptação .83

5.10.1 Modelo de regressão logística................................................ 86

5.11 Quantidade de tentativas para aprendizagem da tarefa mais complexa

5.12 Nível de estabilização e quantidade de tentativas para alcançar os critérios .88

5.13 Análise da associação entre a quantidade de tentativas para alcance do primeiro e segundo critério de desempenho .89

5.14 Análise do tipo de resposta logo após a inserção do novo componente. 91

6. DISCUSSÃO .92 
6.1 Mudança normativa ao longo das fases .....................................93

6.2 Análise da estabilidade interindividual na mudança intraindividual ......96

6.3 Análises sobre os processos envolvidos no aumento de complexidade de habilidades motoras .......................................98

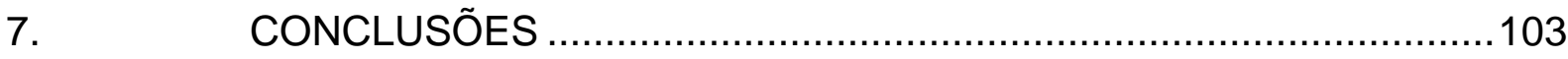

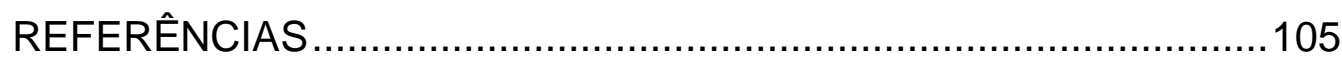

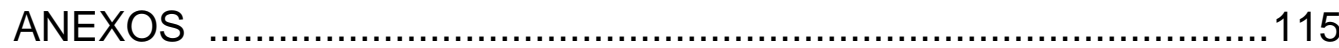




\section{LISTA DE TABELAS}

Página

TABELA 1 - Exemplo de cálculo do DCM. 36

TABELA 2 - Valores individuais para 10 sujeitos da análise do $\kappa \square$ Cohen para uma variável hipotética.

TABELA 3 - Número de sujeitos com valores extremos, analisado para cada tipo de resposta, grupo e bloco.

TABELA 4 - Valores da razão entre a assimetria e o seu erro padrão nas diferentes facetas do desempenho para os 3 grupos. .54

TABELA 5 - Principais estatísticas descritivas para todos os tipos de resposta (Ro, Re, Rc, Ra), por bloco de tentativas. .55

TABELA 6 - Valores da moda, mínimo e máximo do desempenho máximo das respostas e a frequência relativa para cada bloco na fase de aquisição.

TABELA 7 - Valores da moda, mínimo e máximo do desempenho máximo das respostas e a frequência relativa para cada bloco na fase de adaptação.

TABELA 8 - Valores do $\kappa$ geral \pm erro padrão para os três canais e por canal (C1, C2, C3) no DCM para os 5 blocos da fase de aquisição. .66

TABELA 9 - Valores da estatística Kappa e respectivos valores de prova entre as comparações dos blocos.

TABELA 10 - Tabulação cruzada entre as frequências de sujeitos com consistência baixa, moderada e alta entre os blocos 1 e 2 .

TABELA 11 - Tabulação cruzada entre as frequências de sujeitos com consistência baixa, moderada e alta entre os blocos 2 e 3 .

TABELA 12 - Tabulação cruzada entre as frequências de sujeitos com consistência baixa, moderada e alta entre os blocos 1 e 3 . 69

TABELA 13 - Valores da estatística Kappa e respectivos valores de prova entre as comparações dos blocos 
TABELA 14 - Tabulação cruzada entre as frequências de sujeitos com consistência baixa, moderada e alta entre os blocos 1 e 2 ................................70

TABELA 15 - Tabulação cruzada entre as frequências de sujeitos com consistência baixa, moderada e alta entre os blocos 2 e 3 .

TABELA 16 - Tabulação cruzada entre as frequências de sujeitos com consistência baixa, moderada e alta entre os blocos 1 e 3. .71

TABELA 17 - Porcentagem de sujeitos em cada um dos níveis de estabilidade para o DCM.

TABELA 18 - Número de sujeitos em cada nível de estabilidade e cada canal de desempenho do DCM.

TABELA 19 - Número de sujeitos com estabilidade fraca para cada tendência a mudança entre os canais para cada uma das diferentes facetas do desempenho.

TABELA 20 - Porcentagem de sujeitos em cada um dos níveis de estabilidade para a CDS.

TABELA 21 - Número de sujeitos em cada nível de estabilidade e nível de consistência para a CDS.

TABELA 22 - Número de sujeitos com estabilidade fraca para cada tendência a mudança entre os canais, em cada uma das facetas do desempenho. .75

TABELA 23 - Porcentagem de sujeitos em cada um dos níveis de estabilidade para a CDC. .76

TABELA 24 - Número de sujeitos em cada nível de estabilidade e nível de consistência para a CDC.

TABELA 25 - Número de sujeitos com estabilidade fraca para cada tendência à mudança entre os canais, em cada uma das facetas do desempenho.

TABELA 26 - Número de sujeitos e agrupamento nos novos subgrupos com comportamentos opostos para o DCM. .79

TABELA 27 - Número de sujeitos e agrupamento nos novos subgrupos com comportamentos opostos para a CDS. 
TABELA 28 - Número de sujeitos e agrupamento nos novos subgrupos com comportamentos opostos para a CDS.

TABELA 29 - Número de sujeitos em cada frequência de Ra por tentativa nas primeiras dez tentativas da fase de aquisição

TABELA 30 - Tabulação cruzada entre a frequência de ocorrência dos processos de modularização e adaptação e os sujeitos com estabilidade no $1^{\circ}$ e $3^{\circ}$ canal de desempenho do DMC. .84

TABELA 31 - Tabulação cruzada entre a frequência de ocorrência dos processos de modularização e adaptação e os sujeitos com estabilidade no $1^{\circ} \mathrm{e}$ $3^{\circ}$ nível de desempenho e com tendência à mudança ascendente da CDS.

TABELA 32 - Tabulação cruzada entre a frequência de ocorrência dos processos de modularização e adaptação e os sujeitos com estabilidade no $1^{\circ} \mathrm{e}$ $3^{\text {o }}$ nível de desempenho e com tendência à mudança ascendente da CDC .85

TABELA 33 - Tabulação cruzada entre a frequência de ocorrência dos processos de modularização e adaptação e os grupos G_1A e G_3A. .86

TABELA 34 - Principais preditores da chance de mudança da ocorrência dos processos de adaptação e modularização - resultados do modelo de regressão logística.

TABELA 35 - Valores da correlação de Pearson, nível de significância e coeficiente de determinação para a quantidade de tentativas da fase de estabilização e adaptação.

TABELA 36 - Porcentagem de sujeitos para cada tipo de resposta no primeiro bloco da fase de adaptação para os três grupos. 


\section{LISTA DE FIGURAS}

FIGURA 1 - Modelo de não-equilíbrio de aprendizagem motora (TANI, 2005)......10

FIGURA 2 - Equipamento de rastreamento de sinais luminosos (Visão superior).32

FIGURA 3 - Caracterização do tipo de resposta de acordo com o momento do toque e sensor tocado.

FIGURA 4 - Histogramas das respostas antecipatórias dos 3 grupos (G_3C, G_1A e G_3A), no primeiro, segundo e sexto bloco de prática da fase de estabilização

FIGURA 5 - Proporção de sujeitos que mantêm, ascendem e descendem o seu DMC entre blocos adjacentes nas fases de aquisição e adaptação para o G_3C

FIGURA 6 - Proporção de sujeitos que mantêm, ascendem e descendem o seu DMC entre blocos adjacentes nas fases de aquisição e adaptação para o G_1A.

FIGURA 7 - Proporção de sujeitos que mantêm, ascendem e descendem o seu DMC entre blocos adjacentes nas fases de aquisição e adaptação para o G_3A.

FIGURA 8 - Proporção de sujeitos distribuídos nas três categorias da CDS nos três blocos de tentativas da fase de estabilização para o G_1A........63

FIGURA 9 - Proporção de sujeitos distribuídos nas três categorias da CDS nos três blocos de tentativas da fase de estabilização para o G_3A........63

FIGURA 10 - Proporção de sujeitos distribuídos nas três categorias da CDC nos três blocos de tentativas da fase de estabilização para o G_1A

FIGURA 11 - Proporção de sujeitos distribuídos nas três categorias da CDC nos três blocos de tentativas da fase de estabilização para o G_3A.........65

FIGURA 12 - Canais tercílicos do DCM ao longo de 6 blocos da fase de aquisição. 
FIGURA 13 - Trajetórias intraindividuais e diferenças interindividuais no DCM dos 6 blocos de prática. As linhas tracejadas indicam os diferentes canais.

FIGURA 14. Trajetórias intraindividuais e canais de estabilidade para o DCM ao longo dos 6 blocos de tentativas para os subgrupos com estabilidade excelente no canal 1 (à esquerda) e estabilidade boa no canal 1 (à direita). As linhas tracejadas e pontos cheios indicam os limites dos diferentes canais.

FIGURA 15 - Média e limite de confiança (95\%) da média do tempo entre o estímulo e a resposta dos 5 componentes da tarefa inicial nas fases de estabilização e adaptação.

FIGURA 16 - Média e limite de confiança (95\%) do desvio-padrão do tempo entre o estímulo e a resposta dos 5 componentes da tarefa inicial nas fases de estabilização e adaptação. .83

FIGURA 17 - Média e limite de confiança (95\%) da quantidade de tentativas para alcançar o critério da tarefa com o novo componente para os sujeitos que mantiveram a estrutura na nova situação, e os que reorganizaram.

FIGURA 18 - Média e limite de confiança (95\%) da quantidade de tentativas para alcançar o critério da tarefa com o novo componente para os grupos G_3C, G_1A e G_3A nas fases de estabilização e adaptação. .89

FIGURA 19 - Diagrama de dispersão bivariado da quantidade de tentativas para alcançar o critério das fases de estabilização e adaptação para os diferentes grupos. 


\section{LISTA DE ANEXOS}

Página

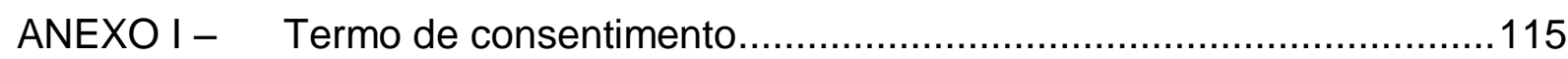

ANEXO II - Valores dos testes de normalidade para os diferentes tipos de proporção de respostas............................................................117

ANEXO III - Tabulação cruzada entre blocos adjacentes do DCM nas fases de estabilização e adaptação 


\title{
RESUMO
}

\section{AUMENTO DE COMPLEXIDADE NA APRENDIZAGEM MOTORA: EFEITOS DOS NÍVEIS DE ESTABILIZAÇÃO E DOS CANAIS DE DESEMPENHO}

\author{
Autor: Luciano Basso \\ Orientador: Prof. Dr. GO TANI
}

O objetivo do presente estudo foi investigar se os níveis de estabilização alcançados no final do processo de aquisição e nos canais de desempenho modificam a probabilidade de um dos dois processos envolvidos no aumento de complexidade em aprendizagem motora - modularização e adaptação - ocorrer, quando novos componentes são inseridos na tarefa já aprendida, e sua influência na aprendizagem da tarefa com novos componentes. Cento e cinquenta e três sujeitos de ambos os sexos, entre 10 e 13 anos de idade, realizaram uma tarefa seriada de rastreamento de sinais luminosos. O experimento constou de duas fases: estabilização e adaptação. Três grupos foram formados de acordo com critérios de desempenho a ser alcançados na estabilização: três séries consecutivas de respostas corretas, uma série de respostas antecipatórias e três séries de respostas antecipatórias, numa tarefa seriada composta de cinco estímulos. A fase de adaptação, igual para todos os grupos, ocorreu até o alcance de uma série de respostas antecipatórias numa tarefa com seis estímulos. Os resultados mostraram a ocorrência de ambos os processos: adaptativo e modularização, em $84 \%$ e $16 \%$ dos sujeitos, respectivamente. Os sujeitos do que alcançaram respostas antecipatórias foram posteriormente divididos em subgrupos com base na estabilidade interindividual da mudança intra-individual nos canais de desempenho ao longo da fase de estabilização. Foram definidos 4 subgrupos: estável no canal superior; estável no canal inferior; com tendência a mudança ascendente; e com oscilação. Os resultados da análise de regressão logística permitiram inferir que o subgrupo estável no canal superior da consistência do desempenho da sequência em 
respostas antecipatórias tem quatro vezes mais probabilidade de utilizar o processo de modularização do que o subgrupo estável no canal inferior, quando novos componentes são inseridos na tarefa já aprendida. Além disso, foi possível identificar que os sujeitos que utilizaram o processo de modularização necessitaram de uma menor quantidade de tentativas para a aprendizagem da nova tarefa.

Palavras-chaves: processo adaptativo, modularização, mudança intraindividual, diferenças interindividuais. 


\title{
ABSTRACT \\ THE INCREASE OF COMPLEXITY IN MOTOR LEARNING: EFFECTS OF STABILIZATION LEVELS AND PERFORMANCE CHANNELS
}

\author{
Author: Luciano Basso \\ Adviser: Prof. Dr. Go Tani
}

The purpose of this study was to investigate whether levels of stabilization achieved by the end of the acquisition process and performance channels modify the probability of occurrence of one of the two processes involved in the increase of complexity in motor learning - modularization and adaptation - when new components are inserted into the task already learned, and their influence on the learning of the task with new components. One hundred and fifty-three subjects of both sexes, between 10 and 13 years of age, performed a serial tracking task of luminous stimuli. The experiment consisted of two phases: stabilization and adaptation. Three groups were formed according to performance criteria to be achieved in the stabilization phase: three consecutive series of correct responses (group G_3C), a series of antecipatory responses (G_1A group) and three series of anticipatory responses (group G_3A) in a task with five stimuli. The adaptation phase, the same for all groups, took place until the achievement of a series of anticipatory responses in a task with six stimuli. The results showed the occurrence of both processes: adaptive and modularization, in $84 \%$ and $16 \%$ of the subjects, respectively. The subjects of G_1A and G_3A were afterwards divided into subgroups based on the interindividual stability of intra-individual change in the performance channels during the stabilization phase. Four groups were established: stable in the upper channel, stable in the lower channel, upward moving tendency, 
and oscillation groups. Based on the results of binary logistic regression analysis it was observed that the stable upper channel subgroup in consistency of the sequence in anticipatory responses is four times more likely to use the process of modularization in relation to the stable lower channel subgroup, when new components are inserted into the task already learned. It was also possible to identify that the subjects who used the process of modularization needed fewer attempts to learn the new task.

Keywords: adaptative process; modularity; intraindividual change; interindividual stability. 


\section{INTRODUÇÃO}

Estudos experimentais acerca do modo como ocorre o aumento de complexidade em aprendizagem motora, mais especificamente, que investigam o efeito da inserção de novos componentes no desempenho de uma tarefa motora já aprendida, iniciaram-se há mais de 30 anos. Exemplos são encontrados em estudos com habilidades de encaixe de objetos (MOSS \& HOGG, 1983), manipulativas (ELLIOT \& CONNOLLY, 1974), de escrever (MANOEL, BASSO, CORRÊA \& TANI, 2002) e de tocar alvos (BASSO, 2002). Os resultados são divergentes e indicam que enquanto alguns aprendizes mantêm tanto o resultado da ação quanto os aspectos espaço-temporais da estrutura aprendida na tarefa com os novos componentes, outros modificam o resultado da ação e reorganizam a estrutura formada inicialmente. Esses resultados foram interpretados como diferentes possibilidades para atingir estados mais elevados de complexidade na aquisição de habilidades motoras e foram explicados por MANOEL e BASSO (2005) por meio de hipóteses advindas de duas abordagens propostas em diferentes áreas de Comportamento Motor: Aprendizagem Motora e Desenvolvimento Motor. A primeira hipótese explanatória é apresentada com base numa abordagem que concebe a aprendizagem motora como um processo adaptativo e a segunda baseia-se na organização da resposta motora a partir do processo de modularização no processo de desenvolvimento motor.

A primeira abordagem origina-se nos trabalhos de $\mathrm{CHOSHI}$ e $\mathrm{TANI}^{1}$ (citado por TANI, 1995) e TANI (1982). Esses pesquisadores explicam o aumento de complexidade no comportamento motor por meio do que eles denominaram de processo adaptativo. Essa abordagem se preocupa para além da formação e estabilização de estruturas e da padronização funcional do desempenho, centrandose na adaptação das estruturas adquiridas às novas situações por meio da sua flexibilidade inerente, reorganização parcial ou auto-organização. Desse modo, caracterizam a aprendizagem motora como um processo contínuo em direção a estados crescentes de complexidade. As evidências empíricas encontradas por estes 
estudos têm sustentado as proposições e hipóteses iniciais. Uma síntese teórica e dos resultados pode ser encontrada em TANI (2005).

A outra explicação tem início na década de 1970, com os trabalhos de Connolly e Bruner, centrada na proposição de que a aquisição de habilidades motoras resulta na formação de unidades que, juntamente com outras, irão a compor habilidades mais complexas, processo esse denominado de modularização (CONNOLLY, 1973; BRUNER, 1970). Desde então, a ideia de que os ganhos de complexidade pressupõem a formação e integração de unidades mais simples em habilidades mais complexas tem sido aceita por muitos pesquisadores da área (TANI, MANOEL, KOKUBUN \& PROENÇA, 1988; CONNOLLY, 1973; BRUNER, 1970; HAKEN, 1991; MANOEL, 1989, 1998).

Recentes estudos têm procurado investigar ambas as proposições de forma separada (MANOEL et alli, 2002; GIMENEZ, MANOEL, LUSTOSA DE OLIVEIRA \& BASSO, 2004; GIMENEZ, 2001; GIMENEZ, MANOEL, \& BASSO, 2006; MANOEL, 2000) ou em conjunto (BASSO, 2002). As evidências têm possibilitado inferir que quando se adquire uma habilidade e se adicionam novos componentes ocorrem situações que favorecem a manutenção da estrutura da habilidade adquirida, assim como situações em que a estrutura da habilidade adquirida é reestruturada. A hipótese explicativa é que a inserção de novos componentes à habilidade aprendida pode gerar ou não variados graus de perturbação ${ }^{2}$, com isso, a aprendizagem da tarefa com os novos componentes se daria ora mediante modularização - quando a inserção não gera perturbação - ora adaptação paramétrica, quando a perturbação gerada é baixa e, em outros momentos, adaptação estrutural, quando a perturbação gerada é alta.

Se a hipótese central para explicar os processos envolvidos no aumento de complexidade na aprendizagem motora está ligada à geração ou não dos diferentes níveis de perturbação que a inserção dos novos componentes provoca no desempenho da tarefa adquirida, então para a sua investigação são necessários

\footnotetext{
${ }^{1} \mathrm{~K}$. CHOSHI \& G. TANI. Stable system and adaptive system in motor learning. In: Japanese Association of Biomechanics (Ed.). The science of movement. V. Tokyo: Kyorin, 1993. (In Japanese).
} 
meios para identificar o nível de estabilização do desempenho na tarefa inicial durante a fase de aquisição. Essa especial atenção se deve, fundamentalmente, ao fato de ambas as possibilidades (modularização e processo adaptativo) serem estreitamente definidas por meio de análises sobre o que muda e a magnitude da mudança, e essa é sempre tratada em termos relativos. Assim, a caracterização do nível de estabilidade da habilidade inicial se torna um dos elementos essenciais para a investigação dessa temática.

Os trabalhos de TANI (1995) e UGRINOWITSCH e TANI (2005) apresentam evidências empíricas para a ideia de que uma modificação na tarefa motora pode gerar ou não diferentes graus de perturbação, dependendo do nível de estabilidade do desempenho alcançado na fase de aquisição. Por exemplo, UGRINOWITSCH e TANI (2005) mostraram que sujeitos que alcançaram elevados níveis de estabilização durante a fase de aquisição mantiveram seu desempenho independentemente do tipo de modificação utilizada no experimento, mas o mesmo não ocorreu quando atingiram níveis inferiores.

Esses resultados adicionados aos dos estudos de CORRÊA (2007) e TANI (1995) possibilitam argumentar que mesmo que os sujeitos tenham atingido o critério de desempenho, há diferenças nos seus comportamentos quando inserida uma modificação na tarefa (modificação de ordem perceptiva e/ou motora). Com isso, nota-se que a perturbação gerada por uma modificação na tarefa depende do nível de estabilização (UGRINOWITSCH \& TANI, 2005), mas defini-lo apenas com base no desempenho alcançado no final da fase de aquisição pode não ser o mais adequado.

O trabalho de BENDA e TANI (2005), a partir da análise de uma série de experimentos (BENDA, CORRÊA, LUSTOSA DE OLIVEIRA \& TANI, 2000; BENDA, 2001), chama a atenção para a limitação para caracterizar o nível de estabilidade, analisando-se apenas o último bloco de aquisição. Para esses autores, o esforço poderia ser direcionado na busca de medidas e instrumentos para analisar 0 processo de estabilização do aprendiz ao longo de todo o processo da fase de

${ }^{2}$ Essa hipótese é uma adaptação à apresentada por Manoel et alli, (2002), mediante a concepção de unidade modular adotada no presente estudo. 
aquisição, ou seja, seria também preciso caracterizar o desempenho do aprendiz como estável ou instável, considerando toda a fase de aquisição da estrutura da habilidade e não apenas o final desse processo.

Para caracterizar o nível de estabilização do desempenho na tarefa inicial pode-se buscar em diferentes áreas do conhecimento algumas ideias e técnicas para a sua operacionalização. No caso do presente estudo, escolheu-se adotar um indicador já utilizado na literatura de Aprendizagem Motora - critério de estabilização (TANI 1995), e um indicador de outra área de conhecimento (Epidemiologia, Estatística Aplicada) - estabilidade nos canais de desempenho (MAIA, GARGANTA, SEABRA, LOPES, SILVA \& MEIRA JÚNIOR, 2007).

Dentro da perspectiva de caracterizar o nível de estabilidade do desempenho ao longo do tempo, em outras áreas do conhecimento, pode-se citar os trabalhos de MAIA, SEABRA, LOPES e SILVA (2002), MAIA, LEFEVRE, BEUNEN e CLAESSENS (2001), TANNER (1990) em estudos do Crescimento e Desenvolvimento Motor, FOULKES e DAVIS (1981) e SCHNEIDERMAN e KOWALSKI (1994) na Odontologia e MEIRA JÚNIOR (2005) na Aprendizagem Motora, utilizando-se das ideias e técnicas de tracking. Essa abordagem possibilita identificar níveis de estabilidade individual ao longo de todo o processo. A ideia geral refere-se à descrição das diferenças interindividuais na mudança intraindividual, ou seja, a essência de seu conteúdo é analisar a tendência de um indivíduo ou subgrupo em permanecer num determinado curso ou canal de mudança ao longo do tempo, o que reflete a estabilidade no seu padrão de mudança. O estudo de tracking é relevante na medida em que permite atribuir significado àquilo que é ou não estável nos indivíduos em função do tempo - no caso da aprendizagem de uma habilidade motora, em função da prática (MEIRA, JR., 2005).

Para investigar se os níveis de estabilização do desempenho alcançados na fase de aquisição da tarefa inicial, por si só, seriam preditores suficientes para modificar a probabilidade de ocorrência entre os dois tipos de processos (modularização e adaptação), quando novos componentes são inseridos, poder-se-ia combinar os procedimentos sugeridos por TANI (1995) - critério de desempenho - e as ideias e técnicas de tracking - canais de desempenho - apresentadas por MAIA et 
alli (2007).

Com base no exposto, as principais questões a serem investigadas são:

Os níveis de estabilidade atingidos ao final da aquisição e nos canais de desempenho na fase de aquisição modificam a probabilidade de um dos processos modularização ou adaptativo - ocorrer quando forem inseridos os novos componentes?

Caso o nível de estabilização do desempenho da habilidade aprendida inicialmente tenha efeito na probabilidade de um dos processos ocorrer, estes apresentarão efeito na aprendizagem subsequente da tarefa com os novos componentes?

Para fundamentar a presente tese foram organizadas cinco seções na revisão de literatura.

A primeira seção tem o objetivo de apresentar as principais proposições da abordagem do processo adaptativo, evidenciando os experimentos e resultados que envolvem as discussões referentes à estabilização do desempenho, tipos de modificação da tarefa e os graus de perturbação gerados.

A segunda seção tem o objetivo de apresentar as ideias e resultados referentes ao processo de modularização, destacando a evolução dos estudos que investigaram o aumento de complexidade no comportamento motor.

A terceira seção tem o objetivo de apresentar algumas distinções entre os estudos que analisaram a modularização intra-habilidade daqueles que analisaram a modularização inter-habilidades. Também serão apresentadas as limitações na definição de módulo atual (MANOEL et alli, 2002), assim como uma possível reinterpretação da versão original de unidade modular proposta por CONNOLLY (1970) e BRUNER (1973), mas com uma visão pautada na atual concepção de programa de ação (TANI, 1995). Também são apresentadas algumas reflexões e ideias sobre uma visão integrada dos processos de modularização e adaptação, para explicar o aumento de complexidade na aprendizagem motora.

A quarta seção tem o objetivo de apresentar as principais ideais e estudos sobre a estabilidade nos canais de desempenho ao longo do tempo, explorando estudos de diferentes áreas do conhecimento e refletindo sobre a sua implicação para a presente pesquisa. 
A quinta e última seção é destinada à caracterização da tarefa motora utilizada.

\section{OBJETIVO GERAL}

O objetivo do presente estudo foi investigar se os níveis de estabilização modificam a probabilidade de um dos processos envolvidos no aumento de complexidade - modularização e adaptativo - ocorrer, quando novos componentes são inseridos na tarefa já aprendida, e sua influência na aprendizagem da tarefa com novos componentes.

\section{$2.1 \quad$ Objetivos específicos}

Analisar se os níveis de estabilização alcançados no final do processo de aquisição modificam a probabilidade dos processos de modularização e adaptativo ocorrerem quando os novos componentes forem inseridos.

Analisar se os níveis de estabilidade individual nos canais de desempenho na aquisição modificam a probabilidade dos processos de modularização $e$ adaptação ocorrerem quando novos componentes forem inseridos na tarefa.

Analisar se a ocorrência de um dos processos envolvidos no aumento de complexidade apresenta efeito na aprendizagem da tarefa com os novos componentes.

\section{REVISÃO DE LITERATURA}

\subsection{Modelos de aprendizagem motora}

Qualquer que seja a questão investigada em uma pesquisa de aprendizagem motora é importante contextualizá-la num modelo teórico que expresse uma estrutura relacional e explicativa. Os modelos trazem a vantagem de auxiliar nas relações entre as variáveis investigadas/manipuladas e os resultados encontrados, reforçando os fundamentos estruturais para a descrição e explicação do próprio modelo, 
ampliando, assim, o entendimento do fenômeno.

Os primeiros modelos teóricos da área de Aprendizagem Motora estavam voltados a descrever o processo até a automatização do desempenho de uma habilidade específica, como o de Circuito Fechado de ADAMS (1971) e o de Esquema Motor de SCHMIDT (1975).

Modelos voltados à automatização tentam definir as características do desempenho dos indivíduos em diferentes fases do processo de aprendizagem. De forma geral, esses modelos oferecem uma elegante descrição das atividades ocorridas entre o começo e o final dos estágios de aprendizagem, juntamente com algumas das características observáveis do desempenho motor (SCHMIDT \& WRISBERG, 2001). O início da aprendizagem é caracterizado por tentativas do indivíduo de adquirir uma ideia do movimento (GENTILE, 1972) ou entender o padrão básico de coordenação (NEWELL, 1985). Para tanto, ele deve engajar-se num processo de resolução de problema, envolvendo processos cognitivos (FITTS \& POSNER, 1967) e verbais (ADAMS, 1971) aliados às tentativas físicas de execução da tarefa. Já nas fases mais avançadas da aprendizagem, os indivíduos atingem um estágio em que o desempenho se torna mais preciso e consistente, possibilitando o processo de refinamento do padrão de movimento mediante detecção e correção dos seus próprios erros até atingir a automatização.

Apesar de esses modelos explicarem minuciosamente o processo até a automatização, uma omissão importante diz respeito ao fato de que a aprendizagem é vista como um processo finito e não como parte de um processo contínuo em que o que é aprendido antes e depois seja considerado de forma dinâmica. Dessa forma, apesar de ser um referencial importante para a aquisição de habilidades motoras, os modelos de ADAMS (1971) e SCHMIDT (1975) limitam-se a explicar a aprendizagem até a fase autônoma ou de automatização. Eles se prendem à formação de uma estrutura na aquisição de habilidades motoras, porém, como essa formação ocorre a partir de estruturas já existentes, não foi explicada, ou simplesmente não foi considerada nesses modelos, tampouco o processo em que novas habilidades são formadas a partir daquelas já adquiridas (TANI, 1995). Por enfatizarem a 
automatização e estabilização, eles são denominados de modelos de equilíbrio (TANI, 2005).

TANI (2005) alerta que, além de se prenderem à fase de automatização, esses modelos têm dificuldades para tratar a coexistência de aspectos como ordem/desordem e consistência/variabilidade no comportamento motor e, por isso, caracterizam-se como modelos de equilíbrio. Nessa concepção, instabilidade, variabilidade e erro são vistos sempre como prejudiciais ao comportamento habilidoso e por isso devem ser reduzidos ou mesmo eliminados. A ênfase na estabilidade e o tratamento negativo dado à variabilidade e instabilidade no processo fazem com que os modelos de equilíbrio sejam limitados para explicar o aumento de complexidade na aquisição de habilidades motoras (para uma vasta revisão sobre as limitações e implicações dos modelos centrados na automatização do desempenho, ver TANI, 2005).

As características citadas acima evidenciam que o foco principal desses modelos é sobre o processo de automatização e, justamente por causa dessa visão finita, CHOSHI e TANI ${ }^{3}$ (citado por TANI, 1995) e TANI (1982, 1989, 1995) propuseram um modelo que concebe a aprendizagem motora como um processo além da estabilização, denominado de processo adaptativo.

O modelo do processo adaptativo, por propor um referencial teórico considerando a aprendizagem como um processo contínuo e dinâmico, possibilita condições adequadas para investigar o aumento de complexidade na aprendizagem motora. Isso se deve à apresentação de fundamentos, proposições e considerações, além da descrição das características presentes no processo de automatização de uma habilidade específica. Dessa forma, serão descritos a seguir os principais elementos constituintes do modelo do processo adaptativo. Posteriormente, será discutida uma ideia oriunda da área de Desenvolvimento Motor, que também busca descrever processos envolvidos para além da estabilização de uma habilidade, denominado de modularização (CONNOLLY, 1973; BRUNER, 1970). Essas

\footnotetext{
${ }^{3}$ K. CHOSHI \& G. TANI. Stable system and adaptive system in motor learning. In: Japanese Association of Biomechanics (Ed.). The science of movement. V. Tokyo: Kyorin, 1993. (In Japanese).
} 
informações têm como objetivo descrever os principais elementos do processo adaptativo e do processo de modularização, para reunir subsídios que sustentem os principais argumentos do presente estudo.

\subsubsection{Aquisição de habilidades motoras orientada ao processo adaptativo}

Com base nas limitações de modelos voltados ao processo de automatização e em mudanças paradigmáticas no âmbito da ciência, CHOSHI (1978, 1981, 1982), CHOSHI e TANI (1983) citados por TANI $(1982,1989)$, TANI BASTOS, CASTRO, JESUS, SACAY e PASSOS (1992) e TANI (1995) propuseram, um modelo de não-equilíbrio em aprendizagem motora em que dois processos fundamentais são considerados: estabilização e adaptação.

O pressuposto básico é que a aquisição de habilidades motoras é um processo de desenvolvimento hierárquico (TANI, 1982, 1989) que compreende, pelo menos, duas fases: estabilização e adaptação. A primeira refere-se à estabilização funcional, que resulta na padronização espacial e temporal do movimento (formação de estrutura) via atuação de feedback negativo. Quando a função estabiliza, infere-se que uma estrutura foi formada. Nessa fase, movimentos inicialmente inconsistentes vão sendo padronizados espacial e temporalmente. Entretanto, considerando que 0 indivíduo é um sistema aberto em constante interação com o meio ambiente, podem ocorrer situações que exigem modificações no padrão de movimento, ou seja, adaptação.

As mudanças no ambiente podem ser de tal magnitude que o sistema consegue gerar modificações necessárias mediante a flexibilidade inerente à estrutura adquirida, ou seja, pela alteração de parâmetros do movimento, denominada de adaptações paramétricas. Por outro lado, algumas mudanças no ambiente podem exigir a modificação da própria estrutura da habilidade e uma posterior reorganização. Isso tem sido denominado de adaptação estrutural. Nesse caso, há um desmantelamento da estrutura, ocorrendo a formação de uma nova estrutura a partir da já existente. A esse processo se seguirá uma nova estabilização, mas num nível superior de complexidade (TANI et alli, 1992). Desta forma, o 
processo de aquisição de habilidades motoras compreende um processo cíclico e dinâmico de instabilidade-estabilidade-instabilidade, que resulta em um aumento crescente de complexidade do comportamento (FIGURA 1).

Baseada nas proposições desse modelo uma série de estudos com o intuito de obter evidências empíricas foi realizada (para uma visão geral dos resultados, ver TANI, 2005). Alguns desses estudos testaram os próprios elementos do modelo, por exemplo, TANI, et alli (1992); TANI (1995); BENDA (2001); UGRINOWITSCH (2003); CATTUZZO (2007). Enquanto outros discutiram o efeito de diferentes fatores no processo de aprendizagem, como CORRÊA (2001); CORRÊA, BENDA e TANI (2001); PAROLI (2004); MEIRA JÚNIOR (2005); TANI, MEIRA JUNIOR e GOMES (2005); CORRÊA, GONÇALVES, BARROS e MASSIGLI (2006) e PINHEIRO (2006).

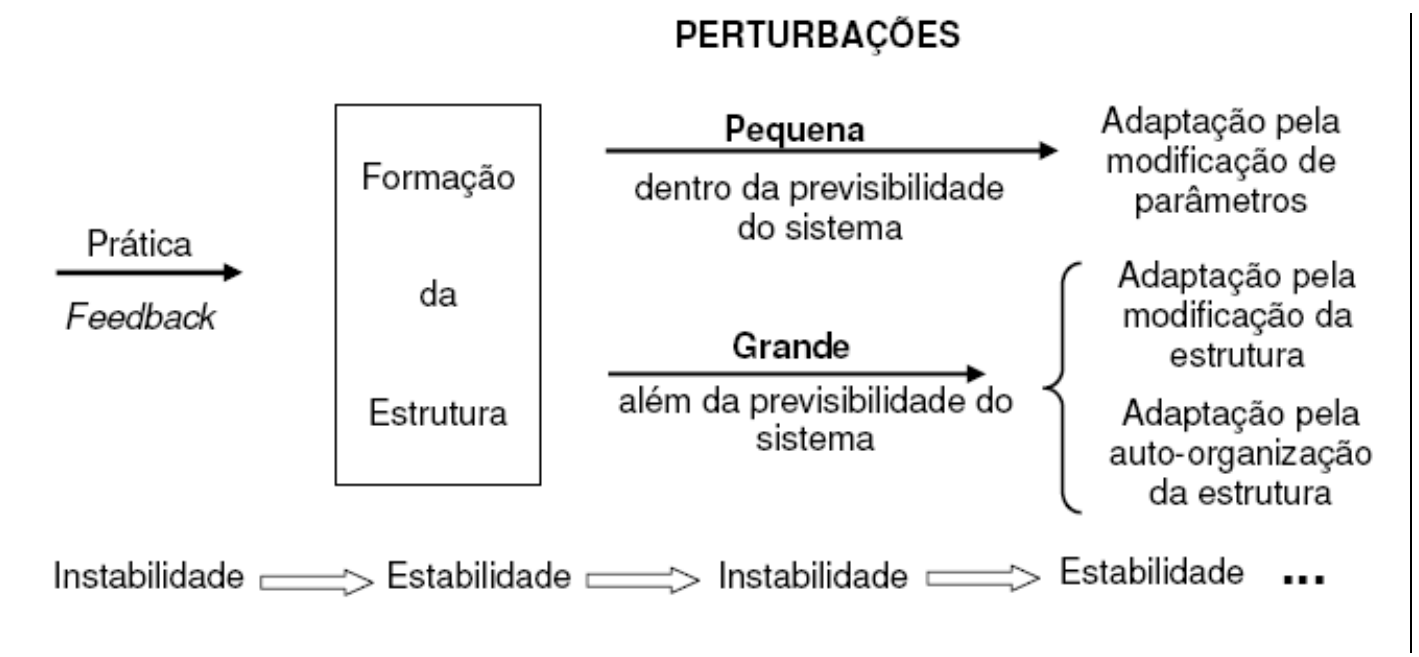

FIGURA 1 - Modelo de não-equilíbrio de aprendizagem motora (TANI, 2005).

O intuito deste capítulo não é realizar um levantamento completo de todos os trabalhos, mas apresentar aqueles que possibilitam a discussão sobre os aspectos relacionados ao nível de estabilização e os tipos de perturbação, com o objetivo de buscar sustentação aos principais argumentos do presente estudo. Nesta linha, deve-se destacar o trabalho de TANI (1995), cujo objetivo foi investigar a ligação entre o estado do sistema e o tipo de modificação, gerando diferentes tipos de perturbação. Com base nos resultados do experimento com uma tarefa de rastreamento de um padrão luminoso seriado, notou-se que a modificação gerou 
uma perturbação em todos os níveis de resposta, levando sempre o sistema a adaptar-se num nível hierárquico imediatamente inferior ao alcançado. Isto é, quando o sistema atinge o topo da hierarquia de respostas - antecipatórias - mesmo frente a perturbações, ele se adapta com respostas funcionais satisfatórias, ou seja, corretas.

Com uma tarefa que possibilitou analisar a organização espaço-temporal da habilidade, UGRINOWITSCH (2003) também investigou os efeitos do tipo de perturbação e do nível de estabilização no processo adaptativo em aprendizagem motora. Foram realizados três experimentos, manipulando o nível de estabilização alcançado: pré-estabilização, estabilização e superestabilização. Em cada experimento, os grupos foram submetidos a diferentes modificações dos aspectos da tarefa: perceptivo, motor e perceptivo-motor. O conjunto dos resultados permitiu inferir que: a) a estabilização é um pré-requisito para a adaptação; b) a variabilidade presente na organização espaço-temporal após a estabilização parece ser diferente da variabilidade na fase inicial da aprendizagem; c) níveis mais baixos de estabilização permitem visualizar uma hierarquia no tipo de perturbação; d) desempenhos superestabilizados respondem da mesma forma a diferentes tipos de perturbação: mantêm-se inalterados ou estabilizam-se muito rapidamente.

Com isso pode-se argumentar que a modificação da tarefa pode gerar ou não perturbação no desempenho. Para se configurar a perturbação, a modificação da tarefa é condição importante, mas não suficiente quando a estrutura apresenta altos níveis de estabilização. A perturbação depende do estado do sistema.

Outro trabalho com evidências importantes para o modelo de processo adaptativo é o de BENDA (2000). Este trabalho teve por objetivo analisar o papel da variabilidade do desempenho no processo adaptativo. Após a estabilização do desempenho, os sujeitos com alta e baixa variabilidade apresentaram os mesmos resultados frente à modificação da tarefa. Com isso, o autor sugere que a alta variabilidade surgida na superestabilização não caracteriza inconsistência, pois não foi prejudicial à aprendizagem frente a uma nova tarefa, já que ambos os grupos apresentaram o mesmo desempenho. A diferença ficou na fase de aquisição, pois o grupo de alta variabilidade atingiu resultados sempre menores do que o grupo com baixa variabilidade. Segundo o autor, isto configura um quadro favorável às 
predições do modelo, pois indica que variabilidade observada após a estabilização pode caracterizar flexibilidade do sistema. Evidências semelhantes foram ressaltadas em BENDA (2001), no que diz respeito aos parâmetros do movimento. No entanto, se a variabilidade nos aspectos relacionados à estrutura do movimento for alta, a mesma não tem a função mencionada - a de flexibilidade no sistema - sendo contrária às proposições do modelo teórico. Parece que a baixa variabilidade na estrutura do movimento mostrou-se um indicativo de melhor organização do sistema também quando o nível de perturbação é mais elevado.

O trabalho de BENDA e TANI (2005), a partir da análise dos estudos apresentados acima (BENDA et alli, 2000; BENDA, 2001), chama a atenção para a limitação para caracterizar o nível de estabilidade, analisando-se apenas o último bloco dessa fase. Para esses autores, o esforço poderia ser o de buscar medidas e instrumentos para analisar o processo de estabilização do aprendiz ao longo de toda a fase de aquisição, ou seja, seria importante também caracterizar o desempenho do aprendiz como estável ou instável, considerando toda a fase de aquisição e não apenas o final desse processo.

Com exceção dos estudos de BENDA et alli (2000) e BENDA (2001), que se utilizaram de platôs de desempenho e da divisão dos sujeitos a partir de maiores e menores níveis de erro variável, os demais estudos apresentados utilizaram-se de um critério de desempenho individual para estabelecer maiores e menores níveis de estabilização (inicialmente apresentado por TANI, 1995). Ainda, no esforço para investigar a associação entre os níveis de estabilidade e o processo adaptativo, pode-se citar o trabalho de CORRÊA (2007). O objetivo foi investigar o efeito da quantidade de prática para se alcançar um determinado critério de desempenho no processo adaptativo. $\mathrm{O}$ autor mostra que os sujeitos que empregaram mais tentativas para alcançar o desempenho esperado tiveram maior consistência no resultado da ação, quando inserida a modificação. Esses resultados são importantes a partir do momento que sugerem uma forte heterogeneidade interindividual. Resultados semelhantes também foram encontrados por TANI (1995).

Com base nesses trabalhos pode-se argumentar que há interação entre 0 nível de estabilização e 0 tipo de perturbação no processo adaptativo 
(UGRINOWITSCH, 2003). Níveis de estabilização mais elevados têm maior capacidade de lidar com as modificações sem reestruturar a habilidade. No entanto, há heterogeneidade na resposta a uma mesma modificação, associada à quantidade de prática para se chegar ao desempenho critério (UGRINOWITSCH, 2003; TANI, 1995). Com isso, nota-se que a perturbação gerada por uma modificação na tarefa depende do nível de estabilização (UGRINOWITSCH, 2003; TANI, 1995; BENDA \& TANI, 2005) e também de "como" o sujeito chegou até ela (CORRÊA, 2007; TANI, 1995).

Apesar de esses resultados e discussões focarem o modo como uma habilidade vai se modificando ao longo do eixo temporal, eles apresentam relevantes contribuições para refletir sobre a forma de resposta quando novos componentes são inseridos a uma tarefa já aprendida. Uma vez que se encontram resultados favoráveis à ideia de manutenção do resultado da ação e da estrutura, quando maiores níveis de estabilização são atingidos, independentemente do tipo de modificação da tarefa durante o processo adaptativo, o que possibilita especular que a estrutura formada até a estabilização já tinha capacidade para lidar com tais modificações e, assim, mantém-se intacta na nova tarefa. Com isso, é possível questionar se a manutenção do desempenho da tarefa aprendida seria esperada quando inseridos novos componentes em sujeitos com altos níveis de estabilização. Cabe questionar ainda, se o nível de estabilização definido apenas com base na fase final desse processo seria suficiente para diferenciar a estabilização do desempenho de uma habilidade. Vale lembrar que a hipótese central apresentada para explicar a forma de resposta nessa situação (manutenção ou adaptação) focalizou o local, número e outras características dos novos componentes (BASSO, 2002; MANOEL \& BASSO, 2005), ou seja, para o tipo de perturbação que as características dos novos componentes iriam gerar. No entanto, com base no exposto acerca das investigações sobre nível de estabilização e tipos de perturbação, para o mesmo tipo de modificação originam-se diferentes tipos de perturbação em diferentes indivíduos, o que, em parte, é influenciado pelo nível de estabilização alcançado inicialmente. Assim, entende-se que para avançar nessa discussão é fundamental identificar os níveis de estabilização e observar a sua influência no desempenho da habilidade 
aprendida quando novos componentes são inseridos.

\subsubsection{Aumento de complexidade entre habilidades via modularização}

No início da década de 1970, uma explicação para o aumento de complexidade sugeriu que a aquisição de habilidades motoras resultava na formação de unidades que viriam a compor, juntamente com outras, habilidades mais complexas. Esse processo foi denominado de modularização (CONNOLLY, 1973; BRUNER, 1970). Desde então, a ideia de que os ganhos de complexidade pressupõem a formação e integração de unidades mais simples em habilidades mais complexas tem sido aceita por muitos pesquisadores da área (TANI et alli, 1988; CONNOLLY, 1973; BRUNER, 1970; HAKEN, 1991; MANOEL, 1998). No entanto, são relativamente poucas as investigações empíricas que buscam testar as proposições acerca desse processo (MANOEL, 1998).

A ideia da modularização possibilita pensar no ganho de complexidade como o processo de incorporação/combinação entre diferentes habilidades, por exemplo, a habilidade como andar ereto depende de habilidades de controle postural (McGRAW, 1945); as habilidades manipulativas dependem de habilidades de alcançar e pegar (VON HOFSTEN, 1993; JEANNEROD, 1994); ou, ainda, habilidades seriadas, como driblar, seriam compostas de habilidades como correr e quicar (TANI et alli, 1988). Quando se pensa na aquisição dessas diferentes habilidades no eixo temporal de vida do indivíduo, vê-se que a aquisição de várias delas precede a aquisição de outras, com as quais elas mantêm relação. Assim, cada habilidade isolada, como apreender, quicar ou alcançar, constituiria um módulo a ser utilizado na composição de novas habilidades (BRUNER, 1970; CONNOLLY, 1973).

O suporte teórico para essa concepção veio originalmente da teoria de processamento de informações aplicada ao estudo do comportamento motor. Segundo essa visão, cada comportamento resultaria, por exemplo, da elaboração de um programa de ação no nível central do sistema nervoso (CONNOLLY, 1977). Esses programas seriam constituídos por componentes que, num período anterior, teriam sido programas mais simples (FITTS \& POSNER, 1967; BRUNER, 1970; 
CONNOLLY, 1973).

Esses programas mais simples ou unidades básicas, que compõem 0 programa de ação, são considerados como análogas a sub-rotinas, unidades que fazem parte de um programa que governa computadores. A sub-rotina é considerada como um ato, cuja execução é uma condição necessária, mas não suficiente para a execução de sequências de sub-rotinas, hierarquicamente organizadas e mais complexas, nas quais ela é incluída (ELLIOTT \& CONNOLLY, 1974). Dessa forma, é definida claramente a disposição hierárquica de níveis superiores e inferiores de controle do sistema nervoso central, pois as sub-rotinas correspondem às unidades automatizadas de movimento que, em algum momento, foram programas, mas por causa dos processos de mudança, foram delegadas ao controle de níveis mais inferiores do sistema nervoso central.

Entretanto, para que essa unidade básica ou sub-rotina torne-se parte de uma seqüência mais complexa, ela deveria passar por um processo denominado de modularização (BRUNER, 1970; CONNOLLY, 1973). Na modularização, uma unidade torna-se padronizada, altamente previsível e consistente. Assim, ela representa 0 processo pelo qual se supõe que programas de ação, uma vez adquiridos (consistentes e padronizados), podem tornar-se componentes de programas mais complexos. A sub-rotina seria uma unidade modular na medida em que ela pode ser colocada em outros programas, em contextos diferentes daqueles em que ela foi adquirida (CONNOLLY, 1973). A modularização corresponderia à estabilização da habilidade, apresentando como diferencial a liberação dessa unidade para compor programas mais complexos.

Um dos aspectos mais importantes da concepção modular diz respeito à noção de que as sub-rotinas podem ser organizadas e justapostas numa infinidade de formas para solucionar novos problemas. Nesse sentido, a ação motora habilidosa é "generativa", visto que uma série mínima de regras permite a produção de uma ampla gama de regras de transformação, e que um grande número de padrões de ação pode ser gerado (BRUNER, 1970). A partir desse referencial, alguns estudos foram realizados, investigando tanto a existência da unidade modular como também as suas características. 
A experimentação dessas ideias iniciaram-se por um dos seus proponentes na década de 70 do século passado. ELLIOTT e CONNOLLY (1974) apresentam evidências suficientes para argumentar que a construção de uma habilidade manipulativa mais complexa estaria sustentada na organização hierárquica de unidades (sub-rotinas). No entanto, quando se reúne os principais resultados encontrados na literatura sobre o processo de modularização, nota-se que a existência da unidade modular ainda é uma questão mal resolvida. Por exemplo, BISHOP e HARRISON (1977), VIVIANI (1986) e MANOEL (1993) encontraram evidências, o que não aconteceu com MARTENIUK e ROMANOW (1983).

Segundo MANOEL (1989, 1993), MANOEL e CONNOLLY (1997) a divergência nos resultados pode ser devida à concepção de unidade modular. Aspectos como a natureza rígida do módulo e a ênfase na estabilidade do módulo foram fortemente marcadas nas proposições iniciais (CONNOLLY, 1973; BRUNER, 1970). A crítica à proposição inicial recai sobre a noção de que a estabilidade da unidade seria suficiente para garantir sua inserção num programa mais complexo. Essa ideia não considera que seriam necessários ajustes para acomodar diferentes unidades modulares para a formação da habilidade mais complexa.

A ênfase na estabilidade da unidade modular foi muito clara e dificultou bastante a compreensão da noção de unidade modular (MANOEL \& CONNOLLY, 1997). De acordo com a concepção inicial, a variabilidade do comportamento motor é tratada como um ruído. Nesse aspecto, a concepção modular ressente-se de uma visão parcial do que seja estabilidade. MANOEL $(1989,1993)$, MANOEL e CONNOLLY (1997) argumentam ainda que as unidades estáveis não podem ser fixas sob pena de não conseguirem ajustar-se às mínimas variações do ambiente. Estabilidade no resultado da ação só existe porque o sistema consegue variar a organização espaço-temporal das suas respostas. Vale lembrar que a variabilidade na organização espaço-temporal tem diferentes significados, pois depende da fase de aquisição. No início, ela se relaciona com erro/incerteza, mas com o processo de aquisição, o sujeito estabelece relações entre a organização do movimento e o resultado da sua ação, tornando-se, nesse momento, funcional (MANOEL \& CONNOLLY, 1995). Ainda que a concepção modular assuma que a associação entre 
unidades ocorra quase que de forma aditiva, isso não significa que não ocorram modificações em cada uma delas.

Com base nessas limitações e fundamentado numa uma visão sistêmica do comportamento motor, MANOEL et alli (2002) propuseram que a unidade modular seria um programa de ação organizado hierarquicamente em dois níveis: macroestrutura e microestrutura. Esse programa, uma vez estabilizado, poderia ser combinado a outros diferentes programas, formando, assim, habilidades mais complexas. A ideia básica é que as regras seriam fixas (aspectos da macroestrutura), e as estratégias, flexíveis (aspectos da microestrutura). Enquanto a utilização das regras em diferentes situações permitira visualizar o módulo num contexto mais complexo, a modificação das estratégias permitiria a combinação com outros programas.

Com base nessa visão, um conjunto de estudos foi conduzido (MANOEL et alli, 2002; GIMENEZ et alli, 2004; GIMENEZ, 2001; GIMENEZ, MANOEL \& BASSO, 2006; MANOEL, 2000). Até o momento, os resultados confirmaram parcialmente essa hipótese, isto é, as macro e microestruturas apresentaram uma diminuição gradual de sua variabilidade durante a aquisição do padrão inicial. Porém, na fase em que a tarefa mais complexa é executada, alguns aspectos da macroestrutura mantiveram-se constantes enquanto outros não.

A partir da confirmação apenas parcial a favor do processo de modularização encontrados nesses estudos, BASSO (2002) argumenta que a discussão torna-se frágil a partir do momento em que parte dos estudos atuais analisaram apenas a variabilidade da estrutura formada. Mais especificamente, argumenta que para ter maiores elementos para investigar a hipótese de modularização seria necessário analisar tanto a magnitude dos aspectos da macroestrutura quanto a sua variabilidade nas habilidades mais complexas, e não somente a manutenção da variabilidade (por exemplo, a análise de qual sequênciamento foi utilizado, e não somente a sua variabilidade). Nesse caso, ao ocorrer a manutenção da macroestrutura da unidade dentro do programa mais complexo, com as mudanças ocorrendo somente em termos da microestrutura, seria possível discutir em favor da modularização como processo de aumento de complexidade em habilidades 
motoras.

Por outro lado, para explanar sobre a divergência das evidências empíricas poder-se-ia incorporar a ideia de que nesse momento também pode ocorrer 0 processo adaptativo (TANI, 1995, 2005). Isto porque para alguns tipos de combinação entre programas, a flexibilidade da estrutura não conseguira suportar, e deste modo ocorreria a reorganização dos programas envolvidos, caracterizando assim o processo adaptativo para a formação da estrutura mais complexa (BASSO, 2002; MANOEL \& BASSO, 2005).

Partindo dessas premissas, e incorporando a ideia de haver efeito da configuração espacial da tarefa mais complexa na manutenção da macroestrutura dentro da habilidade mais complexa (conforme MANOEL et alli, 2002), BASSO (2002) realizou dois experimentos. Foram manipulados diferentes locais para inserir os novos componentes na tarefa mais complexa, além da definição do sequênciamento: livre e determinado pelo experimentador. Os resultados indicaram ambos os processos, pois, dependendo da configuração espacial da tarefa mais complexa, obteve-se resultados favoráveis tanto à modularização quanto à adaptação estrutural. No entanto, quando comparados os resultados dos experimentos em que o sequênciamento foi definido a priori pelo experimentador, com o experimento em que o próprio sujeito estabelecia o sequênciamento, notou-se resultados contraditórios, ou seja, se para o sequênciamento determinado houve a manutenção da estrutura quando da inserção de novos componentes antes da estrutura aprendida, o inverso ocorreu no experimento com sequênciamento livre.

O autor sugere que essa diferença pode ter sido em virtude de os indivíduos do segundo experimento terem mais demanda de processamento durante a prática, já que tinham de decidir qual caminho seguir a todo instante; por outro lado, esse envolvimento cognitivo mais profundo pode ter levado a um reforço do programa na memória, aumentando a tendência do mesmo ser utilizado em novas situações (BASSO, 2002). Com isso, o autor supôs que a resposta do sujeito quando novos componentes são inseridos poderia ocorrer tanto mediante o processo de modularização, quanto de adaptação estrutural. Nesse sentido, o autor sugeriu que futuros trabalhos poderiam detectar quais fatores levariam ao processo de 
modularização, e quais levariam à adaptação estrutural no que se refere ao aumento de complexidade em habilidades motoras (para uma revisão mais detalhada sobre esse tema, MANOEL \& BASSO, 2005).

Após apresentar as ideias originais do processo de modularização (CONNOLLY, 1973; BRUNER, 1970), suas limitações conceituais (MANOEL, 1989, 1993; MANOEL \& CONNOLLY, 1997), uma nova concepção de unidade modular (MANOEL et alli, 2002) e as discussões sobre a importância de se utilizar dois modelos para descrever os processos envolvidos no aumento de complexidade na aprendizagem motora (BASSO, 2002; MANOEL \& BASSO, 2005), cabe apresentar algumas reflexões e questões a este conjunto de estudos, aspectos esses abordados no próximo tópico.

\subsubsection{Notas sobre o processo de modularização integrado ao processo de adaptação}

O primeiro aspecto a ser abordado diz respeito ao contexto da elaboração e experimentação da concepção de unidade modular. Inicialmente testada no âmbito do Desenvolvimento Motor, na década de 70 do século passado por ELLIOTT e CONNOLLY (1974) e, mais recentemente, por GIMENEZ (2001) e GIMENEZ et alli, (2004), sempre envolveu a combinação de habilidades diferentes (por exemplo, preensão manual e alcançar ou correr e arremessar), ou seja, o aumento de complexidade no comportamento motor se dá entre habilidades. Neste contexto, a unidade pode ser uma sequência de ações realizadas por movimentos concomitantes de diferentes membros (por exemplo, movimentos dos braços e pernas na ação de arremessar).

Há dois tipos de experimentos, um em que o sujeito aprende uma habilidade e depois uma nova habilidade é apresentada (ELLIOTT \& CONNOLLY, 1974) e outro em que o sujeito aprende cada habilidade isoladamente e depois realiza as duas conjuntamente (GIMENEZ, 2001; GIMENEZ et alli, 2004). Essas formas de simular o processo de aumento de complexidade no desenvolvimento motor ganham sustentação, uma vez que há um entendimento de que uma habilidade como andar 
ereto depende de habilidades de controle postural (McGRAW, 1945), uma habilidade manipulativa depende de habilidades de alcançar e pegar (VON HOFSTEN, 1993; JEANNEROD, 1994), e ainda habilidades seriadas, como driblar, seriam compostas pelas habilidades de correr e quicar (TANI et alli, 1988). Com isso, a ideia de uma habilidade motora ser vista como uma unidade modular dentro de uma habilidade mais complexa passou a ser reconhecida por muitos (TANI et alli, 1988; CONNOLLY, 1973; BRUNER, 1970; HAKEN, 1991; MANOEL \& BASSO, 2005).

Quando a ideia de unidade modular é utilizada no âmbito da Aprendizagem Motora, há uma clara distinção, pois a mesma sempre foi testada em situações em que houve inserção de novos componentes a uma mesma habilidade já aprendida, por exemplo, aprender a escrever um caráter chinês e depois adicionar mais um caráter (MANOEL et alli, 2002), ou seja, o aumento de complexidade se dá intrahabilidade. Nessas pesquisas, a unidade modular configurou-se num programa de ação organizado hierarquicamente (TANI, 1995; MANOEL et alli, 2002) e em grande parte esteve ligada à aprendizagem de ações unimanuais.

Se no âmbito do Desenvolvimento Motor a unidade foi concebida como uma determinada habilidade, em Aprendizagem Motora, a unidade foi definida em relação a componentes da estrutura de ação. A partir dessa diferenciação, entende-se que a utilização da ideia de unidade modular para investigar o processo de aumento de complexidade da mesma tarefa motora é plausível, mas é preciso cuidado com a transposição de exemplos e explicações, pois a definição de unidade é diferente nas duas áreas. No presente estudo toda a discussão será no contexto da mesma habilidade, inserindo novos componentes.

O segundo aspecto que merece atenção diz respeito à proposta apresentada por MANOEL (1989 e 1993) para superar o problema do infinito regresso que a noção de regras de transformação carrega consigo. A solução consistiu em assumir que o módulo deveria ser dotado de certa autonomia para ajustar-se às demandas inerentes às associações entre diferentes módulos. Para isso, o autor recorreu a uma ferramenta conceitual da teoria hierárquica. MANOEL $(1989,1993)$ propõe que o módulo seria correspondente a um hólon, ou seja, uma entidade que é, ao mesmo tempo, parte e todo. Segundo KOESTLER (1969), hólons possuem regras fixas - que 
Ihes dão identidade, e estratégias flexíveis - que possibilitam os ajustes diante das demandas do ambiente. Ele argumenta que a forma como a unidade modular se ajusta a outras está associada à modificação das estratégias, mais especificamente, pela alteração dos aspectos da microestrutura - via adaptação paramétrica. E aqui reside o ponto central dessa discussão, pois se o módulo tem como vantagem ser um programa de ação que não demanda tanto controle consciente para a sua execução, uma vez que ele seria delegado a níveis inferiores do sistema nervoso central (CONNOLLY, 1970; BRUNER 1973), considerar que o mesmo necessita de adaptações em algumas das suas características quando integrado em estruturas mais complexas é entender que é necessário processamento em nível superior, ou seja, controle consciente. A solução apresentada ao problema das regras de transformação não poderia ir contra os princípios que definem a própria natureza de um módulo: independência e controle por níveis inferiores de processamento.

A presente pesquisa centra-se apenas no aumento de complexidade na aprendizagem motora e, desse modo, em situações em que o sujeito aprende uma habilidade e, posteriormente, novos componentes são inseridos. Nesse contexto, entende-se que não seria necessário conceber o comportamento do módulo análogo ao do holón, ao contrário, poder-se-ia conceber o módulo como um programa de ação estável tanto no aspecto da macro quanto da microestrutura. Em linhas gerais, o programa com características estáveis em ambos os níveis da sua hierarquia seria o ponto de partida para o sujeito aprender o novo programa. A ideia base seria algo como construir um novo programa "em torno" de um programa já existente, sem adaptar o que já está pronto. Vale lembrar que os novos componentes são apresentados ao sujeito apenas quando ele já apresenta diferentes níveis de estabilização no desempenho da habilidade inicial. O processo de modularização ocorreria no caso do sujeito conseguir utilizar as estruturas previamente aprendidas na nova situação, concentrando-se em executá-las como um dos componentes da nova estrutura elaborada com os novos componentes. $O$ todo seria uma parte, pois a estrutura tornar-se-ia uma unidade funcional dentro da nova estrutura formada. A estrutura elaborada para controlar os novos componentes seria fortemente restringida à natureza da estrutura já formada da habilidade inicial e às 
características dos novos componentes inseridos.

Ao descrever os principais mecanismos e processos dos sistemas adaptativos complexos, HOLLAND (1997) apresenta a concepção de que, frente a uma nova situação, o primeiro processo que se pode pensar para obter soluções é uma espécie de processo aleatório de tentativa e erro que efetue alterações aleatórias. No entanto, tal processo não parece gerar soluções válidas para a nova situação. Ele então sugere que o processo seria mais plausível se o sujeito partisse da decomposição de cenas visuais complexas, na busca por elementos que já possuísse maior experiência em lidar com ele, por meio de blocos constituintes. Entende-se por blocos constituintes aqueles que foram amplamente utilizados com sucesso pelo sujeito no seu passado. Dir-se-ia então que um bloco constituinte que fosse utilizado consistentemente com sucesso nas situações vividas seria um bom candidato à utilização nas novas situações. HOLLAND (1997) demonstra que grande parte das inovações tecnológicas emerge a partir de blocos bem definidos, por exemplo, a construção de computadores baseou-se nos conhecimentos anteriores sobre transistores.

Poder-se-ia pensar que o processo de modularização ocorreria quando o sujeito, ao ser defrontado com a nova situação faria a decomposição na busca por componentes conhecidos que já possuísse maior experiência em lidar com eles, ou seja, já experimentados com sucesso no passado, objetivando sua reutilização. Pensando com HOLLAND (1997), a reutilização poderia significar repetição, e assim o sujeito começaria a ver como poderia ter repetições de componentes apesar de sempre ser confrontado com novas situações. Assim, a experiência ocorreria mediante a utilização recorrente de programas, ainda que estes possam nunca aparecer duas vezes na mesma combinação exata.

Dentro deste contexto, um aspecto fundamental é a identificação de blocos constituintes que foram fortemente utilizados com sucesso em situações passadas. Essas seriam as melhores candidatas a tornarem-se os blocos constituintes na geração da solução na nova situação.

A releitura dos experimentos realizados por BASSO (2002) e GIMENEZ et alli, (2004) permite argumentar que há algumas evidências para se conceber o 
módulo como um programa organizado hierarquicamente com regras e estratégias (macro e microestrutura) estáveis na aprendizagem de tarefas mais complexas quando da inserção de novos componentes. O mesmo pode ser observado nos estudos em que foram apenas inseridas algumas alterações nas características perceptivas e/ou motoras nas tarefas, por exemplo, nos trabalhos de MARINOVIC (2003) e UGRINOWITSCH e TANI (2005), em que mesmo com as alterações perceptivas e/ou motoras na fase de adaptação, não houve adaptação, mas sim a manutenção tanto dos aspectos da macro quanto da microestrutura. Tais resultados sugerem que nem toda modificação na tarefa e/ou introdução de novos componentes leva à reorganização da estrutura adquirida. Uma vez que a prática na situação inicial teria tornado o sistema complexo o bastante para lidar com as novas situações.

Após realizar a diferenciação do aumento de complexidade na Aprendizagem Motora e no Desenvolvimento Motor e a forma como se entende o processo de modularização em relação ao processo adaptativo, para explicar o aumento de complexidade no processo de aquisição de habilidades motoras, entende-se que há um longo caminho a ser percorrido na busca de identificar quais características aumentariam a probabilidade do sujeito utilizar-se de um ou outro processo, quando inseridos os novos componentes.

Com base na ideia de HOLLAND (1997) sobre os blocos utilizados com êxito em situações passadas, como os possíveis candidatos a blocos constituintes durante a elaboração das novas regras; os resultados de UGRINOWITSCH e TANI (2005), indicando que desempenhos com elevados níveis de estabilização tendem a manterse frente a modificações na tarefa, e os resultados de CORRÊA (2007) e TANI (1995), indicando heterogeneidade de respostas frente a mesma modificação da tarefa, pode-se argumentar que há fortes indicativos para investir na análise do nível de estabilidade do desempenho alcançado ao final da aquisição e ao longo do processo como um dos fatores que influencia o modo pelo qual ocorre o aumento de complexidade na aprendizagem motora.

\subsection{O estudo da estabilidade ao longo do tempo}


O estudo da estabilidade de uma determinada característica, estado ou traço ao longo do tempo tem sido preocupação em diversas áreas do conhecimento (TANNER, 1990; MAIA et alli, 2001; FOULKS \& DAVIS, 1981; SCHNEIDERMAN \& KOWALSKI, 1994; MORTIMER, FINCH \& KUMKA, 1982). Dentro desse contexto, a ideia chave é a de tracking, genericamente entendida como uma pista que deixa marcas visíveis no terreno; também se refere à distância constante entre um par de rodas. Segundo MAIA et alli (2002) destas duas definições originam-se quatro aspectos importantes: (1) presença de indicadores no terreno, (2) estabilidade das pistas, (3) facilidade em seguir uma pista, e (4) antecipar pontos da pista a partir de outros previamente conhecidos.

Para que se possa entender a amplitude das ideias de tracking torna-se necessário esclarecer o significado de três elementos nucleares: mudança, estabilidade e previsão. Em primeiro lugar é importante frisar que o foco de atenção de qualquer investigação sobre a estabilidade precisa residir na identificação direta da mudança ocorrida em cada indivíduo ao longo do tempo (NESSELROADE, 1991), uma vez que a mudança é tida como um fenômeno de natureza intraindividual, uma propriedade intrínseca de cada unidade individual de observação (MAIA et alli, 2007).

A ideia de estabilidade é diversa e bem abrangente. MORTIMER et alli (1982) apresentam quatro conceitos e operacionalizações distintas da noção de estabilidade: invariância estrutural - referindo-se ao grau de continuidade do fenômeno sobre investigação; b) estabilidade normativa - o foco reside na estabilidade das diferenças interindividuais e nas mudanças intraindividuais; c) nível de estabilidade - referindo-se à persistência da magnitude da mudança ao longo do tempo num traço ou característica; e d) estabilidade ipsativa - referindo-se à consistência e à mudança intraindividual na organização dos traços ou atributos ao longo do tempo. Quando o foco é o estudo do tracking, as questões de investigação situam-se no plano da estabilidade normativa, pois o foco de atenção reside, genericamente, na análise da manutenção da posição relativa do sujeito na distribuição dos valores do seu grupo ao longo do tempo (SCHNEIDERMAN \& KOWALSKI, 1994).

É somente com base na estabilidade de um determinado comportamento que 
é possível discutir, com alguma segurança, sobre a sua predição no futuro, ou seja, resultados de desempenho estáveis possibilitam efetuar previsões acerca do comportamento no futuro (MAIA et alli, 2007). Por outro lado, a baixa estabilidade impossibilita ou dificulta a precisão da previsão, carregando consigo, contudo, a possibilidade de ser interpretada como um momento com um alto potencial para a mudança.

Embora exista um consenso relativo à noção genérica de que o tracking traduz a tendência de um sujeito ou grupo de sujeitos permanecerem num dado curso de mudança, isto é, a manutenção de uma posição relativa no seio da distribuição de valores (SCHNEIDERMAN \& KOWALSKI, 1994), dois aspectos devem ser ressaltados: a) a diversidade de sua operacionalização estatística, por exemplo, mediante autocorrelação $\kappa$ de Cohen, Gama ( $\mathrm{Y}$ ) de FOULKES e DAVIS; b) ausência de uma definição operacional unânime acerca do que se entende por posição relativa.

Uma forma elegante de operacionalizar e evidenciar a aplicabilidade do conceito de tracking pode ser vista nos trabalhos de Tanner (TANNER, 1990). O autor, preocupado com a estabilidade do crescimento somático, especificamente o estudo da estatura, traz o conceito de canalização de WADDINGTON (1957). A ideia básica é que o crescimento e desenvolvimento se processam ao longo de um dado canal numa paisagem epigenética com múltiplas possibilidades, onde é evidente não só um comportamento regular, mas também uma tendência para se dirigir para um alvo geneticamente determinado e atualizado pelo ambiente. Essas ideias ganham evidências quando ilustradas por TANNER (1990) a partir de cartas de crescimento da estatura, em que os sujeitos mantinham-se "perseverantes" em determinados percentis de crescimento ao longo de toda a infância e adolescência. Apenas modificações ambientais muito severas atuariam em alguns sujeitos levando-os a sair do seu canal de crescimento (TANNER, 1990). Uma vez sanadas as restrições ambientais, esses sujeitos voltavam ao seu canal de crescimento.

A ideia de canalização do desempenho é uma forma bastante versátil de se investigar a estabilidade normativa, uma vez que permite mediante o emprego da estatística $\kappa$ de Cohen investigar a estabilidade individual das trajetórias 
intraindividuais ao longo de canais de desempenho. A estatística $\kappa$ de Cohen evidencia a ocorrência de estabilidade de uma dada trajetória de mudança quando permanece entre um par de percentis adjacentes empiricamente construídos e selecionados pelo pesquisador (por exemplo, P1-33; P33-P66). Cada par de percentis é definido como um canal específico de desempenho. Partindo da análise da frequência do desempenho de cada sujeito dentro de cada um dos canais, estimase a estabilidade da mudança entre os canais. Trata-se de uma estatística descritiva não paramétrica, e assim não exige qualquer tipo de estruturação na distribuição dos dados. Os resultados variam de 0 a 1 e, baseado nas sugestões de LANDIS e KOCH (1977), assume-se a seguinte interpretação para os valores: $\kappa>0,75=$ estabilidade excelente; $0,40 \leq \kappa \leq 0,75=$ estabilidade boa; $\kappa<0,40=$ estabilidade fraca.

A aplicação dessas ideias e procedimentos a estudos de aprendizagem motora parecer ser promissora, uma vez que permite atribuir significado àquilo que é ou não estável nos indivíduos em função da prática (MEIRA, JR., 2005). Vale ressaltar que apresentar estabilidade não implica em ausência de mudança, salvo quando não há mudança normativa e o desempenho individual não se altera ao longo da prática. Com isso, pode-se identificar o nível de heterogeneidade na mudança intraindividual e apresentar as semelhanças e diferenças nas trajetórias individuais dentro dos canais. Essas informações também possibilitam discutir se as diferenças entre os sujeitos é apenas uma questão de escala, e suas trajetórias são semelhantes (paralelas) ou então, quando há pouca estabilidade nas diferenças interinviduais, pode-se pensar em agrupar os sujeitos que apresentam maiores semelhanças entre as suas trajetórias e identificar a relação dessas diferenças com o desempenho diante de novas situações enfrentadas pelos sujeitos.

Com base nessas ideias o presente estudo pretende identificar o nível de estabilidade da trajetória individual dentre os diferentes canais de desempenho, além de observar o canal mais frequente para os sujeitos estáveis e a forma de oscilar entre os canais para os sujeitos com baixa estabilidade. Espera-se identificar trajetórias de desempenho que permaneçam frequentemente em canais superiores, intermediários e inferiores, assim como trajetórias que oscilem entre os canais de desempenhos. Essas informações serão utilizadas para formar subgrupos e testar se 
a estabilidade do desempenho ao longo do processo de formação da habilidade inicial influencia a aprendizagem quando inserido os novos componentes.

\subsection{Modelo experimental}

Uma discussão atual na literatura de Comportamento Motor é a de que a especificidade da tarefa desempenha um papel fulcral na construção de teorias do comportamento motor (SUMMERS, 1998; TANI, 1995). É muito frequente observar que as abordagens utilizadas na Aprendizagem Motora são baseadas em habilidades discretas (Esquema Motor - SCHMIDT, 1975), em habilidades contínuas (Circuito Fechado - ADAMS, 1971) e, mais recentemente, a teoria de sistemas dinâmicos é bem orientada para habilidades cíclicas (SUMMERS, 1998).

A escolha da tarefa para a experimentação de ideias na Aprendizagem Motora tem de ser clara e cuidadosamente justificada com uma argumentação muito estruturada (TANI, 1995). Na área de Comportamento Motor há a compreensão de que a execução de uma tarefa motora como escrever, tocar piano e/ou digitar envolve a realização de uma série de ações motoras, e que essas ações podem ser compostas por várias unidades, em que a tarefa do sistema controlador implica a seleção e a organização espaço-temporal dessas unidades - tradicionalmente denominada de problema da ordem seriada (ROSEMBAUM, COHEN, JAX, WEISS \& VAN DER WEL, 2008), apresentado inicialmente por LASHEY (1951). Com isso, o pesquisador busca tarefas motoras em que os componentes sejam facilmente identificáveis.

A tarefa de rastreamento de um padrão luminoso seriado caracterizada pelo toque em resposta a estímulos luminosos sequênciais, não se trata de uma tarefa de tempo de reação de escolha. RESTLE (1970) afirma que a aprendizagem de um padrão seriado é a integração de uma sequência de respostas que são organizadas de uma forma significativa. TANI (1995) adiciona que em muitas tarefas do mundo real, a aprendizagem consiste na organização de uma série de respostas a estímulos ambientais. E ainda, que o sucesso nessas situações não está em responder isoladamente aos estímulos, mas a certas características da sequência de estímulos, como a sua ordem de aparecimento (estrutura espacial da tarefa) e o tempo entre 
cada estímulo (estrutura temporal da tarefa). Em tarefas de rastreamento de um padrão luminoso seriado tais características são facilmente simuladas e manipuladas.

Nessas tarefas seriadas de rastreamento, o sujeito pode até responder isoladamente a cada estímulo no início da prática, tentando ser o mais rápido possível em cada estímulo, semelhante às tarefas de tempo de reação de múltipla escolha (PARK \& SHEA, 2005). No entanto, com a repetição dos estímulos o sujeito percebe algumas regularidades entre eles e começa a responder à sequência. Diante da aprendizagem da ordem dos estímulos, o sujeito, após prática extensiva, passa a responder de forma antecipada (TANI, 1995). Esse tipo de resposta indica claramente que o sujeito já não responde isoladamente a cada estímulo, mas sim à sequência, e que uma estrutura para aquela tarefa foi formada. Pode-se dizer que a resposta nesse momento torna-se independente da sequência dos estímulos.

Outra característica que deve ser ressaltada nesse tipo de tarefa é a estrutura de respostas. Existem basicamente quatro tipos de respostas qualitativamente diferentes: omissas, erradas, corretas e antecipatórias. Segundo CHOSHI (2000) a aprendizagem é um processo e por isso as medidas devem representar esse processo. Para analisar o processo, é importante se ter medidas que sejam complementares, pois a modificação na relação dessas medidas explica mais adequadamente o processo de aprendizagem.

Para TANI (1995), CHOSHI (2000) e CATTUZZO (2007) há uma ordem para essas diferentes respostas: as respostas omissas são inferiores às erradas, que por sua vez são inferiores às respostas corretas, e o mais alto nível de resposta é o das antecipatórias; esse último nível de respostas demonstra que o aprendiz não só compreendeu a seqüência do acendimento das luzes, como também o padrão seriado. É esperado que os aprendizes substituam as respostas omissas e erradas pelas corretas e antecipatórias, evidenciando a mudança hierárquica e complementar entre os tipos de resposta. Diferentemente de estudos em que a resposta do sistema é dicotomizada em errada ou correta - o que reduz a possibilidade de uma melhor análise qualitativa do desempenho - esses quatro tipos de resposta que mudam ao longo do processo permitem avaliar como o aprendiz busca as respostas funcionais, 
aquelas que atendam à meta da tarefa.

Apesar de CHOSHI (2000) exemplificar a ideia dessas medidas no âmbito do processo ensino-aprendizagem, é importante apresentá-la na sua integra, pois ressalta aspectos qualitativos do processo de aprendizagem que tradicionalmente não são focados e descreve a tarefa de rastreamento que um padrão luminoso seriado pode apresentar.

"...na fase inicial predominam as respostas omissas. Os indivíduos utilizam a autorreferência, que é o nível de consciência do sujeito, que tem uma característica circular de pensamento: quem responde de forma omissa fica se autorreferenciando. Ao observar esse tipo de resposta numa situação de ensino-aprendizagem, o professor fala "Tente, mesmo que erre", subindo, assim, um nível na hierarquia. Embora o professor enfatize esse comportamento, como a resposta errada não é muito apreciada pela criança, torna-se difícil vencer a barreira das respostas omissas, mas o importante é tentar. É óbvio que ela fique omissa, pois não sabe qual é a resposta correta, mas o importante é que após fazer isso ela sobe um nível, passando para as respostas erradas. Quando as respostas erradas predominam, o professor requer do indivíduo respostas corretas, assim, o indivíduo vai para o nível acima, começando a circular no nível de respostas corretas. Quando alguém abandona respostas erradas e vai para respostas corretas, temos a atuação de um controle via "feedback". Mas como a situação de aprendizagem envolve novos desafios, o indivíduo tem que estar preparado e tentar subir mais um nível da hierarquia, passando a responder antecipadamente. Desse modo, a análise da aprendizagem motora dentro de uma mesma tarefa indica que o nível mais alto de comportamento adaptativo é o de respostas antecipatórias..." (pg. 21).

Um aspecto central para a utilização desse tipo de tarefa é a sequência de estímulos a ser utilizada, que na presente pesquisa pautou-se nos resultados de alguns estudos sobre a estrutura e efeito da posição de cada componente. RESTLE (1970) estudou as estruturas das sequências em padrões seriados e, de acordo com seus resultados, as denominadas runs (2-3-4), trills (5-4-5-4) e repetitions (1-1-1) facilitam a aprendizagem. Por exemplo, se o padrão run "2-3-4" aparece, os sujeitos o aprendem rapidamente. Com isso, para que a tarefa tenha uma sequência 
desafiadora e que seja aprendida, a ordem dos estímulos não deve contar a formação de runs, trills e repetitions.

Outro aspecto a ser considerado quanto à tarefa diz respeito aos critérios para selecionar o local da inserção do novo componente na sequência de estímulos - quando na realização da fase de adaptação. No presente estudo, eles foram baseados nas noções de programação on-line e pré-programação (BURTON, 1987; FISCHMAN, 1984; MANOEL, 1993). De acordo com esses princípios, quando se tem uma série de ações a ser executada, existe uma maior propensão de realizar-se as últimas ações on-line com predominância do uso de feedback na regulação das ações (BURTON, 1987). Essas ideias, apesar de não terem sido testadas especificamente para a tarefa do presente estudo, possibilitam pensar que a inserção do novo componente antes da sequência aprendida deixa o controle da ação mais suscetível a um processamento on-line e conseqüentemente a uma maior perturbação à estrutura aprendida, que levaria a um eventual abandono da mesma. Essa situação seria expressa pelo comportamento do sujeito em apresentar respostas num nível inferior do que ele vinha apresentando até o momento da inserção do novo componente.

O presente estudo enfoca fundamentalmente o efeito dos níveis de estabilização, seja ao final do processo de aquisição ou ao longo dos canais de desempenho, na eventual ocorrência dos processos de adaptação e modularização para explicar o aumento de complexidade em habilidade motora. Com isso, optou-se em utilizar a inserção do novo componente no local que levaria a maior probabilidade de perturbação. Essa decisão foi tomada para minimizar a possibilidade de ocorrência do processo de modularização pela pouca perturbação que o novo componente apresentaria. Espera-se com isso, elaborar uma situação experimental que seja favorável aos dois processos que podem estar envolvidos no aumento de complexidade na aquisição de habilidades motoras.

\section{MATERIAL E MÉTODOS}

\subsection{Amostra}


Duzentos e vinte e seis sujeitos de ambos os sexos, entre 10 e 13 anos de idade, que possuíam o termo de consentimento assinado pelos pais e/ou responsáveis (ANEXO I), realizaram o experimento. Nenhum deles tinha experiência na tarefa de aprendizagem. Os sujeitos foram escolares: a) participantes do Projeto Esporte Talento desenvolvido pelo CEPEUSP - Centro de Práticas Esportivas da Universidade de São Paulo; b) Colégio Lyceu Anglo de Muzambinho-MG; c) Colégio Anglo de Pouso Alegre-MG e d) Escola Estadual Presidente Arthur da Costa e SilvaMG. Do total de sujeitos que realizaram o experimento, somente os que alcançaram os dois critérios foram analisados, totalizando 153 sujeitos.

Essa pesquisa foi aprovada pelo comitê de Ética da Escola de Educação Física e Esporte da Universidade de São Paulo.

\subsection{Equipamento e tarefa experimental}

Para testar as hipóteses do presente estudo, foi utilizada uma tarefa de rastreamento de um padrão seriado composto por estímulos luminosos apresentados sequêncialmente e ininterruptamente. $\mathrm{O}$ objetivo da tarefa foi tocar, com a ponta dos dedos da mão de preferência, sensores numa sequência correspondente ao padrão de estímulos, de forma a descobrir a regularidade de acendimento das luzes e apreender a estrutura do padrão seriado. A determinação do número de estímulos e do intervalo entre os mesmos na fase de aquisição foram baseados no estudo de TANI (1995) e em estudos-piloto. A sequência utilizada constou de 5 estímulos (4-25-3-1) com intervalos interrestímulos de $800 \mathrm{~ms}$. Esses estímulos foram suficientemente desafiadores e possibilitaram, com a prática, a melhora do desempenho. $\mathrm{Na}$ fase de adaptação, foi adicionado um novo sensor. A localização da inserção do novo estímulo foi testada em estudos-piloto e optou-se pela inserção de um estímulo no início da sequência. A segunda tarefa constou de 6 estímulos (64-2-5-3-1).

O equipamento é composto por um conjunto de até 10 sensores de resposta, com dimensão de $3 \times 3 \mathrm{~cm}$, dispostos linearmente a uma distância de $5,5 \mathrm{~cm}$ entre 
eles. À frente desses sensores, estão posicionados leds em correspondência aos mesmos, separados por uma distância de $6 \mathrm{~cm}$ (FIGURA 2). O equipamento fica conectado a um microcomputador portátil, no qual foi instalado um software especificamente desenvolvido para esse trabalho: o STT v1.08, construído pela Lynx Tecnologia Eletrônica Ltda.

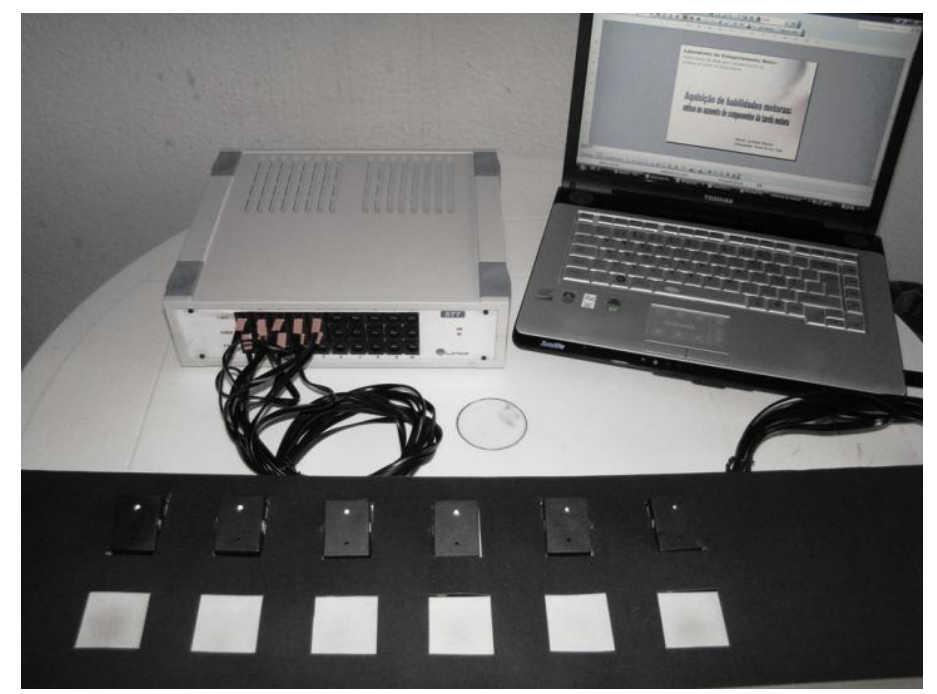

FIGURA 2 - Equipamento de rastreamento de sinais luminosos (Visão superior)

\subsection{Procedimentos}

Cada sujeito foi encaminhado individualmente a uma sala, e foi convidado a sentar à mesa onde estava disposto o equipamento. $O$ sujeito ficou de frente para 0 equipamento, de modo que o sensor central correspondesse à linha mediana do seu corpo, a uma distância que possibilitasse seu cotovelo permanecer a $90^{\circ}$ quando tocasse o sensor central.

Após a acomodação do sujeito em seu lugar, o próximo procedimento consistiu em familiarizá-lo com a situação experimental. Após a explicação do objetivo da tarefa, eles realizaram 6 tentativas com o toque em 3 sensores (sequência 1,4,6), com intervalo interrestímulo de 950ms. As instruções apresentadas aos sujeitos foram:

"Esse é um jogo de acendimento de luzes e tocar sensores. O seu objetivo é aprender a sequência de acendimento das luzes. 
Para isso, você deve tocar os sensores de resposta correspondentes às luzes que acendem. A sequência de acendimento das luzes irá se repetir várias e várias vezes.

Toda vez que você conseguir tocar corretamente, ganhará pontos. Uma vez que você compreenda a sequência de acendimento, pode tentar antecipar o acendimento de uma luz, ou seja, se você sabe qual a próxima luz que acenderá, então você pode tentar tocar o sensor antes que ela acenda. Com isso você ganhará bastante pontos. Há 3 observações: Se você errar um toque (por exemplo, tocar o sensor 3 quando acendeu a luz 4), não há problema; é só observar o próximo acendimento e responder a ele. Se tocar duas vezes o mesmo sensor, deixe passar o acendimento de uma luz e volte a responder a próxima. Se você for responder a uma luz e, antes de tocar o sensor, acender outra luz, deixe o primeiro toque $e$ vá para o sensor da luz que acabou de acender. Você vai praticar algumas tentativas de uma sequência bem fácil, para se familiarizar com a tarefa e com o equipamento e, depois, quando você disser que está pronto, eu soltarei a sequência mais desafiadora, que você irá aprender. A tarefa seriada poderá mudar, dependendo do seu desempenho".

\subsection{Delineamento}

O experimento constou de duas fases: estabilização e adaptação.

A fase de estabilização ocorreu até que o sujeito alcançasse o critério de desempenho, sendo:

Três séries consecutivas de respostas corretas (denominado de grupo G_3C);

Uma série de respostas antecipatórias (denominado de grupo G_1A);

Três séries de respostas antecipatórias (denominado de grupo G_3A).

A fase de adaptação ocorreu até que os sujeitos de todos os grupos alcançassem o critério de desempenho de uma série de respostas antecipatórias.

Os sujeitos tiveram até 120 tentativas, em cada fase, para alcançar os critérios. Em estudos-piloto, observou-se que os sujeitos que não alcançaram o critério até a $100^{\underline{a}}$ ou $110^{\underline{a}}$ tentativa tinham uma queda no seu desempenho e começavam a queixar-se da tarefa. 


\subsection{Organização dos dados}

Após a coleta de cada sujeito, o software gerava automaticamente um relatório com os dados de cada toque, evidenciando o tipo de resposta a cada estímulo. Cada tentativa foi composta por cinco (fase de estabilização) ou seis (fase de adaptação) respostas correspondentes ao acendimento dos leds. Como o número de tentativas para alcançar os critérios foi específico para cada sujeito, o número total de tentativas foi dividido em 6 blocos ${ }^{4}$ para cada fase. Esse procedimento foi executado por meio de uma sintax programada em Python e executada de maneira integrada ao Spss v.17 para gerar automaticamente os 6 blocos de tentativas para cada sujeito, em cada fase. Quando um sujeito apresentava um número de tentativas para a obtenção de um dos critérios inferior a 6 tentativas, eram designados blocos sem valores (missing value). Para as medidas de consistência, foram construídos apenas 3 blocos, devido às particularidades apresentadas nessas medidas (ver resultados).

Após a organização da informação para cada sujeito, todos os arquivos foram unificados para a elaboração das medidas, descritas abaixo.

\subsection{Medidas}

As medidas da tarefa de rastreamento de um padrão luminoso seriado originam-se da diferença de tempo entre o aparecimento do estímulo e o toque no sensor de resposta, assim como da correspondência entre estímulo e o sensor de resposta tocado (FIGURA 3), possibilitando elaborar quatro tipos de respostas qualitativas: omissas, erradas, corretas e antecipatórias.

Resposta omissa (Ro): nenhuma resposta ocorre entre dois estímulos consecutivos, exceto em caso de resposta antecipatória seguida de resposta correta

\footnotetext{
${ }^{4}$ Também foram testados 3 e 4 blocos de tentativas em análises exploratórias, mas não foram observadas diferenças substanciais.
} 
ou errada;

Resposta errada $(\mathrm{Re})$ : resposta a um estímulo não correspondente realizada antes da apresentação do estímulo subsequente;

Resposta correta $(\mathrm{Rc})$ : resposta a um estímulo correspondente realizada antes da apresentação do estímulo subsequente;

Resposta antecipatória (Ra): resposta correta realizada antes da apresentação do estímulo correspondente.
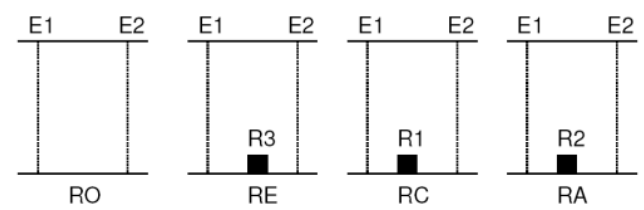

FIGURA 3 - Caracterização do tipo de resposta de acordo com o momento do toque e sensor tocado.

A partir das respostas qualitativas, foi elaborado um conjunto de medidas com o intuito de caracterizar diferentes aspectos do desempenho. O primeiro referese a medidas que expressam a estrutura da habilidade: a) proporção de cada tipo de resposta; b) desempenho coletivo máximo; c) consistência do desempenho da sequência; d) consistência do desempenho dos componentes. Para caracterizar os parâmetros da estrutura, utilizou-se a medida do tempo entre o estímulo e a resposta e, para caracterizar a ocorrência dos processos de modularização e adaptação, utilizou-se o indicador de ocorrência dos processos.

\subsubsection{Proporção de ocorrência de cada tipo de resposta}

A proporção de ocorrência de cada tipo de resposta em cada tentativa foi calculada pela razão entre a frequência de toques com respostas omissas, erradas, corretas e antecipatórias e o número de estímulos da tentativa. Após isso, foi calculada a média dessa proporção para cada um dos 6 blocos. Essa medida foi denominada porcentagem de respostas por bloco (Ro[\%], $\operatorname{Re}[\%], \mathrm{Rc}[\%]$ e $\mathrm{Ra}[\%]$ ). 


\subsubsection{Desempenho Coletivo Máximo (DCM)}

Para obter um indicativo de todas as respostas apresentadas numa mesma tentativa, elaborou-se uma única medida que sintetiza a frequência das diferentes respostas. Buscou-se expressar a composição de respostas da tentativa. A estratégia utilizada foi a de calcular a frequência de cada tipo de resposta dentro de uma sequência, e atribuir para cada tipo de resposta uma pontuação 10 vezes maior que o tipo de resposta anterior, iniciando com 1 ponto para cada Ro, 10 pontos para cada Re, 100 pontos para cada Rc e 1000 pontos para cada Ra, como no exemplo de uma tentativa com 5 estímulos (TABELA 1).

TABELA 1 - Exemplo de cálculo do DCM.

\begin{tabular}{|c|c|c|}
\hline Estímulo & Resposta & Pontuação \\
\hline 1 & Errada & $1(\mathrm{Ro})$ * 1 \\
\hline 2 & Omissa & $1(R e)^{*} \quad 10$ \\
\hline 3 & Correta & $2(\mathrm{Rc})$ * 100 \\
\hline 4 & Correta & $1(\mathrm{Ra}) * 1000$ \\
\hline 5 & Antecipada & Resposta=1211 \\
\hline
\end{tabular}

Dos 5 estímulos desta tentativa-exemplo, nota-se que o sujeito realizou um toque com resposta omissa, um com resposta errada, dois com resposta correta e um com resposta antecipatória. Assim, multiplicando-se a frequência de cada tipo de resposta por sua respectiva pontuação, nota-se que a pontuação final foi de 1211. Da esquerda para a direita, é possível ler: $1 \mathrm{Ra}, 2 \mathrm{Rc}, 1 \mathrm{Re}$ e $1 \mathrm{Ro}$. Como o desempenho da tarefa foi analisado por meio do alcance de critérios, optou-se por descrever o desempenho máximo por bloco de tentativas ${ }^{5}$. Após a atribuição de pontos a cada tipo de resposta para cada tentativa, foi calculado o valor máximo para cada um dos blocos de tentativas. Com essa medida foi possível observar o maior desempenho

5 Outra estratégia testada foi calcular o desempenho coletivo mais frequente para cada sujeito em cada bloco por meio da moda. No entanto, para muitos sujeitos não houve moda ou o comportamento foi multimodal. 
que o sujeito alcançou para cada bloco de tentativas. Essa medida foi denominada Desempenho coletivo máximo (DCM).

\subsubsection{Consistência do desempenho dos componentes (CDC) e da sequência (CDS)}

As respostas antecipatórias representam o mais alto nível de desempenho alcançado na tarefa utilizada no presente estudo, uma vez que expressam a competência do sujeito em integrar os estímulos e, assim, apresentar não só a compreensão da sequência do acendimento das luzes, como também do padrão seriado dentro de uma estrutura temporal (RESTLE, 1970). Com isso, uma forma de obter um indicativo do nível de estabilização do desempenho está na mensuração da proporção de respostas antecipatórias. Tradicionalmente, o cálculo da proporção de respostas antecipatórias realiza-se pela quantificação do número de respostas antecipatórias em relação à quantidade de estímulos apresentados. Se um sujeito realiza 10 tentativas com 5 estímulos-resposta e realiza 10 respostas antecipatórias, o cálculo da proporção de respostas antecipatórias se faz pela razão 10/50 (5 estímulos x 10 tentativas). No entanto, esse procedimento não considera se as respostas antecipatórias estão concentradas em poucas tentativas ou distribuídas entre as tentativas do bloco; ou seja, não distingue, por exemplo, um sujeito que apresentou $10 \mathrm{Ra}$ em 2 tentativas ( $5 \mathrm{Ra}$ em cada) de outro que as apresenta distribuídas nas 10 tentativas (1 Ra em cada). Considerar a distribuição das $\mathrm{Ra}$ diferencia a consistência da sequência (primeiro caso) da consistência nos componentes (segundo caso).

O presente estudo investigou o efeito da consistência a partir destas duas perspectivas. Para análisar a consistência nos componentes, calculou-se a proporção de respostas antecipatórias em relação ao número total de tentativas do bloco. Para a consistência do desempenho na sequência, calculou-se a proporção de tentativas em que pelo menos 3 componentes (mais da metade dos estímulos da sequência) foram executados com respostas antecipatórias em relação ao número total de tentativas do bloco.

Como relatado na análise exploratória e resultados, a distribuição da 
proporção de Ra nos blocos de tentativas expressa algumas particularidades. Com isso, optou-se por classificar a consistência da sequência em 3 níveis: baixa quando nenhuma tentativa apresentou pelo menos três respostas antecipatórias; moderada - quando houve até $10 \%$ de tentativas com pelo menos 3 respostas antecipatórias, e alta - quando houve mais de $10 \%$ de tentativas com pelo menos 3 respostas antecipatórias. Essa medida foi denominada de Consistência do Desempenho da Sequência (CDS). Os mesmos critérios foram adotados para o que denominamos Consistência no Desempenho dos Componentes (CDC): baixa quando não houve pelo menos uma resposta antecipatória; moderada - quando houve até $10 \%$ de respostas antecipatórias; e alta - quando houve mais de $10 \%$ de respostas antecipatórias.

\subsubsection{Tempo entre o estímulo e a resposta}

O tempo entre o estímulo e a resposta foi calculado apenas para os sujeitos que apresentaram a manutenção da estrutura de respostas antecipatórias adquirida na fase de estabilização na fase de adaptação. Ela será utilizada para identificar se houve a manutenção da magnitude e variação dos parâmetros da estrutura da habilidade aprendida na fase de estabilização quando inserido o novo componente, utilizando-se da média e do desvio padrão do tempo entre o estimulo e resposta dos 5 componentes da última tentativa da fase de estabilização e da primeira da fase de adaptação com os 5 componentes praticados inicialmente com respostas antecipatórias. Essa medida foi denominada Tempo entre Estímulo e Resposta (TER).

\subsubsection{Quantidade de tentativas para o alcance dos critérios nas fases de aquisição e adaptação}

Para estimar o efeito do nível de estabilização e dos processos de modularização e adaptação sobre o quantidade de tentativas para alcançar o critério na tarefa mais complexa optou-se em quantificar o número de tentativas para 
alcançar o primeiro e o segundo critério.

\subsection{Análises e testes estatísticos}

\subsubsection{Análise exploratória dos dados}

Inicialmente, os dados foram submetidos a uma análise exploratória com o intuito de conhecer sua distribuição em cada bloco. Essa tarefa foi realizada observando-se os histogramas, diagramas de extremos e quartis, medida de assimetria e achatamento, bem como a aplicação do teste de normalidade de Shapiro Wilk e Kolmogorov-Smirnov. A ocorrência de casos discrepantes (outliers) foi inspecionada por meio do diagrama de extremos e quartis. As análises exploratórias foram realizadas no SPSS v.17.

A distribuição da proporção de ocorrência das respostas antecipatórias, omissas e erradas e do DCM, CDS e CDC apresentaram algumas particularidades (apresentadas nos resultados) e exigiu a adição de procedimentos exploratórios, com o intuito de melhor entender a estrutura dos dados e adequar as análises. Foi analisada a frequência de casos com valores maiores que zero, a frequência de sujeitos com valores extremos, a razão entre o valor do skewness e seu erro padrão e, por fim, a inspeção aos histogramas para cada tipo de resposta em cada bloco de prática.

\subsubsection{Análise relativa às questões da mudança normativa}

\subsubsection{DCM}

Para a análise da mudança normativa do DCM, foi utilizado o teste não paramétrico de Friedman. Quando o valor do $\chi^{2}$ se revelou significativo na análise de todos os blocos, foi aplicado o procedimento sugerido por SIEGEL e CASTELLAN JR. (2006) para realizar as comparações múltiplas e identificação do locus das diferenças. O desempenho do grupo foi expresso pelo desempenho coletivo máximo 
mais frequente (moda) para cada grupo por bloco. Também foram apresentados valores mínimos e máximos do grupo, assim como o valor em porcentagem de sujeitos que mostram esses comportamentos.

Com o intuito de descrever o sentido da mudança individual do DCM ao longo dos blocos, foram elaboradas tabelas cruzadas entre os blocos adjacentes por toda a fase de aquisição e adaptação. Com base nas tabelas cruzadas, foi quantificada a proporção de sujeitos que mudaram o DCM, tanto para maiores e menores níveis, quanto os que se mantiveram entre blocos adjacentes. Foram construídos gráficos de linhas com as proporções desses três tipos de mudança, denominadas: a) ascendente; b) descendente; c) ausência de mudança.

\subsubsection{CDS e CDC}

Dada a natureza da distribuição da CDS e CDC (apresentada nos resultados), uma forma de explorar se há incrementos significativos foi codificá-las numa escala ordinal. Foram elaborados 3 níveis de consistência: baixa - com $0 \%$ de ocorrência; moderada - com até $10 \%$ de ocorrência e alta - acima de $10 \%$ de ocorrência. Como os valores da consistência do desempenho nos primeiros blocos não apresentou variação, os 6 blocos foram reorganizados em 3 novos blocos: os blocos 1 e 2 passaram a ser o bloco 1; os blocos 3 e 4 passaram a ser o bloco 2 e os blocos 5 e 6 passaram a ser o bloco 3. Para analisar o comportamento da CDS e CDC ao longo dos blocos, foram calculadas as proporções de sujeitos nas 3 categorias.

\subsubsection{Análise da estabilidade interindividual na mudança intra-individual}

\subsubsection{DCM}

A estimativa da estabilidade das diferenças interindividuais na mudança intraindividual do DCM foi efetuada no programa estatístico Longitudinal Data Analysis (LDA - KOWALSKI e SCHNEIDERMAN, 1992), construído especialmente para lidar 
com alguns dos problemas decorrentes da análise de informações longitudinais. A estabilidade foi descrita pela estatística de Kappa $(\kappa)$ de Cohen.

A estatística $\kappa$ de Cohen evidencia a ocorrência de estabilidade de uma dada trajetória de mudança quando permanece entre um par de percentis adjacentes empiricamente construídos e selecionados pelo pesquisador (por exemplo, P1-33; P33-P66). Cada par de percentis é definido como um canal específico de desempenho. Partindo da análise da frequência do desempenho de cada sujeito dentro de cada um dos canais, estima-se a estabilidade da mudança entre os canais. Trata-se de uma estatística descritiva não-paramétrica, ou seja, que não exige qualquer tipo de estruturação na distribuição dos dados. Os resultados variam de 0 a 1 e, com base nas sugestões de LANDIS e KOCH (1977), assume-se a seguinte interpretação para os valores: $\kappa>0,75=$ estabilidade excelente; $0,40 \leq \kappa \leq 0,75=$ estabilidade boa; $\kappa<0,40=$ estabilidade fraca. $\mathrm{O}$ estudo da estabilidade com base no $\kappa$ de Cohen é um recurso útil, na medida em que possibilita pensar que os desempenhos dos sujeitos podem pertencer a diferentes canais, os quais refletem subgrupos de níveis distintos de estabilização funcional do desempenho. No presente estudo foi considerada, em termos exploratórios, a presença de 3 canais ${ }^{6}$. Como no último bloco todos os sujeitos alcançaram o mesmo valor, considerou-se para efeito do calculo do $\kappa$ de Cohen e dos canais apenas os cinco blocos iniciais. Para essa análise, utilizou-se apenas os sujeitos do grupo G_1A e G_3A.

Os resultados finais desta análise consistem: a) nos valores tercílicos para cada bloco de prática; b) num valor do $\kappa$ de Cohen geral para estimar a estabilidade do grupo; c) num valor do $\kappa$ de Cohen para cada canal; d) num valor do $\kappa$ de Cohen para cada sujeito; e e) na frequência de permanência de cada sujeito nos diferentes canais.

\subsubsection{CDS e CDC}

Para estimar a estabilidade das diferenças interindividuais na mudança intra-

\footnotetext{
${ }^{6}$ Também foram explorados 2 e 4 canais, mas não houve diferenças substanciais nos resultados gerais.
} 
individual da CDS e CDC foi utilzada a estatística Kappa, que avaliou se os sujeitos tendem a permanecer com o mesmo nível de consistência (baixa, moderada e alta) entre os blocos de tentativas. Vale ressaltar que, pelo fato de a natureza dos dados da CDS e CDC ser ordinal em 3 categorias, não foi possível utilizar $0 \kappa$ de Cohen para estimar a estabilidade individual. Com isso, a estabilidade individual foi estimada pela frequência do sujeito em cada um dos níveis, sendo: a) excelente - quando permaneceu em apenas um dos níveis durante os 3 blocos; b) moderada - quando permaneceu em um dos níveis pelo menos em dois blocos; c) fraca - quando alternou entre os 3 níveis nos 3 blocos. Para essa análise foram utilizados apenas os sujeitos do grupo G_1A e G_3A.

\subsubsection{Análise da associação entre os níveis de estabilidade e comportamentos modais individuais e a formação de subgrupos}

\subsubsection{DCM}

Uma possibilidade de análise do $\kappa$ Cohen é apresentar informação sobre 0 nível de estabilidade de cada sujeito em relação aos canais de desempenho do grupo e da frequência de permanência em cada canal. Há ainda a possibilidade de qualificar os valores do $\kappa$ de Cohen de acordo com a sugestão de interpretação de LANDIS e KOCH (1977) em: estabilidade excelente (EE), estabilidade boa (EB), e estabilidade fraca (EF).

Para efeito elucidativo, a TABELA 2 apresenta um exemplo hipotético sobre a análise do $\kappa$ Cohen de 10 sujeitos para 3 canais em 12 blocos de tentativas. $O$ primeiro sujeito apresenta seu desempenho durante os 12 blocos no canal 1 , o valor kappa é 1 e pode ser classificado como estabilidade excelente (tracking perfeito). Por outro lado, o sujeito 2 tem o seu desempenho distribuido pelos três canais: 3 vezes no primeiro, 3 vezes no segundo e 6 vezes no terceiro, um kappa de 0,32, classificando estabilidade fraca. 
TABELA 2 - Valores individuais para 10 sujeitos da análise do $\kappa$ Cohen para uma variável hipotética.

\begin{tabular}{rccccc}
\hline Suj & Canal 1 & Canal 2 & Canal 3 & Kappa & $\begin{array}{c}\text { Nível de Estabilidade (Landis \& } \\
\text { Koch, 1977) }\end{array}$ \\
\hline 1 & 12 & & & 1,00 & Excelente \\
2 & 3 & 3 & 6 & 0,32 & Fraca \\
3 & 8 & 3 & 1 & 0,47 & Boa \\
4 & 10 & 2 & & 0,70 & Boa \\
5 & 5 & 6 & 1 & 0,38 & Fraca \\
6 & 8 & 3 & 1 & 0,47 & Boa \\
7 & & 5 & 7 & 0,47 & Boa \\
8 & & 3 & 9 & 0,59 & Boa \\
9 & 9 & 3 & & 0,59 & Boa \\
10 & 8 & 2 & 2 & 0,45 & Boa \\
\hline
\end{tabular}

As análises da associação do canal modal e do nível de estabilidade nos canais foram realizadas para os sujeitos com estabilidade excelente e boa, mediante o cálculo do canal com maior frequência de permanência do desempenho ao longo dos blocos de prática. No entanto, para os sujeitos com estabilidade fraca houve a preocupação de analisar se a instabilidade foi devida a uma mudança "permanente" (num único sentido) entre os canais (por exemplo, do canal 1, para o 2 e 3 ), ou se oscilou "erraticamente". Para isto, foi determinado o canal com maior frequência dentre os três primeiros blocos de prática, e o canal com maior frequência dentre os três últimos blocos de prática. Daí decorre a obtenção de três tipos de tendência na mudança: oscilação - quando a moda nos três primeiros blocos foi igual à moda nos três últimos blocos; descendente - quando a moda dos três primeiros blocos foi maior do que a moda dos três últimos blocos; e ascendente - quando a moda dos três primeiros blocos foi menor do que a moda dos três últimos blocos. É importante 
enfatizar que para os sujeitos com boa e excelente estabilidade o canal modal expressa o seu comportamento; no entanto, o mesmo não ocorre para os sujeitos com baixa estabilidade. Deste modo, este tipo de análise auxilia a distinguir as diferentes tendências nas mudanças que os sujeitos apresentam.

Com base na análise do desempenho modal e nível de estabilidade individual, foram formulados os seguintes subgrupos: estabilidade excelente no primeiro canal (EE1), estabilidade excelente no segundo (EE2), e estabilidade excelente no terceiro (EP3); estabilidade boa no primeiro canal (EB1), estabilidade boa no segundo (EB2) e estabilidade boa no terceiro (EB3); estabilidade fraca com oscilação (EFO), estabilidade fraca descendente (EFD), e estabilidade fraca ascendente (EFA). O comportamento das trajetórias individuais e seus respectivos canais desses subgrupos serão apresentados em gráficos.

É importante ressaltar que os sujeitos que apresentam uma excelente estabilidade nas diferentes facetas de resposta têm 0 seu desempenho, constantemente, nos canais extremos: terceiro canal (EE3) e primeiro canal (EE1). São sujeitos que durante toda a prática sempre apresentam os maiores e menores valores para o DCM, em relação aos demais sujeitos. Os sujeitos que apresentam uma estabilidade boa nas diferentes facetas de respostas têm o seu desempenho mais frequentemente no primeiro canal (EB1), no segundo (EB2) ou no terceiro (EB3), mas apresentam esporadicamente o desempenho em outros canais. Já os sujeitos com estabilidade fraca (EF) têm o seu desempenho com tendência a mudança ascendente (EFA), descendente (EFD) e oscilando entre os três canais ao longo da prática, sem permanência em um canal específico.

\subsubsection{CDS e CDC}

Uma vez estimada a estabilidade da CDS para cada sujeito, sua associação com os níveis de consistência operacionalizou-se pelo cáculo do nível modal para os sujeitos com estabilidade excelente e boa, e para os sujeitos com estabilidade fraca ocorreu por meio do sentido da mudança entre os níveis, configurando-se: ascendente (quando, a cada bloco, o nível foi superior ao anterior); descendente 
(quando, a cada bloco, o nível foi inferior ao anterior); oscilação (quando mudava-se de um nível em um bloco e depois no próximo votava-se ao mesmo nível de consistência). Com base nessas estratégias, formulou-se subgrupos com: estabilidade excelente no primeiro nível (EF1), no segundo (EF2), e no terceiro (EE3); estabilidade boa no primeiro nível (EB1), no segundo (EB2) e no terceiro (EB3); estabilidade fraca com oscilação (EFO), descendente (EFD), e ascendente (EFA).

\subsubsection{Formação dos subgrupos com comportamentos opostos para o DCM, a CDS e a CDC}

Quando classificados os sujeitos dentro de cada canal/nível de estabilidade e canal/nível modal, notou-se que para alguns tipos de subgrupo o número de sujeitos foi baixo (ver nos resultados). Com isso, optou-se por agrupar os subgrupos mais próximos em termos de estabilidade e apenas investigar o efeito do nível de estabilidade entre subgrupos com comportamentos opostos. A formação destes novos grupos fez-se pela combinação dos subgrupos anteriormente apresentados.

Para o DCM, foram definidos 4 subgrupos: a) Estabilidade excelente e boa no canal 3 (E_C3); b) estabilidade excelente e boa no canal 1 (E_C1); c) estabilidade fraca com tendência a mudança ascendente (MA), e d) estabilidade fraca com tendência a mudança descendente (MD).

Para o CDS e CDC, foram definidos 3 subgrupos: a) Estabilidade excelente e boa no nível 3 (E_N3); b) estabilidade excelente e boa no nível 1 (E_N1); c) estabilidade fraca com tendência a mudança ascendente (MA).

\subsubsection{Análise da manutenção da estrutura das respostas antecipatórias na tarefa mais complexa}

Para obter um indicativo sobre a ocorrência dos processos de modularização e adaptação quando inserido o novo componente, um primeiro passo constou da observação da manutenção da estrutura das respostas antecipatórias na tarefa mais 
complexa logo nas primeiras tentativas. Para isso, realizou-se uma inspeção nas primeiras dez tentativas da fase de adaptação, com o intuito de observar tentativas com respostas antecipatórias nos 5 componentes já aprendidos na fase de estabilização. A partir dessa inspeção, foram denominados os comportamentos: Modular (quando dentre as 10 tentativas em pelo menos uma ocorreu respostas antecipatórias para os 5 componentes) e Adaptativo (quando dentre as 10 tentativas, nenhuma ocorreu com respostas antecipatórias para os 5 componentes). Essa identificação distingue a ocorrência dos dois processos envolvidos no aumento de complexidade, e foi utilizada como resposta da variável dependente.

\subsubsection{Tempo entre o estímulo e a resposta dos sujeitos que mantiveram a estrutura de respostas antecipatórias na fase de adaptação}

Foi utilizado o teste $\mathrm{t}$ para amostras dependentes para cada medida dos parâmetros da estrutura da habildade (média e desvio padrão do TER) para os sujeitos que apresentaram a manutenção da estrutura de respostas antecipatórias da fase de estabilização na tarefa mais complexa.

\subsubsection{Análise do efeito do nível de estabilização na probabilidade de ocorrência dos processos de modularização e adaptação}

Estudos com variáveis de saída (dependentes) com apenas dois valores possíveis (dicotômicas) - sim ou não, alto ou baixo, bom ou ruim - e a decisão por um deles dependente de uma série de atributos relacionados ao evento (variáveis independentes contínuas e/ou categóricas) são possíveis de serem realizados por meio de modelos de regressão logística binária. Esse tipo de estatística não requer qualquer tipo de distribuição dos dados da variável de saída, e também caracterizase como uma regressão múltipla (FIELD, 2009). Busca-se, fundamentalmente, estimar a influência de alguns fatores (com natureza intervalar ou dicotômica) na probabilidade de mudança da ocorrência de um evento dicotômico.

Essa análise torna-se bastante adequada para estimar a probabilidade de 
mudança na ocorrência dos processos de modularização e adaptação por meio dos níveis de estabilidade alcançados na fase de estabilização. Uma vez que se tem uma variável dependente com resposta dicotômica (ocorrência de modularização ou adaptação) e quatro variáveis independentes, também categóricas, encontra-se:

- Nível de estabilização alcançado ao final do processo de aquisição, com dois níveis: G_1A (alcançar uma tentativa com respostas antecipatórias) e G_3A (alcançar três tentativas com respostas antecipatórias).

- Nível de estabilidade ao longo dos canais do DMC, com quatro níveis: E_C1; E_C3; MA e MOD.

- Nível de estabilidade ao longo dos canais do CDS, com três níveis: E_N1; E_N3 e MA;

- Nível de estabilidade ao longo dos canais do CDC, com três níveis: E_N1; E_N3 e MA;

Os demais subgrupos, ausentes da descrição acima, foram excluídos da análise por não terem um número adequado de sujeitos.

$\mathrm{Na}$ regressão logística binária, como em outros tipos de regressão, estabelece-se um modelo inicial (ou modelo nulo - sem as variáveis indepententes) e, posteriormente, se estabelece os demais modelos com as variávies indepententes escolhidas. E então pode-se realizar as comparações entre eles, observando o ganho no poder de explicação dos dados para então optar pelo modelo que melhor descreva os dados com o mínimo de parâmetros. Para isso, foi selecionado o modelo Stepwise por Forward:Fr. Essa opção permite análisar passo a passo a inclusão de uma variável para observar se o modelo consegue explicar mais casos quando uma unidade da variável preditora (independente) muda. Segundo FIELD (2009), esse método é o mais indicado quando não há estudos que apontem quais variáveis independentes poderão ser preditoras confiáveis. Outro aspecto importante na escolha da opção de Stepwise refere-se à questão da (multi)colinearidade ser considerada, uma vez que o próprio algoritmo verifica a contribuição extra trazida pelas variáveis que irão (ou não) ingressar no modelo, a cada passo.

O mais importante para a interpretação da regressão logística é o valor da $\exp b(\operatorname{Exp}(B)$ na saída do SPSS). É um indicador da mudança nas probabilidades 
resultantes da mudança de uma unidade no previsor. Ele expressa a oportunidade de um evento ocorrer dividida pela probabilidade dele não ocorrer.

Além da análise das melhores variáveis independentes que constituirão o modelo, é importante avaliar se este se ajusta adequadamente aos dados. A avaliação do ajuste do modelo foi embasada em diferentes indicadores. O primeiro foi a observação dos valores da máxima verossimilhança logarítmica (-2LL), seguida da $\mathrm{R}^{2}$ de Cox e Snell; $\mathrm{R}^{2}$ de Nagelkerke; o teste de Hosmer e Lemeshow.

A expressão “-2LL" significa: 2 multiplicado pelo logaritmo decimal da probabilidade (em inglês likelihood) de se obter os resultados da amostra com base nas estimativas obtidas pelo modelo logístico. Valores menores do "-2LL" indicam melhores ajustes do modelo, ao comparar probabilidades previstas e observadas. Vale lembrar que não há padrões pré-estabelecidos de valores com os quais se balizar, e tampouco essa estatística tem limites superior ou inferior (HAIR JR., ANDERSON, TATHAM \& BLACK, 2005). Com isso, espera-se que ao introduzir uma variável independente os valores de -2LL apresentem-se menores, com o valor do $p$ do qui-quadrado abaixo do nível de significância estabelecido.

As medidas de $\mathrm{R}^{2}$ (de Cox e Snell e de Nagelkerke) buscam se aproximar do $\mathrm{R}^{2}$ em regressão linear múltipla, de modo a facilitar a avaliação da qualidade do ajuste, sendo consideradas comparáveis. Tais medidas permitem apenas verificar se a qualidade das predições melhora ou não com determinado modelo em relação a outros concorrentes. Então, segundo esses autores, havendo modelos igualmente válidos, é preferível aquele que apresentar maior $\mathrm{R}^{2}$.

Para HAIR JR. et alii (2005), o melhor indicador do ajustamento do modelo é dado pelo teste de Hosmer e Lemeshow. O bom ajuste é indicado por diferenças pequenas entre a classificação observada e a prevista, sendo desejável não rejeitar a hipótese nula (de que não há diferenças entre as distribuições observadas e previstas). Esse teste deve ser preferido, para essa finalidade, também em relação às matrizes de classificação.

O teste de Hosmer e Lemeshow apesar de este ser um qui-quadrado (aliás, outro nome pelo qual é conhecido), é considerado mais robusto do que os testes tradicionais baseados nessa estatística (em especial, se a amostra é pequena ou há 
covariáveis contínuas). Já a matriz de classificação, por apresentar as proporções de sucesso (classificação correta), e por permitir a verificação do desempenho do modelo em relação a cada um dos grupos, pode fornecer informações úteis sobre possíveis problemas do modelo com a classificação de algum grupo em particular, ainda que no geral tenha se mostrado adequado (HAIR JR. et alli, 2005).

Para a obtenção do indicativo da aderência do modelo, foi utilizado o método de inspeção dos resíduos standardized, além das opções resíduos padronizados acima de 3 desvios-padrão, tanto por caso quanto para todos os casos e de Hosmer-

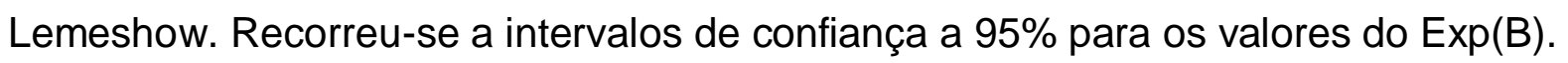

É importante lembrar que para proceder à análise de regressão logística foram realizados, inicialmente, alguns procedimentos:

- Definir a ordem das classes nas variáveis independentes, por serem categóricas;

- Definição da categoria/subgrupo de referência;

- Aplicação de testes de qui-quadrado entre as variáveis independentes e dependentes;

Os valores encontrados do $\operatorname{Exp}(\mathrm{B})$ no modelo sempre estarão relacionados à probabilidade de mudança de oportunidade de ocorrência do evento mais frequente (adaptação ou modularização). Por exemplo, se houver maior ocorrência do processo de adaptação o modelo nulo (sem as variáveis independentes) calcula os resíduos e o maior peso é devido aos casos de modularização, pois são desvios não explicados. No entanto, pelo método stepwise busca-se analisar se há diminuição dos resíduos, ou seja, um melhor ajustamento aos casos do processo de modularização e adaptação quando introduzida uma das variáveis independentes. Uma vez introduzida a variável independente, com o subgrupo de referência, calculase se há aumento de probabilidade da ocorrência do evento menos frequente (nesse exemplo, a modularização) aumentar quando uma unidade da variável de independente mudar em relação à referência. Por exemplo, se a variável introduzida for o DCM e a referência for o subgrupo com estabilidade no primeiro canal, será calculado se houve aumento na predição dos casos de adaptação e modularização; se for positivo, calcula-se quantas vezes mais isso ocorreu em comparação ao 
subgrupo com estabilidade no terceiro canal, e atribui-se um valor à taxa de mudança de ocorrência $\operatorname{Exp}(B)$, ou seja, busca-se analisar se o número de ocorrências no subgrupo com estabilidade em canais superiores aumenta a probabilidade do processo de modularização ocorrer em relação ao processo de adaptação.

\subsubsection{Análise da quantidade de tentativas para o alcance dos critérios na fase de aquisição e adaptação: efeito do nível de estabilização e processos envolvidos no aumento de complexidade da habilidade motora}

Para analisar o efeito do nível de estabilização alcançado ao final da fase de estabilização na quantidade de prática para o alcance dos critérios da fase de estabilização e adaptação foi utilizada a análise de variância mista: fator fixo (3 Grupos: G_3C, G_1A e G_3A) e fator repetido no tempo (2 Fases: estabilização e adaptação). Sempre que o valor de $\mathrm{F}$ se revelou significativo para a interação e/ou para o fator principal das mudanças temporais foi realizado um teste sequêncial de múltiplas comparações. O teste utilizado foi o de Bonferroni que ajusta o alfa $(\alpha)$ ao número de multiplas comparações efetuadas.

Para analisar se a quantidade de tentativas utilizadas pelos sujeitos que realizaram o processo de modularização para alcançar o critério da tarefa com novos componentes foi diferente dos sujeitos que realizaram o processo de adaptação, utilizou-se o teste $t$ de Student para medidas independentes. Como frequência da ocorrência dos processos de modularização e adaptação não foi semelhante, optouse pela randomização dos casos para o balanceamento do número de sujeitos em cada um dos processos.

Para analisar a associação entre a quantidade de tentativas para alcançar os critérios das duas fases utilizou-se da correlação de Pearson em cada grupo: G_3C; G_1A e G_3A.

\subsubsection{Análise do tipo de resposta logo após a inserção do novo componente}

Para analisar o tipo de resposta após a inserção do novo componente 
computou-se a proporção de sujeitos que realizaram cada um dos tipos de respostas (Ro, Re, Rc, Ro) e a sua frequencia de componentes para os três grupos. Para comparar as diferenças na proporção de sujeitos entre os três grupos para cada tipo de resposta foi utilizado o teste de qui-quadrado e suas múltiplas comparações, mediante o módulo Trend do programa Pepi 4.0.

\section{RESULTADOS}

A exposição dos resultados seguirá a ordem dos objetivos formulados. Inicialmente será apresentada a análise exploratória, seguida dos resultados normativos, estimativa da estabilidade interinvididual na mudança intraindividual, técnicas exploratórias para a formação de subgrupos, identificação da ocorrência do processo adaptativo e modular, resultados da regressão logística, e o efeito de tais processos na aprendizagem da nova tarefa motora. As análises principais serão apresentadas a seguir, e as análises secundárias serão inseridas na seção de Anexos.

\subsection{Análise exploratória dos dados}

$\mathrm{Na}$ análise exploratória foram encontrados, no máximo, $6 \%$ de casos discrepantes ${ }^{7}$ para o G_1A e G_3A, porém para G_3C os valores chegaram a 76\% em todas as facetas do desempenho, especialmente nos últimos blocos (TABELA 3). A série de testes de Shapiro-Wilk e Kolmogorov-Smirnov ${ }^{8}$ indicou ausência de normalidade na distribuição dos dados para todos os blocos nas diferentes facetas do desempenho (Anexo II).

\footnotetext{
${ }^{7}$ Valores acima de \pm 3 z score.

${ }^{8}$ Quando houve menos de 40 sujeitos na amostra foi utilizado o teste de Shapiro Wilk, e para um número maior o teste de Kolmogorov-Smirnov.
} 
TABELA 3 - Número de sujeitos com valores extremos, analisado para cada tipo de resposta, grupo e bloco.

\begin{tabular}{rlcccccc}
\hline Resposta & Grupo & B1 & B2 & B3 & B4 & B5 & B6 \\
\hline Re & & & & & & & \\
& G_3C & 3,92 & 5,88 & 5,88 & 52,94 & 56,86 & 78,43 \\
& G_1A & 0,00 & 0,00 & 1,92 & 0,00 & 1,92 & 3,85 \\
& G_3A & 0,00 & 0,00 & 0,00 & 0,00 & 0,00 & 2,00 \\
Rc & & & & & & & \\
& G_3C & 1,96 & 1,96 & 1,96 & 50,98 & 56,86 & 78,43 \\
& G_1A & 0,00 & 0,00 & 0,00 & 0,00 & 0,00 & 3,85 \\
& G_3A & 0,00 & 0,00 & 0,00 & 0,00 & 0,00 & 2,00 \\
Ra & & & & & & & \\
& G_3C & 3,92 & 3,92 & 5,88 & 52,94 & 58,82 & 78,43 \\
& G_1A & 1,92 & 1,92 & 1,92 & 0,00 & 3,85 & 3,85 \\
& G_3A & 4,00 & 2,00 & 2,00 & 2,00 & 0,00 & 2,00 \\
Ro & & & & & & & \\
& G_3C & 5,88 & 3,92 & 3,92 & 50,98 & 58,82 & 78,43 \\
& G_1A & 1,92 & 1,92 & 0,00 & 1,92 & 1,92 & 5,77 \\
& G_3A & 0,00 & 2,00 & 2,00 & 2,00 & 2,00 & 4,00 \\
\hline
\end{tabular}

Na FIGURA 4 encontram-se três exemplos de distribuição para as respostas antecipatórias dos 3 grupos, evidenciando que em diferentes momentos da prática há uma forte assimetria à direita, principalmente nos primeiros blocos 

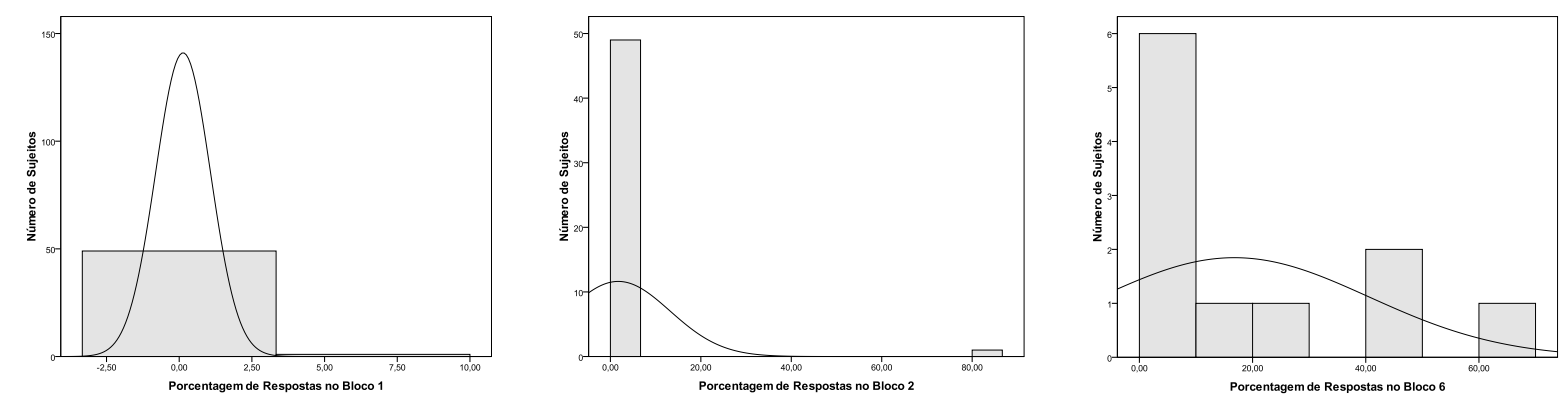

Ra do G_3C
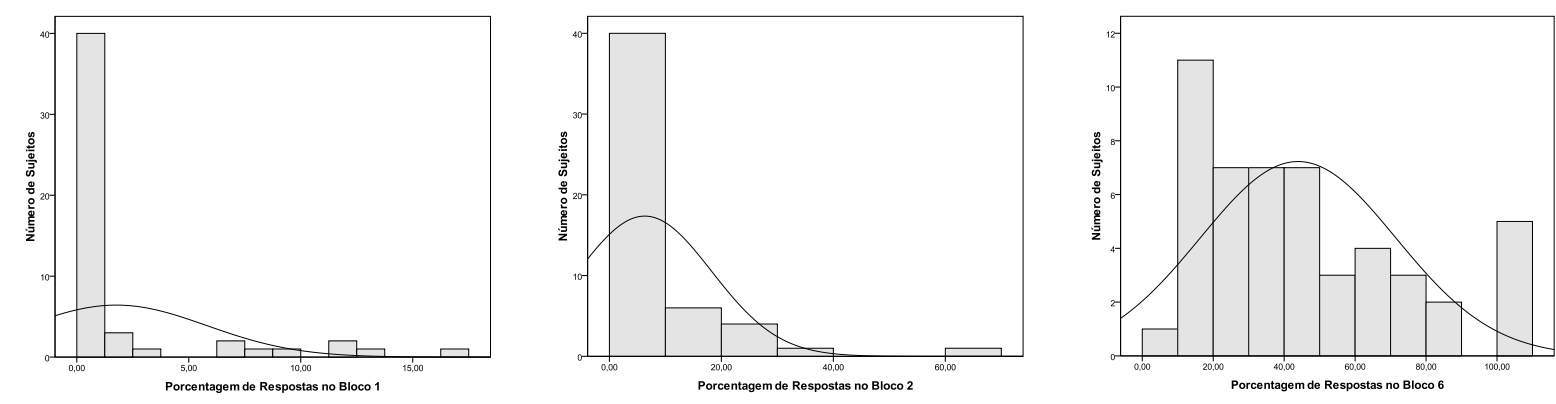

Ra do G_1A
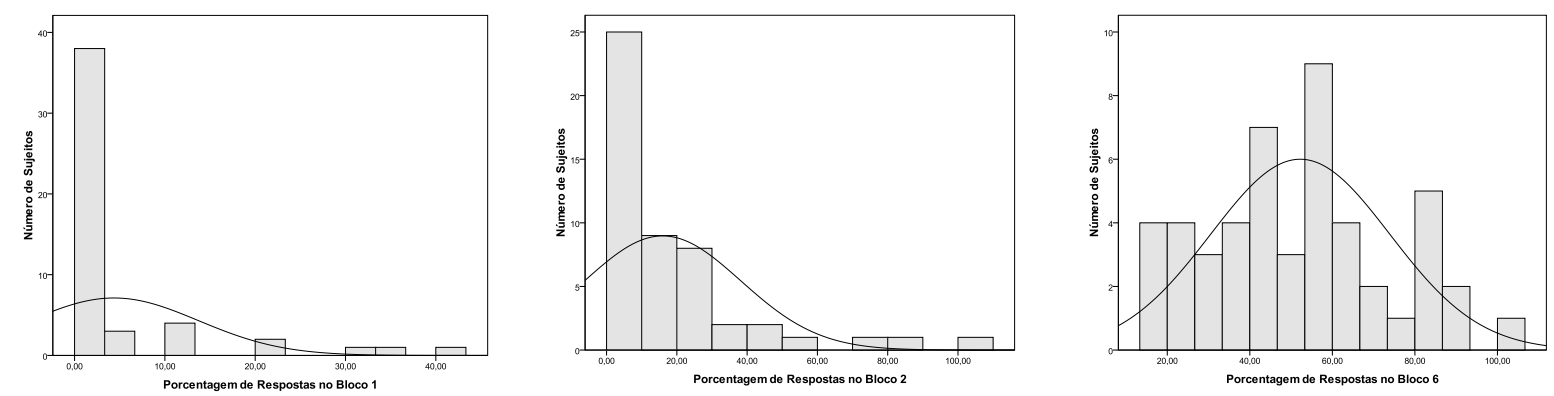

Ra do G_3A

FIGURA 4 - Histogramas das respostas antecipatórias dos 3 grupos (G_3C, G_1A e G_3A), no primeiro, segundo e sexto bloco de prática da fase de estabilização.

No geral, os blocos apresentam assimetria à direita, o que é assinalado pela razão entre $o$ valor da assimetria e seu erro padrão, situada entre \pm 2 apenas para a Rc dos grupos G_1A e G_3A. Segundo BERNSTEIN (1988) e STEVENS (2002), o 
teste $\mathrm{F}$ é robusto o bastante para violações desta natureza. No entanto, todos os outros blocos das diferentes facetas do desempenho apresentaram características muito particulares, pois os valores da razão entre a assimetria e o seu erro padrão ficaram frequentemente entre 5 e 10, chegando a 20 (TABELA 4). Entende-se que isso pode advir da elevada ocorrência de sujeitos com frequência de resposta igual a zero nas diferentes facetas do desempenho, dado que muitos não apresentam qualquer nível de respostas antecipatórias, omissas e erradas em vários blocos (TABELA 5).

TABELA 4 - Valores da razão entre a assimetria e o seu erro padrão nas diferentes facetas do desempenho para os 3 grupos.

\begin{tabular}{|c|c|c|c|c|c|c|c|c|c|c|c|c|}
\hline \multirow[t]{2}{*}{ Bloco } & \multicolumn{3}{|c|}{$\mathbf{R a}$} & \multicolumn{3}{|c|}{ Rc } & \multicolumn{3}{|c|}{$\mathbf{R e}$} & \multicolumn{3}{|c|}{ Ro } \\
\hline & $3 C$ & $1 \mathrm{~A}$ & $3 A$ & $3 C$ & $1 \mathrm{~A}$ & $3 A$ & $3 C$ & $1 \mathrm{~A}$ & $3 A$ & $3 C$ & $1 \mathrm{~A}$ & $3 A$ \\
\hline 1 & 21,0 & 7,2 & 7,6 & $-4,2$ & $-1,4$ & $-1,8$ & 6,2 & 2,8 & 2,9 & 10,4 & 6,9 & 2,7 \\
\hline 2 & 20,9 & 9,7 & 6,2 & $-3,4$ & $-1,4$ & $-0,9$ & 6,1 & 4,0 & 4,0 & 10,3 & 9,9 & 4,0 \\
\hline 3 & 12,4 & 4,6 & 4,3 & $-2,8$ & 0,5 & 0,6 & 7,6 & 2,5 & 3,5 & 6,7 & 1,5 & 6,9 \\
\hline 4 & 10,6 & 2,8 & 3,3 & $-1,3$ & $-0,2$ & 0,5 & 3,9 & 2,4 & 4,0 & 3,1 & 3,8 & 5,1 \\
\hline 5 & 5,3 & 3,9 & 2,6 & $-0,8$ & $-0,6$ & 1,8 & 3,1 & 4,8 & 2,8 & 4,8 & 3,4 & 5,5 \\
\hline 6 & 2,0 & 2,3 & 0,5 & 0,0 & 0,3 & 0,2 & 2,9 & 0,7 & 2,7 & 1,5 & 6,6 & 5,3 \\
\hline
\end{tabular}

Mesmo com essas particularidades, ao calcular valores médios e de desvio padrão, pode-se notar que os valores deste último evidenciam o problema bem conhecido da sensibilidade a observações muito discrepantes, apresentando-se com magnitude próxima aos valores médios, ou até de duas a quatro vezes superiores (TABELA 5). 
TABELA 5 - Principais estatísticas descritivas para todos os tipos de resposta (Ro, $\mathrm{Re}, \mathrm{Rc}, \mathrm{Ra})$, por bloco de tentativas.

\begin{tabular}{clcccccc}
\hline Resposta & Medida & B1 & B2 & B3 & B4 & B5 & B6 \\
\hline Ro & & & & & & & \\
& Sujeitos sem Ro (\%) & 19,2 & 23,1 & 30,8 & 28,8 & 25 & 30 \\
& Média & 11,9 & 10,3 & 9,2 & 9,9 & 10 & 6,7 \\
& Desvio-padrão & 14,1 & 13,8 & 8,5 & 10,6 & 10 & 8,4 \\
& Mínimo & 0 & 0 & 0 & 0 & 0 & 0 \\
& Máximo & 74 & 82 & 28,9 & 46,7 & 42,2 & 42,5 \\
Re & & & & & & & \\
& Sujeitos sem Re (\%) & 21,2 & 13,5 & 17,3 & 17,3 & 17,3 & 16 \\
& Média & 22 & 24,9 & 26,7 & 17,4 & 20 & 16,7 \\
& Desvio-padrão & 22,2 & 23,9 & 23,6 & 16,1 & 21,2 & 12,5 \\
& Mínimo & 0 & 0 & 0 & 0 & 0 & 0 \\
& Máximo & 80 & 100 & 100 & 53,3 & 96 & 47,3
\end{tabular}

Rc

$\begin{array}{lllllll}\text { Sujeitos sem Rc (\%) } & 1,9 & 1,9 & 1,9 & 0 & 3,8 & 10\end{array}$

Média $\begin{array}{llllll}64,4 & 58,5 & 52,7 & 56,5 & 43,6 & 32,7\end{array}$

Desvio-padrão $25,2 \quad 26,1 \quad 26,2 \quad 20,8 \quad 20,1 \quad 18,9$

Mínimo $\begin{array}{llllll}5,5 & 0 & 0 & 12,3 & 0 & 0\end{array}$

Máximo $\begin{array}{llllll}100 & 100 & 100 & 93,3 & 90 & 75\end{array}$

$\mathbf{R a}$

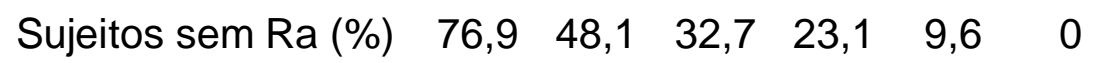

Média

$\begin{array}{llllll}1,8 & 6,3 & 11,4 & 16,3 & 26,4 & 43,9\end{array}$

Desvio-padrão

$\begin{array}{llllll}4,0 & 11,8 & 14,1 & 16,5 & 24,1 & 27,3\end{array}$

Mínimo

$\begin{array}{llllll}0 & 0 & 0 & 0 & 0 & 7,1\end{array}$

Máximo

$\begin{array}{llllll}16,8 & 66,7 & 60 & 65 & 100 & 100\end{array}$

Estes resultados indicam que essas variáveis gerariam fortes violações na utilização de quaisquer métodos estatísticos, sejam eles paramétricos ou não paramétricos, para sua análise inferencial. Assim, optou-se em reorganizar os 
resultados em medidas que permitissem, mesmo que de forma inicial, discutir as questões de estudo.

\subsection{Análise normativa}

\subsubsection{Análise do DCM ao longo da prática}

A análise do DCM constou da inspeção da mudança ao longo das duas fases, com o intuito de apresentar, de forma integrada, a mudança dos diferentes tipos de resposta, indicando a dinâmica da formação da estrutura durante a fase de aquisição e a sua reorganização ou manutenção na fase de adaptação.

Com base na TABELA 6 é possível notar que já no primeiro bloco da fase de aquisição, o comportamento modal de todos os grupos apresenta 5 respostas corretas (DMC de 500); é possível afirmar que isso ocorre para a maioria dos sujeitos, uma vez que a frequência relativa da moda ultrapassa os $60 \%$. No entanto, enquanto o grupo G_3C mantém esse comportamento ao longo dos 6 blocos, os demais grupos, no bloco 4, alcançam a melhor tentativa com 4 respostas antecipatórias e 1 correta (DMC de 4100), com a diferença de que o grupo G_1A apresenta duas modas, ainda mantendo 5 respostas corretas como valor modal. Ao se observar os valores da frequência relativa da moda para o G_3C ao longo dos blocos, nota-se que ela é elevada nos dois primeiros blocos, tendendo a diminuir em seguida. Isso pode ser devido ao fato de muitos sujeitos alcançarem o desempenho critério logo nas primeiras tentativas.

O grupo G_1A apresenta 5 respostas antecipatórias já no quinto bloco, o que era esperado, pois era necessário apresentar 3 vezes esse comportamento para atingir o critério desta fase. Observando-se os valores mínimos apresentados nos blocos, nota-se que no grupo G_3A houve sujeitos com uma tentativa completa com respostas corretas, enquanto os outros dois grupos ainda apresentaram (como desempenho mínimo) sujeitos com predomínio de respostas erradas e omissas (DCM de 410 e 5). Outro aspecto a ressaltar é a ocorrência, mesmo que pequena, de comportamentos totalmente antecipatórios logo no primeiro bloco para o grupo G_3A 
(2\% de sujeitos apresentando DCM de 5000 no B1). Esses resultados, no seu conjunto, indicam mudança do DCM ao longo dos blocos, bem como uma forte heterogeneidade entre os sujeitos nas respostas ao longo dos blocos.

TABELA 6 - Valores da moda, mínimo e máximo do desempenho máximo das respostas e a frequência relativa para cada bloco na fase de aquisição.

\begin{tabular}{|c|c|c|c|c|c|c|c|}
\hline Grupo & Estatística & B1 & B2 & B3 & B4 & B5 & B6 \\
\hline \multicolumn{8}{|l|}{ G_3C } \\
\hline & \multirow[t]{2}{*}{ Moda } & 500 & 500 & 500 & 500 & 500 & 500 \\
\hline & & $(72,5 \%)$ & $(70,5 \%)$ & $(68,6 \%)$ & $(35,2 \%)$ & $(43,1 \%)$ & $(7,8 \%)$ \\
\hline & \multirow[t]{2}{*}{ Mínimo } & 5 & 50 & 50 & 140 & 311 & 500 \\
\hline & & $(1,9 \%)$ & $(3,9 \%)$ & $(1,9 \%)$ & $(1,9 \%)$ & $(1,9 \%)$ & $(7,8 \%)$ \\
\hline & \multirow[t]{2}{*}{ Máximo } & 1400 & 4100 & 4100 & 3200 & 3110 & 4100 \\
\hline & & $(1,9 \%)$ & $(1,9 \%)$ & $(3,9 \%)$ & $(1,9 \%)$ & $(1,9 \%)$ & $(1,9 \%)$ \\
\hline \multicolumn{8}{|l|}{ G_1A } \\
\hline & \multirow[t]{2}{*}{ Moda } & 500 & 500 & 500 & $500 / 4100$ & 4100 & 5000 \\
\hline & & $(69,2 \%)$ & $(38,4 \%)$ & $(28,8 \%)$ & $(21,1 \%)$ & $(38,4 \%)$ & $(96,1 \%)$ \\
\hline & \multirow[t]{2}{*}{ Mínimo } & 140 & 50 & 50 & 311 & 140 & 5000 \\
\hline & & $(1,9 \%)$ & $(1,9 \%)$ & $(1,9 \%)$ & $(1,9 \%)$ & $(1,9 \%)$ & $(96,1 \%)$ \\
\hline & \multirow[t]{2}{*}{ Máximo } & 3200 & 5000 & 5000 & 5000 & 5000 & 5000 \\
\hline & & $(5,7 \%)$ & $(1,9 \%)$ & $(1,9 \%)$ & $(1,9 \%)$ & $(9,6 \%)$ & $(96,1 \%)$ \\
\hline \multicolumn{8}{|l|}{ G3A } \\
\hline & \multirow[t]{2}{*}{ Moda } & 500 & 500 & 500 & 4100 & 5000 & 5000 \\
\hline & & (64\%) & $(30 \%)$ & $(22 \%)$ & $(30 \%)$ & $(50 \%)$ & $(98 \%)$ \\
\hline & \multirow[t]{2}{*}{ Mínimo } & 500 & 140 & 50 & 500 & 410 & 5000 \\
\hline & & $(64 \%)$ & $(4 \%)$ & $(2 \%)$ & $(8 \%)$ & $(2 \%)$ & $(98 \%)$ \\
\hline & \multirow[t]{2}{*}{ Máximo } & 5000 & 5000 & 5000 & 5000 & 5000 & 5000 \\
\hline & & $(2 \%)$ & $(12 \%)$ & (14\%) & $(22 \%)$ & $(50 \%)$ & $(98 \%)$ \\
\hline
\end{tabular}

Esses resultados foram confirmados pela série de testes de Friedman, que indicou diferença significativa entre os blocos para todos os grupos (G_3C [x2=22,11; $\left.p<0,0001] ; G \_1 A[x 2=169,8 ; p<0,0001] ; \quad G \_3 A[x 2=137,3 ; p<0,0001]\right) ; 0$ teste de comparação múltipla indicou diferenças signficativas entre todos os blocos, com 
exceção dos blocos adjacentes (não houve diferença entre B1 e B2; B2 e B3; B3 e B4, e B4 e B5). Com base nesses resultados, é possivel inferir que o comportamento muda ao longo da prática, mas não há ganhos entre todos os blocos.

O DCM na fase de adaptação apresenta um comportamento modal com 6 respostas corretas já no primeiro bloco, para todos os grupos (TABELA 7). Entretanto, o grupo G_3C apresenta $72 \%$ dos sujeitos com esse comportamento, contra apenas 17\% e 22\% para G_1A e G_3A, respectivamente. A presença do valor modal em 6 respostas corretas persiste nos dois próximos blocos. O G_1A e G_3A apresentam comportamentos modais com respostas antecipatórias em blocos mais iniciais (quarto bloco) do que o G_3C (quinto bloco). Na fase de adaptação, contrariamente à fase de aquisição, foi o G_3A que demorou mais para ter a moda invariavelmente composta de respostas antecipatórias, pois, no quarto bloco, foi registrado tanto o comportamento modal de seis respostas corretas quanto o de cinco respostas antecipatórias e uma correta. O máximo valor do DCM, logo no primeiro bloco, foi composto por duas respostas antecipatórias para o G_3C e de quatro respostas antecipatórias para os outros grupos. Por outro lado, o G_1A e G_3C foram os grupos que apresentaram as seis respostas antecipatórias mais rapidamente (no bloco 2), diferentemente do G_3A que somente as apresentou no Bloco 4.

Esses resultados foram confirmados pela série de testes de Friedman, que indicou diferença significativa entre os blocos em todos os grupos (G_3C [x2=152,3; $p<0,0001] ;$ G_1A [x2=131,96; $\left.p<0,0001] ; G \_3 A[x 2=127,52 ; p<0,0001]\right) ; 0$ teste de comparação multipla indicou diferenças significativas entre B1 e B3, B4, B5 e B6, entre B2 e B5, B6, entre B3 e B6, e entre B4 e B6. Com base nesses resultados, pode-se inferir que o comportamento muda ao longo da prática em todos os blocos. Assim como na fase de aquisição, esses resultados, no seu conjunto, indicam mudança positiva do DCM ao longo dos blocos, mas também uma forte heterogeneidade entre os sujeitos nas suas respostas. 


\begin{tabular}{cccccccc}
\hline Grupo & Estatística & B1 & B2 & B3 & B4 & B5 & B6 \\
\hline G_3C & & & & & & & \\
& Moda & 600 & 600 & 600 & 600 & 5100 & 6000 \\
& & $(72,5 \%)$ & $(66,6 \%)$ & $(41,1 \%)$ & $(19,6 \%)$ & $(19,6 \%)$ & $(84,3 \%)$ \\
& Mínimo & 51 & 114 & 303 & 60 & 330 & 6000 \\
& & $(1,9 \%)$ & $(1,9 \%)$ & $(1,9 \%)$ & $(3,9 \%)$ & $(1,9 \%)$ & $(84,3 \%)$ \\
& \multirow{2}{*}{ Máximo } & 2130 & 6000 & 5100 & 6000 & 6000 & 6000 \\
& & $(1,9 \%)$ & $(1,9 \%)$ & $(5,8 \%)$ & $(3,9 \%)$ & $(9,8 \%)$ & $(84,3 \%)$
\end{tabular}

G_1A

$\begin{array}{ccccccc}\text { Moda } & 600 & 600 & 600 & 600 / 5100 & 5100 & 6000 \\ & (17,3 \%) & (17,3 \%) & (21,1 \%) & (19,2 \%) & (25 \%) & (90,3 \%) \\ \text { Mínimo } & 42 & 60 & 15 & 6 & 6 & 6000 \\ & (1,9 \%) & (3,8 \%) & (1,9 \%) & (1,9 \%) & (1,9 \%) & (90,3 \%) \\ \text { Máximo } & 4200 & 6000 & 5100 & 5100 & 6000 & 6000 \\ & (1,9 \%) & (1,9 \%) & (9,6 \%) & (19,2 \%) & (7,6 \%) & (90,3 \%)\end{array}$

G_3A

$\begin{array}{ccccccc}\text { Moda } & 600 & 600 & 600 & 5100 & 5100 & 6000 \\ & (22 \%) & (26 \%) & (26 \%) & (14 \%) & (16 \%) & (92 \%) \\ \text { Mínimo } & 15 & 6 & 51 & 60 & 60 & 6000 \\ & (2 \%) & (2 \%) & (2 \%) & (2 \%) & (2 \%) & (92 \%) \\ \text { Máximo } & 4200 & 5100 & 5100 & 6000 & 6000 & 6000 \\ & (2 \%) & (4 \%) & (6 \%) & (4 \%) & (4 \%) & (92 \%)\end{array}$

TABELA 7 - Valores da moda, mínimo e máximo do desempenho máximo das respostas e a frequência relativa para cada bloco na fase de adaptação.

\subsubsection{Análise da mudança individual do DCM entre blocos adjacentes}

A análise do sentido da mudança individual do DCM foi realizada com base em tabelas cruzadas de blocos adjacentes (ANEXO III). O sentido da mudança do DCM foi analisado em 3 categorias: a) mantém; b) ascende e c) descende. 
Ao observar a FIGURA 5 é possivel notar que poucos sujeitos do G_3C tendem a melhorar o seu desempenho máximo ao longo dos blocos de tentativas da fase de aquisição, pois nos primeiros blocos (B1 para B2 e B2 para B3) apenas $60 \%$ dos sujeitos conseguem repetir o seu melhor desempenho, e cerca de $20 \%$ tendem a realizar o DMC em níveis inferiores ao alcançado no bloco anterior. No entanto, nos blocos intermediários e finais (B3 a B6) há um forte aumento na proporção de sujeitos que melhoram o DCM.

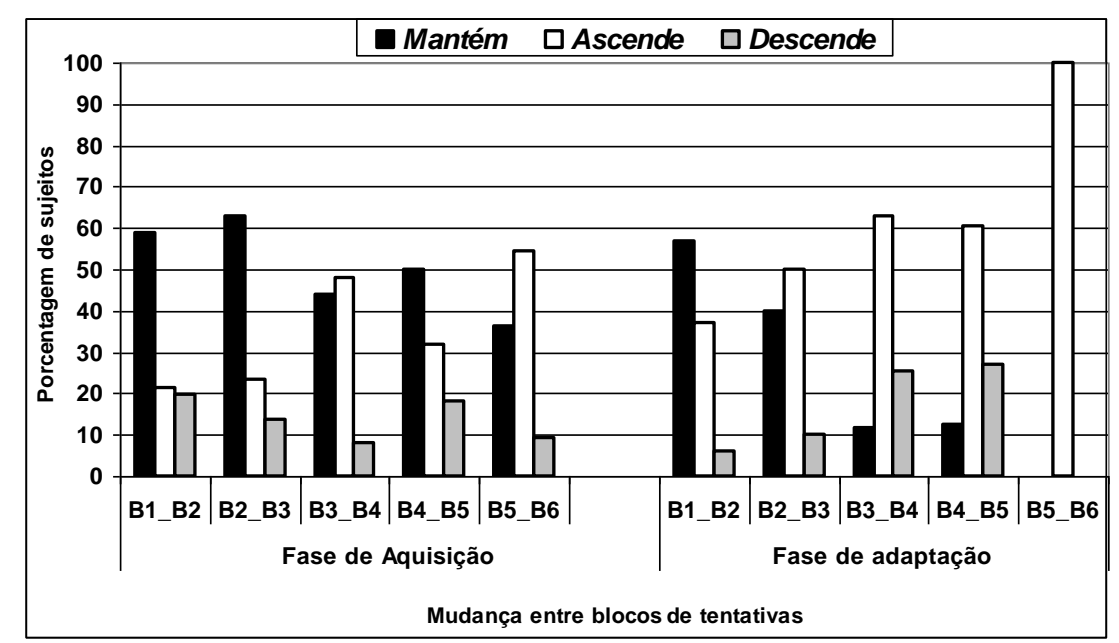

FIGURA 5 - Proporção de sujeitos que mantêm, ascendem e descendem o seu $\mathrm{DMC}$ entre blocos adjacentes nas fases de aquisição e adaptação para o G_3C.

A fase de adaptação é marcada pelo constante aumento na proporção de sujeitos que ascendem nos níveis do DMC ao longo dos blocos de tentativas (FIGURA 5), semelhante à proporção de sujeitos com mudança descendente, mas com sentido inverso. Nos blocos intermediários é possível notar um aumento na proporção de sujeitos que não alcançam níveis do DMC já alcançados anteriormente.

$O$ desempenho coletivo máximo do $G_{-} 1 A$ apresenta sempre maior proporção de sujeitos mudando de forma ascendente entre os blocos durante a fase de aquisição (FIGURA 6). No entanto, ao longo de toda a prática, sempre há entre $30 \mathrm{e}$ $40 \%$ sujeitos que mantêm o seu desempenho entre blocos adjacentes e entre $15 \mathrm{e}$ $20 \%$ que alcançam um desempenho inferior ao bloco anterior. 


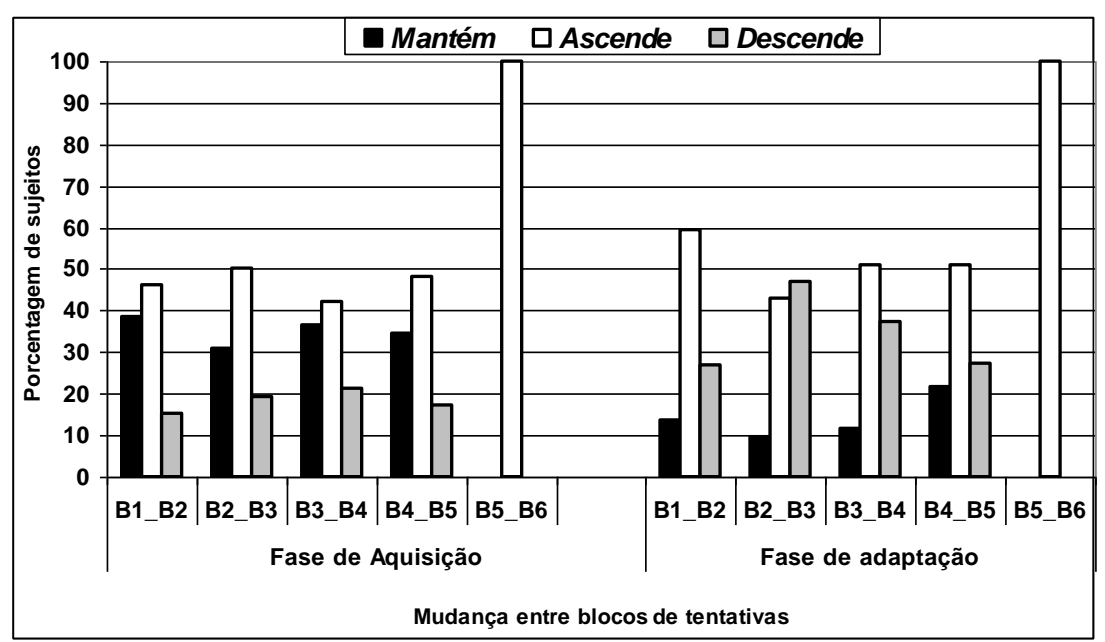

FIGURA 6 - Proporção de sujeitos que mantêm, ascendem e descendem o seu DMC entre blocos adjacentes nas fases de aquisição e adaptação para o G_1A.

Ao longo da fase de adaptação é possível observar que predominam sujeitos que sempre ascendem seu desempenho entre os blocos adjacentes (FIGURA 6), com exceção dos blocos 2 e 3, nos quais a proporção de sujeitos que descendem seu desempenho é superior.

A mudança no desempenho coletivo máximo do G_3A apresenta sempre maior proporção de sujeitos do que as outras formas de mudança nas duas fases (FIGURA 7). Com valores que não ultrapassam $60 \%$ dos sujeitos, há menores proporções de indivíduos que diminuem ou mantêm o seu desempenho entre os blocos adjacentes.

$\mathrm{Na}$ fase de adaptação é possivel notar que a proporção de sujeitos que ascende é sempre muito semelhante entre os blocos 1 e 4 . No entanto, há sempre uma certa proporção de sujeitos que descendem ou mantêm seu desempenho entre os blocos adjacentes. Esses resultados indicam que ao longo dos blocos sempre há mudança, e o sentido com maior proporção de pessoas é o de níveis superiores de desempenho. No entanto, há sujeitos (próximo a 30\%) que não conseguem sequer manter o desempenho já alcançado nos blocos anteriores. 


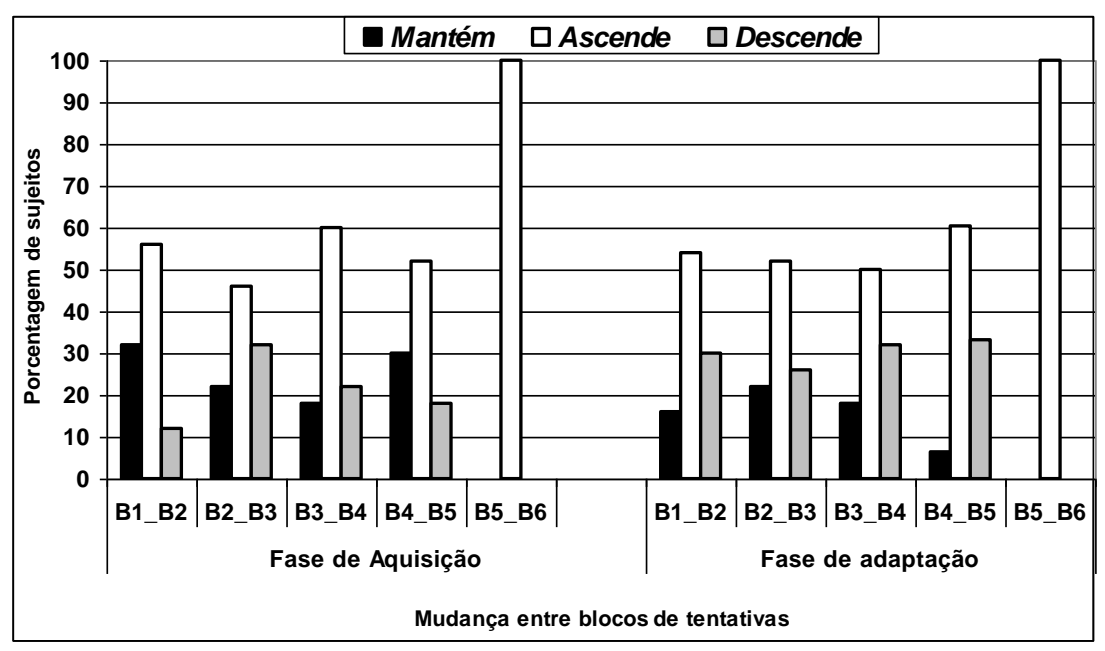

FIGURA 7 - Proporção de sujeitos que mantêm, ascendem e descendem o seu DMC entre blocos adjacentes nas fases de aquisição e adaptação para oG_3A.

\subsubsection{CDS}

A CDS foi analisada durante a fase de estabilização, com o intuito de obter indicativos sobre a dinâmica da formação da estrutura, para posteriormente estimar a estabilidade nos níveis ao longo dos blocos.

Com base na FIGURA 8, nota-se que a maioria dos sujeitos do G_1A apresenta baixos níveis da CDS nos dois blocos iniciais. No entanto, a proporção de sujeitos com consistência baixa tende a cair, enquanto aumenta a proporção de sujeitos com os níveis moderado e alto. No último bloco, todos os sujeitos apresentam algum nível de consistência para as respostas antecipatórias, seja moderado ou alto.

Para o G_3A há predomínio de sujeitos com consistência baixa apenas no primeiro bloco (FIGURA 9). A proporção de sujeitos com consistência baixa cai para menos da metade no segundo bloco (relativamente ao primeiro bloco) e não ocorre no Bloco 3, no qual há predomínio de sujeitos com consistência alta. 


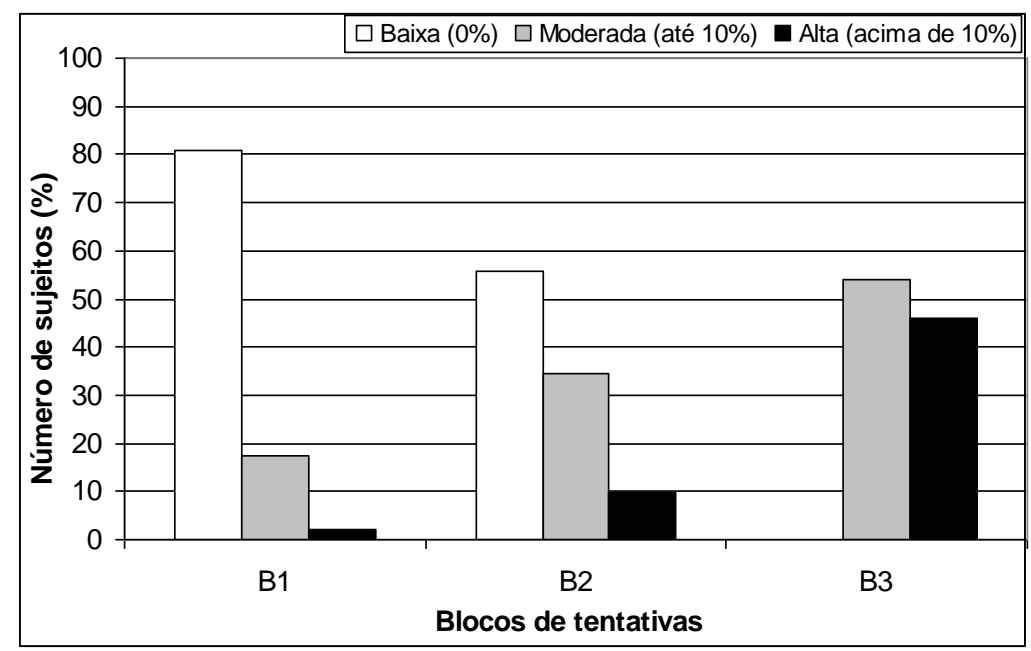

FIGURA 8 - Proporção de sujeitos distribuídos nas três categorias da CDS nos três blocos de tentativas da fase de estabilização para o G_1A.

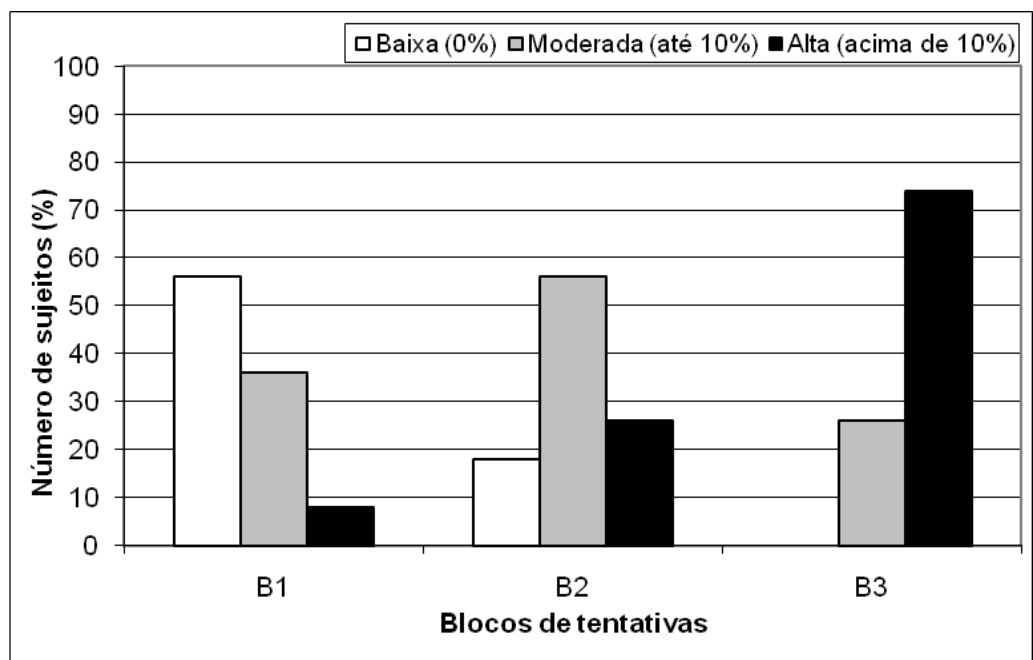

FIGURA 9 - Proporção de sujeitos distribuídos nas três categorias da CDS nos três blocos de tentativas da fase de estabilização para o G_3A.

\subsubsection{CDC}

Assim como a CDS, a CDC foi analisada durante a fase de estabilização, com o intuito de obter indicativos sobre a dinâmica da formação da estrutura, para posteriormente, estimar a estabilidade nos níveis ao longo dos blocos. 
Com base na FIGURA 10, nota-se que a maioria dos sujeitos do G_1A apresenta baixos e moderados níveis da CDC no primeiro bloco de tentativas, No entanto, a proporção de sujeitos com consistência alta já predomina no segundo e terceiro blocos. No último bloco, todos os sujeitos apresentam algum nível consistência para as respostas antecipatórias, com predomínio dos sujeitos com consistência alta.

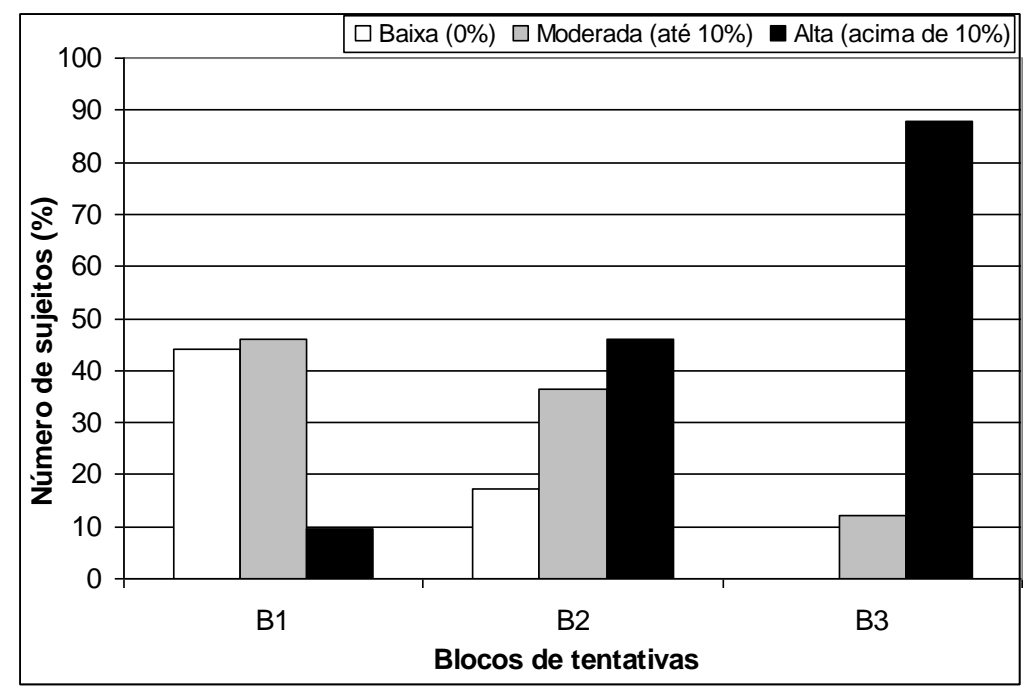

FIGURA 10 - Proporção de sujeitos distribuídos nas três categorias da CDC nos três blocos de tentativas da fase de estabilização para o G_1A.

A FIGURA 11 indica que no primeiro bloco da fase de estabilização os sujeitos estão distribuídos de forma semelhante nas 3 categorias do nível de CDC por volta de $33 \%$. No entanto, a proporção de sujeitos com consistência alta no bloco 2 é superior à dos demais, o que se repete no bloco 3 . Vale destacar que nenhum sujeito apresenta consistência baixa ou moderada no bloco 3 . 


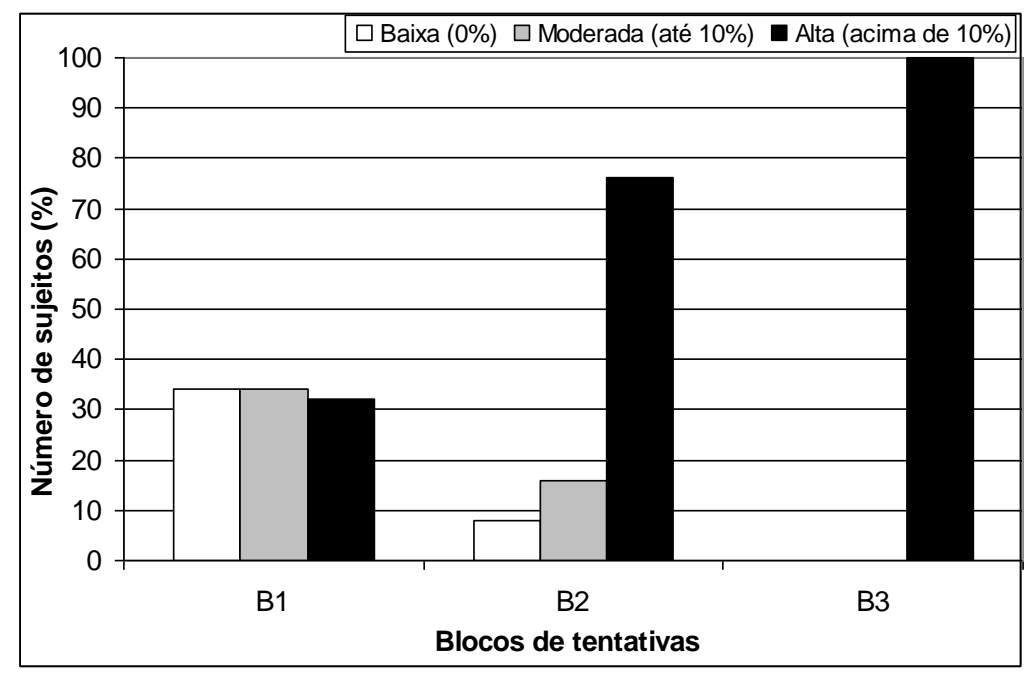

FIGURA 11 - Proporção de sujeitos distribuídos nas três categorias da CDC nos três blocos de tentativas da fase de estabilização para o G_3A.

\subsection{Análise da estabilidade interindividual na mudança intraindividual}

A análise da estabilidade interindividual na mudança intraindividual realizouse para as medidas de DCM, CDS e CDC com base nos sujeitos dos grupos G_1A e G_3A, sem a distinção dos grupos.

\subsubsection{DCM}

Os canais tercílicos e as trajetórias intraindividuais nos canais estão apresentados nas Figuras 12 e 13, respectivamente. É possível observar um alto nível de cruzamento das trajetórias individuais entre os canais. Os valores do $\mathrm{k}$ geral para o DCM foi de 0,37 (TABELA 8). Segundo LANDIS e KOCH (1977), esses valores expressam uma estabilidade muito fraca. Para uma estabilidade boa, esperase um $\kappa$ de 0,40 a 0,75 . Valores de uma estabilidade fraca também são encontrados para os canais específicos (TABELA 8). Vale ressaltar que todos os sujeitos apresentaram os mesmo valores do DCM no bloco 6, dessa forma, esse bloco não foi utilizado para estimar o valor do $\kappa$ de Cohen e os canais. 


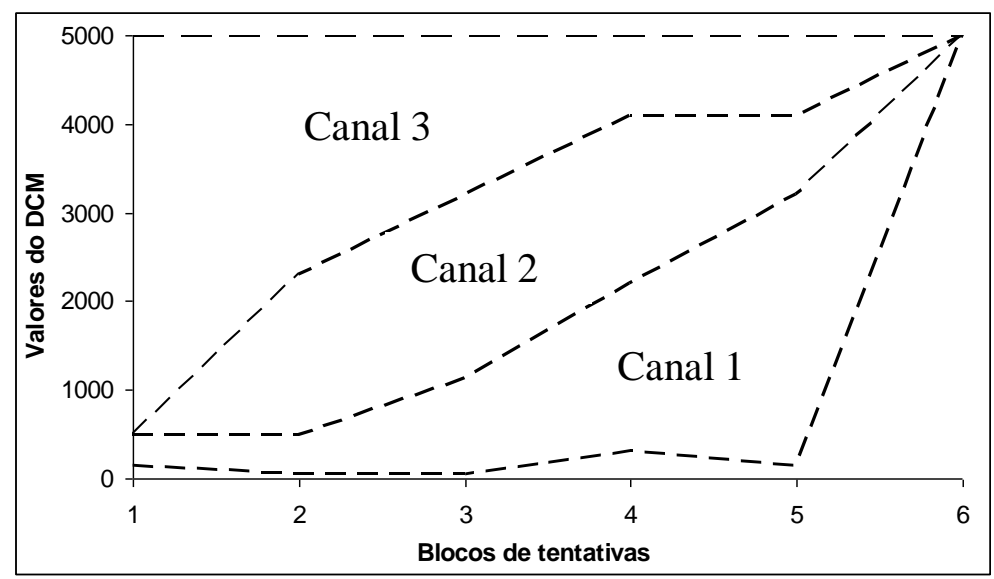

FIGURA 12 - Canais tercílicos do DCM ao longo de 6 blocos da fase de aquisição.

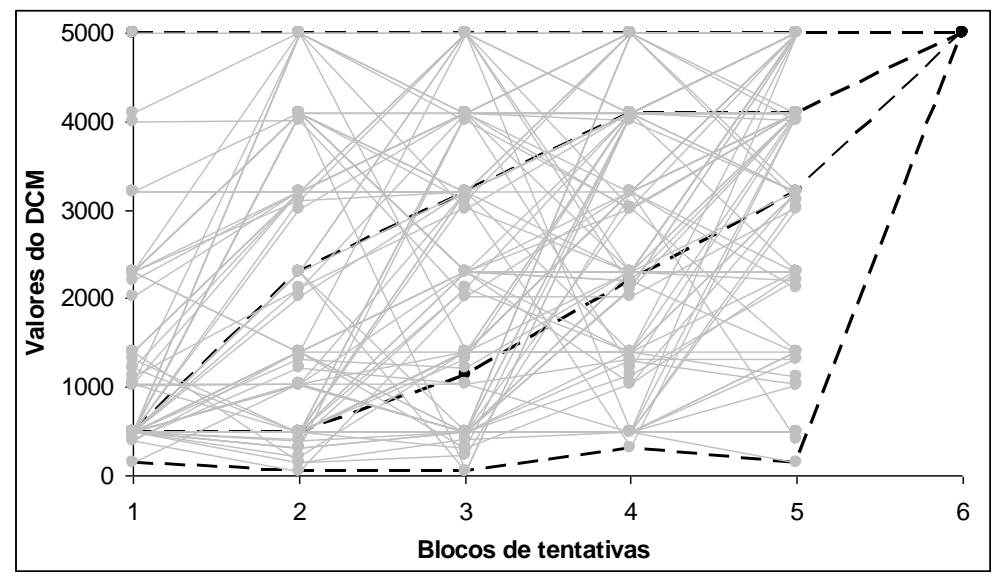

FIGURA 13 - Trajetórias intraindividuais e diferenças interindividuais no DCM dos 6 blocos de prática. As linhas tracejadas indicam os diferentes canais.

TABELA 8 - Valores do $\kappa$ geral \pm erro padrão para os três canais e por canal $(C 1$, C2, C3) no DCM para os 5 blocos da fase de aquisição.

\begin{tabular}{cccc}
\hline \multicolumn{4}{c}{ Valor $\kappa$} \\
Geral & \multicolumn{3}{c}{ Por canais } \\
\hline$\kappa \square \pm \mathrm{ep}$ & C1 & C2 & C3 \\
\hline $0,18 \pm 0,04$ & 0,25 & 0,01 & 0,30 \\
\hline
\end{tabular}

Esses resultados sugerem que o DCM não ocorre em canais tercílicos específicos ao longo dos blocos de prática; nota-se ausência de estabilidade no desempenho ao longo da prática. Os sujeitos podem iniciar em um dos canais e, ao 
longo da prática, mudarem alternadamente para qualquer um dos outros canais. Essa característica dificulta a previsão do comportamento individual e do grupo.

Cabe ressaltar que apesar da grande complexidade informacional expressa pela heterogeneidade das trejetórias intraindividuais entre os canais, o $\mathrm{\kappa}$ de Cohen traz consigo a possibilidade de, com apenas um indicador, estimar sucintamente 0 nível da estabilidade do grupo.

\subsubsection{CDS}

A TABELA 9 apresenta os valores da estatística Kappa entre os blocos 1 e 2 , 2 e 3 e 1 e 3 . É possível notar que os valores do Kappa não indicaram grau de concordância para nenhuma das comparações, expressando que os sujeitos não tendem a manter-se no mesmo tipo de resposta entre os blocos de prática. Para efeito ilustrativo, é apresentada nas TABELAS de 10 à 12 a tabulação cruzada da frequência de sujeitos que apresentam níveis de consistência baixa, moderada e alta nos blocos avaliados. Com base na distribuição dos sujeitos, na TABELA 10, nota-se que aproximadamente metade deles, em cada categoria de resposta, mantém-se nos mesmos valores entre o bloco 1 e 2. Por exemplo, dos 70 sujeitos com níveis baixos no bloco 1, 34 se mantiveram nesses níveis; dos 27 sujeitos com níveis moderados, 15 sujeitos se mantiveram e dos 5 sujeitos com níveis altos, 3 se mantiveram nesse nível. No entanto, na comparação dos outros blocos é possível observar que a maior parte dos sujeitos não permanece nos mesmos níveis de consistência, mas passam para níveis superiores.Por exemplo, na TABELA 12, entre a comparação dos blocos 1 e 3 , dos 27 sujeitos com níveis moderados, apenas 9 se mantiveram nos mesmos níveis. Esses resultados, aliados aos valores de Kappa (TABELA 9), expressam uma baixa estabilidade do desempenho dos sujeitos para a CDS. 
TABELA 9 - Valores da estatística Kappa e respectivos valores de prova entre as comparações dos blocos.

\begin{tabular}{ccc}
\hline Blocos & Kappa & Valor de $p$ \\
\hline $1{ }^{*}$ & 0,20 & $>0,002$ \\
$2 * 3$ & 0,008 & 0,883 \\
$1 * 3$ & 0,006 & 0,884 \\
\hline
\end{tabular}

TABELA 10 -Tabulação cruzada entre as frequências de sujeitos com consistência baixa, moderada e alta entre os blocos 1 e 2 .

\begin{tabular}{ccccccc}
\hline & & \multicolumn{3}{c}{ Bloco 2 } \\
& Nível CDS & Baixa & Modera & Alta & Total \\
\hline$\overline{0}$ & Baixa & 34 & 30 & 6 & 70 \\
$\overline{0}$ & Moderada & 3 & 15 & 9 & 27 \\
$\overline{0}$ & Alta & 1 & 1 & 3 & 5 \\
& Total & 38 & 46 & 18 & 102 \\
\hline
\end{tabular}

TABELA 11 -Tabulação cruzada entre as frequências de sujeitos com consistência baixa, moderada e alta entre os blocos 2 e 3.

\begin{tabular}{cccccc}
\hline & & \multicolumn{3}{c}{ Bloco 3 } \\
& Nível CDS & Baixa & Modera & Alta & Total \\
\hline$\sim$ & Baixa & 1 & 24 & 13 & 38 \\
$\stackrel{O}{O}$ & Moderada & 0 & 14 & 32 & 46 \\
$\frac{0}{\infty}$ & Alta & 0 & 3 & 15 & 18 \\
& Total & 1 & 41 & 60 & 102 \\
\hline
\end{tabular}


TABELA 12 -Tabulação cruzada entre as frequências de sujeitos com consistência baixa, moderada e alta entre os blocos 1 e 3 .

\begin{tabular}{cccccc}
\hline & & \multicolumn{3}{c}{ Bloco 3 } \\
& Nível CDS & Baixa & Modera & Alta & Total \\
\hline$\overline{8}$ & Baixa & 1 & 32 & 37 & 70 \\
$\overline{0}$ & Moderada & 0 & 9 & 18 & 27 \\
$\overline{0}$ & Alta & 0 & 0 & 5 & 5 \\
& Total & 1 & 41 & 60 & 102 \\
\hline
\end{tabular}

\subsubsection{CDC}

A TABELA 13 apresenta os valores da estatística Kappa entre os blocos 1 e 2, 2 e 3 e 1 e 3. É possível notar que os valores do Kappa não indicaram grau de concordância em nenhuma das comparações, expressando que os sujeitos não tendem a manter-se no mesmo tipo de resposta entre os blocos de prática. Para efeito ilustrativo, é apresentada nas TABELAS de 14 a 16 a tabulação cruzada da frequência de sujeitos que tiveram níveis de consistência baixa, moderada e alta nos blocos 1 e 2, 2 e 3 e 1 e 3 . Com base na distribuição dos sujeitos, na TABELA 14, nota-se que poucos sujeitos com baixa consistência se mantêm nos mesmos valores entre os blocos 1 e 2 , já para os níveis moderados, $41,11 \%$ se mantêm. No entanto, para os sujeitos com altos níveis de consistência, todos permanecem no mesmo nível no Bloco 2. Na comparação com os outros blocos, é possível observar que a maior parte dos sujeitos não permanece nos mesmos níveis de consistência, exceto os que já se encontram com níveis altos de consistência. Esses resultados, aliados aos valores de Kappa (TABELA 13), expressam uma baixa estabilidade do desempenho. No entanto, é possível observar que há forte concordância para os sujeitos com níveis altos de consistência no primeiro bloco. Porém, em termos médios, a estabilidade é baixa, devido aos fracos valores do kappa. 
TABELA 13 - Valores da estatística Kappa e respectivos valores de prova entre as comparações dos blocos.

\begin{tabular}{ccc}
\hline Blocos & Kappa & Valor de $\mathrm{p}$ \\
\hline $1{ }^{\star 2}$ & 0,16 & $>0,003$ \\
$2{ }^{*}$ & 0,12 & $>0,003$ \\
$1{ }^{\star 3}$ & 0,01 & 0,632 \\
\hline
\end{tabular}

TABELA 14 -Tabulação cruzada entre as frequências de sujeitos com consistência baixa, moderada e alta entre os blocos 1 e 2 .

\begin{tabular}{cccccc}
\hline & & \multicolumn{3}{c}{ Bloco 2} \\
& Nível CDC & Baixa & Modera & Alta & Total \\
\hline$\overline{8}$ & Baixa & 9 & 16 & 15 & 40 \\
$\frac{0}{0}$ & Moderada & 4 & 11 & 26 & 41 \\
& Alta & 0 & 0 & 21 & 21 \\
& Total & 13 & 27 & 62 & 102 \\
\hline
\end{tabular}

TABELA 15 - Tabulação cruzada entre as frequências de sujeitos com consistência baixa, moderada e alta entre os blocos 2 e 3.

\begin{tabular}{cccccc}
\hline & & \multicolumn{4}{c}{ Bloco 3 } \\
& Nível CDC & Baixa & Modera & Alta & Total \\
\hline $\mathcal{N}$ & Baixa & 1 & 3 & 9 & 13 \\
$\mathcal{O}$ & Moderada & 0 & 2 & 24 & 26 \\
$\frac{O}{\infty}$ & Alta & 0 & 0 & 60 & 60 \\
& Total & 1 & 5 & 93 & 99 \\
\hline
\end{tabular}


TABELA 16 - Tabulação cruzada entre as frequências de sujeitos com consistência baixa, moderada e alta entre os blocos 1 e 3 .

\begin{tabular}{cccccc}
\hline & & \multicolumn{3}{c}{ Bloco 3 } \\
& Nível CDC & Baixa & Modera & Alta & Total \\
\hline$\overline{0}$ & Baixa & 0 & 2 & 36 & 38 \\
$\overline{0}$ & Moderada & 0 & 3 & 37 & 40 \\
$\overline{0}$ & Alta & 1 & 0 & 20 & 21 \\
& Total & 1 & 5 & 93 & 99 \\
\hline
\end{tabular}

5.6 Análise da associação entre os níveis de estabilidade, comportamentos modais individuais e formação de subgrupos.

\subsubsection{DCM}

Com base nos valores individuais do $\kappa$ de Cohen e nas sugestões de interpretação de LANDIS e KOCH (1977), foi calculada a porcentagem de sujeitos no DCM (TABELA 17) em cada um dos níveis de estabilidade. Nota-se uma maior frequência de sujeitos (acima de 50\%) com uma boa estabilidade. Também é possível observar que aproximadamente $10 \%$ dos sujeitos apresentam uma estabilidade excelente. Esses resultados indicam que há um maior número de sujeitos que tendem a manter-se no seu canal de desempenho ao longo dos blocos quando comparados com os sujeitos com estabilidade fraca.

TABELA 17 - Porcentagem de sujeitos em cada um dos níveis de estabilidade para 0 DCM.

\begin{tabular}{cc}
\hline Estabilidade & Sujeitos (\%) \\
\hline Excelente & 10,78 \\
Boa & 54,90 \\
Fraca & 34,31 \\
\hline
\end{tabular}


Com base na informação sobre o nível de estabilidade individual (excelente e boa) e o canal em que os sujeitos mais permanecem (canal modal: primeiro, segundo ou terceiro), foi possível formar subgrupos (TABELA 18). Nota-se que a maior proporção de sujeitos apresenta uma estabilidade boa, distribuida nos 3 canais. Também é possível notar que um terço dos sujeitos apresenta estabilidade fraca.

TABELA 18 - Número de sujeitos em cada nível de estabilidade e cada canal de desempenho do DCM.

\begin{tabular}{cccc}
\hline Estabilidade & Canal & $\mathrm{n}$ & $(\%)$ \\
\hline \multirow{2}{*}{ Excelente } & 1 & 9 & 8,82 \\
& 3 & 2 & 1,96 \\
\hline \multirow{2}{*}{ Boa } & 1 & 24 & 23,53 \\
& 2 & 19 & 18,63 \\
& 3 & 13 & 12,75 \\
\hline Fraca & & 35 & 34,31
\end{tabular}

Uma forma de caracterizar o desempenho do grupo com estabilidade fraca nos canais é calcular o canal modal dos primeiros 3 blocos de tentativas e dos 3 blocos finais, para então identificar se a instabilidade se deve à mudança "permanente" (num único sentido) entre os canais, ou oscila "erraticamente". Caso haja uma mudança "permanente" entre o começo e o fim da prática, cabe investigar se ela tende a ser ascendente ou descendente entre os canais. Com isso, os sujeitos do subgrupo com estabilidade fraca podem ser reagrupados de acordo com a tendência à mudança: estabilidade fraca e oscilam (EFO), estabilidade fraca com mudança ascendente (EFA) e estabilidade fraca com mudança descendente (EFD).

A TABELA 19 apresenta a porcentagem dos subgrupos de sujeitos com estabilidade fraca em todas as tendências. Nota-se que a maior parte dos sujeitos com estabilidade fraca tende à mudança ascendente e à oscilação.

Para efeito ilustrativo, o comportamento das trajetórias individuais e seus respectivos canais para dois subgrupos (estabilidade excelente no primeiro e terceiro canal) são apresentados na FIGURA 14. 
TABELA 19 - Número de sujeitos com estabilidade fraca para cada tendência a mudança entre os canais para cada uma das diferentes facetas do desempenho.

\begin{tabular}{lcc}
\hline \multicolumn{1}{c}{ Tendência à mudança } & $\mathrm{n}$ & $(\%)$ \\
\hline Ascendente & 15 & 14,71 \\
Descentende & 7 & 6,86 \\
Ocilação (flutuação) & 13 & 12,75 \\
Total de suj com EF & 35 & 34,31 \\
\hline
\end{tabular}

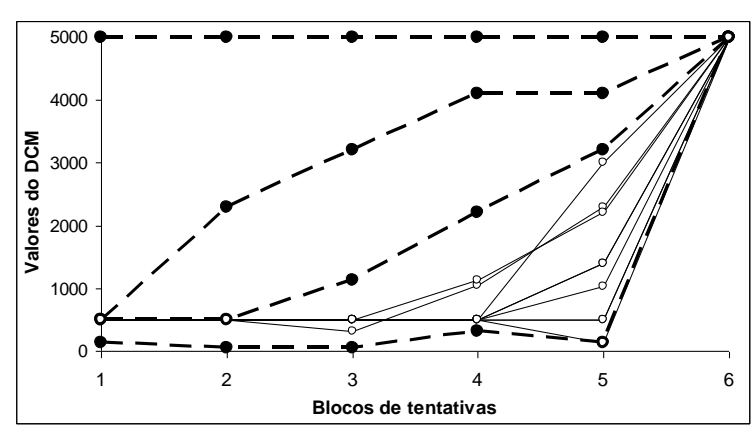

Estabilidade excelente no Canal 1

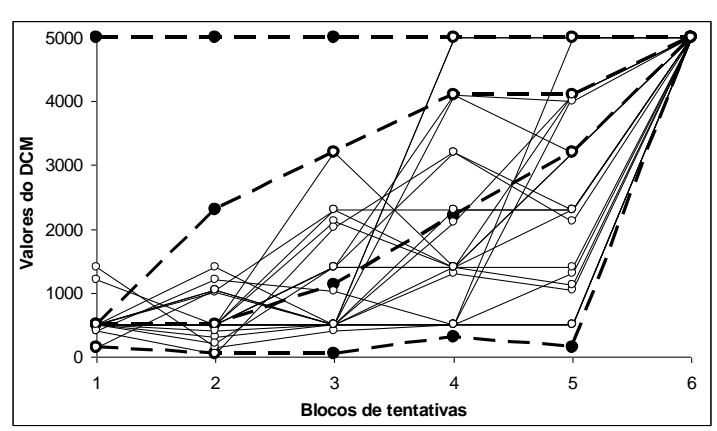

Estabilidade boa no Canal 1

FIGURA 14. Trajetórias intraindividuais e canais de estabilidade para O DCM ao longo dos 6 blocos de tentativas para os subgrupos com estabilidade excelente no canal 1 (à esquerda) e estabilidade boa no canal 1 (à direita). As linhas tracejadas e pontos cheios indicam os limites dos diferentes canais.

\subsubsection{CDS}

Com base na frequência de permanência do sujeito nos diferentes níveis de consistência ao longo dos 3 blocos de tentativas, foi calculado o nível de estabilidade individual. A proporção de sujeitos em cada um dos níveis de estabilidade encontrase na TABELA 20. A maior proporção de sujeitos obteve estabilidade boa (próximo a $70 \%$ ), no entanto, apenas $9 \%$ deles apresenta uma estabilidade excelente. Quando 
contrastado o número de sujeitos com estabilidade boa e excelente com sujeitos com estabilidade fraca, notou-se uma maior proporção de sujeitos com algum nível de estabilidade. Esses resultados indicam que há um maior número de sujeitos que tendem a se manter no seu nível de consistência ao longo dos blocos, se comparados com os sujeitos com estabilidade fraca.

TABELA 20 - Porcentagem de sujeitos em cada um dos níveis de estabilidade para a CDS.

\begin{tabular}{lc}
\hline Estabilidade & Sujeitos (\%) \\
\hline Excelente & 8,8 \\
Moderada & 66,6 \\
Fraca & 24,5 \\
\hline
\end{tabular}

Com base na informação dos sujeitos com o nível de estabilidade individual excelente e boa e o nível de consistência em que estes permaneceram (fraca, moderada e alta), foi possível formar subgrupos (TABELA 21). Nota-se que não houve sujeitos com estabilidade excelente no nível 1 e que o subgrupo com maior proporção de sujeitos é o que apresenta estabilidade boa no primeiro nivel (próximo a $33 \%)$.

Optou-se em subdividir os sujeitos com estabilidade fraca de acordo com a tendência de mudança entre os níveis, configurando-se: ascendente (quando a cada bloco o nível era superior ao anterior); descendente (quando a cada bloco o nível era inferior ao anterior); oscilatória (quando mudava-se de um nível em um bloco, voltando ao nível anterior no bloco seguinte). Com isso, pode-se identificar se a estabilidade fraca é devida a mudança "permanente" (num único sentido) entre os níveis de estabilidade, ou oscila "erraticamente". Caso haja uma mudança "permanente" entre o começo e o fim da prática, cabe investigar se ela tende a ser ascendente ou descendente entre os níveis de consistência. Com isso, os sujeitos do subgrupo com estabilidade fraca puderam ser reagrupados de acordo com a tendência à mudança: estabilidade fraca e oscilam (EFO), estabilidade fraca com mudança ascendente (EFA) e estabilidade fraca com mudança descendente (EFD). 
No entanto, na TABELA 22, nota-se que houve apenas comportamentos com tendência a mudança ascendente (maior proporção) e oscilação.

TABELA 21 - Número de sujeitos em cada nível de estabilidade e nível de consistência para a CDS.

\begin{tabular}{|c|c|c|c|c|}
\hline Nível modal & Estabilidade & Configurações & n (\%) & $\mathrm{n}$ total $(\%)$ \\
\hline \multirow[b]{2}{*}{1} & \multirow[b]{2}{*}{ Boa } & 112 & $23(22,54)$ & \\
\hline & & 113 & $11(10,78)$ & $34(33,33)$ \\
\hline \multirow{5}{*}{2} & Excelente & 222 & $6(5,88)$ & $6(5,9)$ \\
\hline & \multirow{4}{*}{ Boa } & 212 & $1(0,98)$ & \\
\hline & & 122 & $8(7,84)$ & \\
\hline & & 223 & $9(8,82)$ & \\
\hline & & 232 & $2(1,96)$ & $26(19,60)$ \\
\hline \multirow{8}{*}{3} & Excelente & 333 & $3(2,94)$ & $3(2,94)$ \\
\hline & \multirow{4}{*}{ Boa } & 233 & $7(6,86)$ & \\
\hline & & 313 & $1(0,98)$ & \\
\hline & & 323 & $1(0,98)$ & \\
\hline & & 133 & $5(4,9)$ & $17(16,66)$ \\
\hline & \multirow{3}{*}{ Fraca } & 213 & $2(1,96)$ & \\
\hline & & 132 & $1(0,98)$ & \\
\hline & & 123 & $22(21,56)$ & $25(24,50)$ \\
\hline
\end{tabular}

TABELA 22 - Número de sujeitos com estabilidade fraca para cada tendência a mudança entre os canais, em cada uma das facetas do desempenho.

\begin{tabular}{lrr}
\hline Tendência à mudança & $\mathrm{n}$ & $(\%)$ \\
\hline Ascendente & 22 & 21,60 \\
Ocilação (flutuação) & 3 & 2,94 \\
Total de suj com EF & 25 & 24,50 \\
\hline
\end{tabular}




\subsubsection{CDC}

Com base na frequência de permanência do sujeito nos diferentes níveis de consistência ao longo dos 3 blocos de tentativas, foi calculado o nível de estabilidade individual. A proporção de sujeitos em cada um dos níveis de estabilidade encontrase na TABELA 23. A maior proporção de sujeitos apresentou estabilidade boa (próximo a $58 \%$ ), enquanto $21,56 \%$ dos sujeitos apresentam uma estabilidade excelente. Quando contrastado o número de sujeitos com estabilidade boa e excelente com os sujeitos com estabilidade fraca, notou-se uma maior proporção de sujeitos com algum nível de estabilidade. Esses resultados indicam que há um maior número de sujeitos que tendem a manter-se no seu nível de consistência ao longo dos blocos, quando comparados com os sujeitos com estabilidade fraca.

TABELA 23 - Porcentagem de sujeitos em cada um dos níveis de estabilidade para a CDC.

\begin{tabular}{lc}
\hline Estabilidade & Sujeitos (\%) \\
\hline Excelente & 21,56 \\
Moderada & 58,81 \\
Fraca & 16,60 \\
\hline
\end{tabular}

Com base na informação dos sujeitos com o nível de estabilidade individual excelente e boa e o nível de consistência em que os sujeitos mais permaneceram (fraca, moderada e alta), foi possível formar subgrupos (TABELA 24). Nota-se que não houve sujeitos com estabilidade excelente no nível 1 e que o subgrupo com maior proporção de sujeitos foi o que apresentou estabilidade boa no terceiro nivel (próximo a 39\%).

Para os sujeitos com estabilidade fraca, utilizou-se dos mesmos procedimentos empregados para a CDS. Com isso, os sujeitos do subgrupo com estabilidade fraca puderam ser reagrupados de acordo com a tendência à mudança: estabilidade fraca e oscilam (EFO), estabilidade fraca com mudança ascendente (EFA) e estabilidade fraca com mudança descendente (EFD). No entanto, de acordo 
com a TABELA 25, nota-se que houve apenas comportamentos com tendência à mudança ascendente e oscilação, com predominio de sujeitos com tendência a mudança ascendente $(14,7 \%)$.

TABELA 24 - Número de sujeitos em cada nível de estabilidade e nível de consistência para a CDC.

\begin{tabular}{|c|c|c|c|c|}
\hline Nível modal & Estabilidade & Configurações & $\mathrm{n}(\%)$ & total $(\%$ \\
\hline & \multirow{2}{*}{ Boa } & 112 & $2(1,96)$ & \\
\hline & & 113 & $7(6,86)$ & \\
\hline \multirow[t]{2}{*}{1} & & & & $9(8,82)$ \\
\hline & Excelente & 222 & $2(1,96)$ & \\
\hline \multirow{4}{*}{2} & & & & $2(1,96)$ \\
\hline & \multirow{2}{*}{ Boa } & 212 & $2(1,96)$ & \\
\hline & & 223 & $9(8,82)$ & \\
\hline & & & & $11(10,78)$ \\
\hline \multirow{7}{*}{3} & Excelente & 333 & $20(19,6)$ & \\
\hline & & & & $20(19,6)$ \\
\hline & \multirow{3}{*}{ Boa } & 233 & $26(25,49)$ & \\
\hline & & 133 & $14(13,72)$ & \\
\hline & & & & $40(39,21)$ \\
\hline & \multirow[t]{2}{*}{ Fraca } & 213 & $2(1,96)$ & \\
\hline & & 123 & $15(14,7)$ & $17(16,6)$ \\
\hline
\end{tabular}

TABELA 25 - Número de sujeitos com estabilidade fraca para cada tendência à mudança entre os canais, em cada uma das facetas do desempenho.

\begin{tabular}{lrr}
\hline Tendência à mudança & $\mathrm{n}$ & $(\%)$ \\
\hline Ascendente & 15 & 14,7 \\
Ocilação (flutuação) & 2 & 1,96 \\
Total de suj com EF & 17 & 16,6 \\
\hline
\end{tabular}




\subsection{Formação dos subgrupos com comportamentos opostos para o DCM, a CDS e a CDC}

Com o baixo número de sujeitos em alguns subgrupos optou-se por agrupálos em relação aos canais e níveis de estabilidade. Esse procedimento levou à formação de novos subgrupos com comportamentos opostos.

Para o DCM (TABELA 26), os sujeitos com estabilidade excelente e boa, com predomínio de desempenho no canal 1 , foram reunidos num novo subgrupo denominado estável no canal 1 (E_C1). O mesmo ocorreu para os sujeitos com estabilidade excelente e boa do canal 3, formando o subgrupo estável no canal 3 (E_C3). Para os sujeitos com estabilidade fraca, mantiveram-se os subgrupos iniciais: ascendente e oscilação. Assim, para testar os objetivos do presente trabalho, o DCM foi analisado utilizando-se desses 4 subgrupos, comparando-os entre si, e investigando os efeitos dos mesmos na mudança de probabilidade de ocorrência dos processos de modularização ou adaptação.

Como o número de níveis (três), blocos (três) e sujeitos nos subgrupos para a CDS foi reduzido. Com isso, no subgrupo de estabilidade no canal 1 ficaram apenas os sujeitos com estabilidade boa e no subgrupo do canal 3 agrupou-se os sujeitos com estabilidade boa e excelente. A partir desta estratégia, formou-se 3 subgrupos: estável no nível 1, estável no nível 3 e instável ascendente (TABELA 27). Esses procedimentos também foram adotados para a CDC (TABELA 28). 
TABELA 26 - Número de sujeitos e agrupamento nos novos subgrupos com comportamentos opostos para o DCM.

\begin{tabular}{|c|c|c|c|c|c|c|}
\hline Canal & Estabilidade & $\mathrm{n}$ & (\%) & novo subgrupo & $\mathrm{n}$ & $(\%)$ \\
\hline 1 & $\begin{array}{c}\text { Excelente } \\
\text { Boa }\end{array}$ & $\begin{array}{c}9 \\
24\end{array}$ & $\begin{array}{c}8,82 \\
23,53\end{array}$ & Estável C1 & 33 & 32,35 \\
\hline 3 & $\begin{array}{c}\text { Excelente } \\
\text { Boa }\end{array}$ & $\begin{array}{c}2 \\
13\end{array}$ & $\begin{array}{r}1,96 \\
12,75\end{array}$ & Estável C3 & 15 & 14,71 \\
\hline & $\begin{array}{c}\text { Fraca } \\
\text { Ascendente }\end{array}$ & 15 & 14,71 & $\begin{array}{c}\text { Mudança } \\
\text { Ascendente }\end{array}$ & 15 & 14,71 \\
\hline & $\begin{array}{c}\text { Fraca } \\
\text { Ocilação }\end{array}$ & 13 & 12,75 & $\begin{array}{l}\text { Mudança } \\
\text { Oscilação }\end{array}$ & 13 & 12,75 \\
\hline
\end{tabular}

TABELA 27 - Número de sujeitos e agrupamento nos novos subgrupos com comportamentos opostos para a CDS.

\begin{tabular}{ccccc}
\hline \multirow{2}{*}{ Nível } & Estabilidade & $\mathrm{n}(\%)$ & novo subgrupo & $\mathrm{n}(\%)$ \\
\hline 1 & & & & \\
\cline { 2 - 5 } 3 & Boa & 33 & Estável N1 & 33 \\
\cline { 2 - 5 } & Boa & 13,7 & Estável N3 & 16,6 \\
\cline { 2 - 5 } & $\begin{array}{c}\text { Fraca } \\
\text { ascendente }\end{array}$ & 21,56 & $\begin{array}{c}\text { Mudança } \\
\text { ascendente }\end{array}$ & 21,56 \\
\hline
\end{tabular}


TABELA 28 -Número de sujeitos e agrupamento nos novos subgrupos com comportamentos opostos para a CDS.

\begin{tabular}{ccccc}
\hline \multirow{2}{*}{ Nível } & Estabilidade & $\mathrm{n}(\%)$ & novo subgrupo & $\mathrm{n}(\%)$ \\
\hline 1 & & & & \\
\cline { 2 - 5 } 3 & Boa & $9(8,82)$ & Estável_N1 & $9(8,82)$ \\
\cline { 2 - 5 } & Boa & $40(39,21)$ & Estável_N3 & $60(58,81)$ \\
\cline { 2 - 5 } & $\begin{array}{c}\text { Fraca } \\
\text { acedente }\end{array}$ & $15(14,7)$ & $\begin{array}{c}\text { Mudança } \\
\text { ascendente }\end{array}$ & $15(14,7)$ \\
\hline
\end{tabular}

\subsection{Análise da frequência de respostas antecipatórias da sequência aprendida na fase de estabilização na tarefa mais complexa}

O máximo valor de respostas antecipatórias $(\mathrm{Ra})$, por tentativa, para as primeiras 10 tentativas da fase de adaptação, constam na TABELA 29. É possível visualizar que o grupo G_1A apresentou apenas 8 sujeitos com $5 \mathrm{Ra}$, e que o restante dos sujeitos não conseguiu manter apenas respostas antecipatórias: 16 sujeitos realizaram todos os componentes sem nenhuma $\mathrm{Ra}$; 15 realizaram apenas 1 Ra; 7 realizaram $2 \mathrm{Ra}$; 3 realizaram $3 \mathrm{Ra}$, e demais realizaram $3 \mathrm{Ra}$. Resultados semelhantes são evidenciados pelo G_3A. Dos 50 sujeitos, apenas 8 apresentaram todos os componentes com $\mathrm{Ra}$, enquanto 22 realizaram as tentativas sem um componente com Ra, 7 com apenas $1 \mathrm{Ra}, 3$ com $2 \mathrm{Ra}, 4$ com $3 \mathrm{Ra}$ e 6 com $4 \mathrm{Ra}$. 
TABELA 29 - Número de sujeitos em cada frequência de Ra por tentativa nas primeiras dez tentativas da fase de aquisição.

\begin{tabular}{cccc}
\hline Grupo & Freq. Ra & n & Classificação do processo \\
\hline & 0 & 16 & \\
& 1 & 15 & \\
G_1A & 2 & 7 & Adaptação \\
& 3 & 3 & \\
& 4 & 3 & \\
& 5 & 8 & Modularização \\
\hline & 0 & 22 & \\
G_3A & 1 & 7 & \\
& 2 & 3 & Adaptação \\
& 3 & 4 & \\
& 4 & 6 & \\
\hline
\end{tabular}

Com base na TABELA 29, pode-se formar 2 subgrupos: sujeitos que logo após a inserção do novo componente (máximo de até 10 tentativas) já apresentam cinco respostas antecipatórias para os componentes praticados na fase de estabilização (primeiros indicativos da ocorrência do processo de modularização); e sujeitos que logo após a inserção do novo componente não conseguiram apresentar $5 \mathrm{Ra}$, configurando-se, assim, os sujeitos que necessitaram reorganizar a estrutura adquirida na fase de estabilização.

5.9 Análise do tempo entre o estímulo e a resposta dos sujeitos que mantiveram a estrutura de respostas antecipatórias na fase de adaptação

Uma forma de observar se os sujeitos que mantiveram a estrutura na nova 
situação também utilizaram os mesmos parâmetros foi analisar o tempo entre 0 estímulo e a resposta (magnitude e variação) da última tentativa, com respostas antecipatórias na fase de estabilização, e da primeira tentativa na fase de adaptação, com os 5 componentes utilizados na primeira tarefa, também com respostas antecipatórias.

Ao observar a FIGURA 15, nota-se que os valores da média do TER ficam em 300ms antes da ocorrência do estímulo para a fase de estabilização, e atingem menores valores na fase de adaptação. No entanto, os limites de confiança em 95\% indicam que os valores das duas fases têm chances de apresentar semelhança, estando entre 200 a 380 ms do estímulo. Esses resultados são ratificados pelos resultados do teste $\mathrm{t}$ de Student para medidas dependentes, pois indicam não haver diferença entre os valores médios nas duas situações $(t=0,799 ; p=0,437)$.

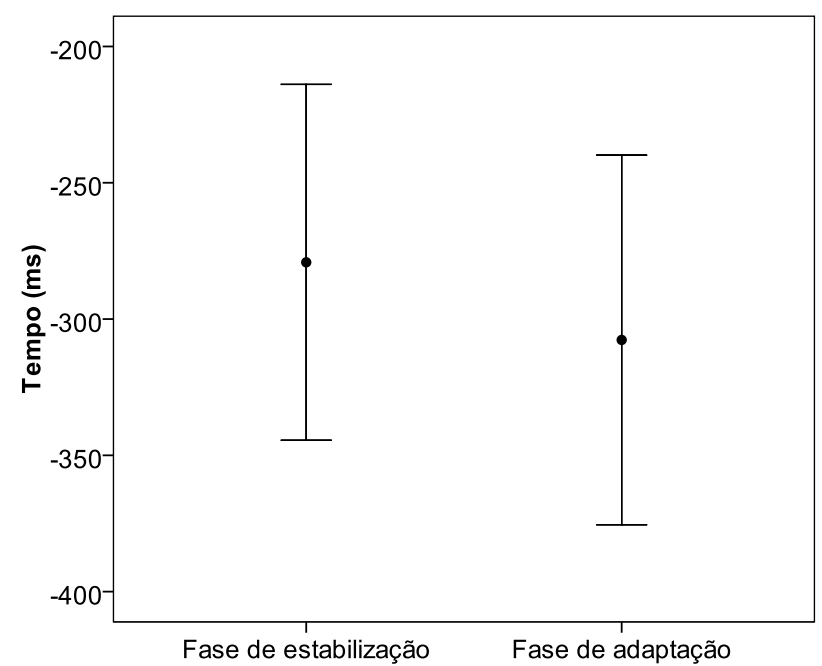

FIGURA 15 - Média e limite de confiança (95\%) da média do tempo entre o estímulo e a resposta dos 5 componentes da tarefa inicial nas fases de estabilização e adaptação.

Ao observar a FIGURA 16, nota-se que os valores médios do desvio-padrão intraindividual do TER ficaram próximos a 120ms na fase de estabilização, e atingem menores valores na fase de adaptação. No entanto, os limites de confiança em 95\% indicam que os valores das duas fases têm chances de serem semelhantes, 
apresentando variação entre 90 e $150 \mathrm{~ms}$. Esses resultados são confirmados pelo teste $t$ de Student para medidas dependentes, pois indicam não haver diferença entre os valores médios da variação nas duas situações ( $t=0,659 ; p=0,520)$.

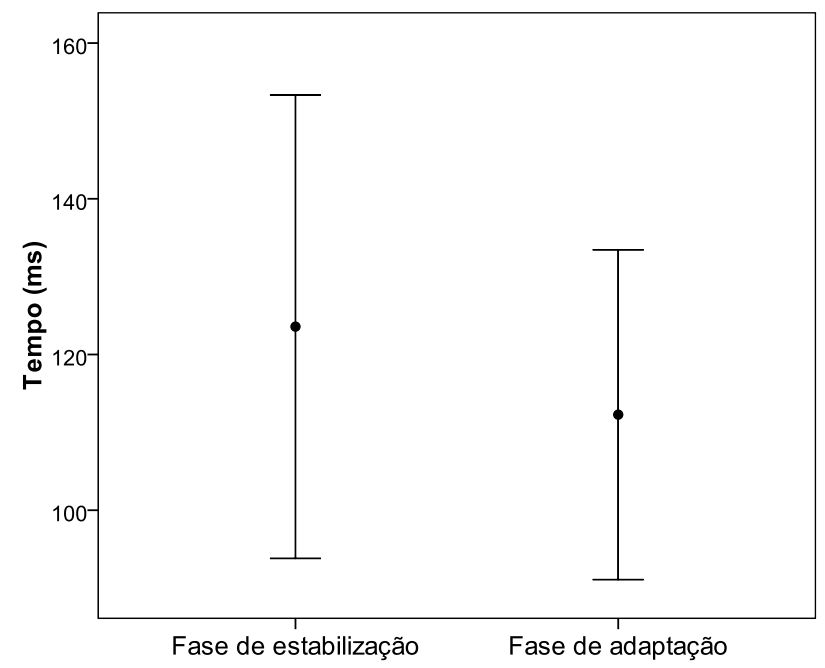

FIGURA 16 - Média e limite de confiança (95\%) do desvio-padrão do tempo entre o estímulo e a resposta dos 5 componentes da tarefa inicial nas fases de estabilização e adaptação.

Esses resultados permitem inferir que os sujeitos que mantiveram a estrutura adquirida na fase de estabilização, na tarefa mais complexa, também mantiveram os parâmetros dessa estrutura, pois, tanto em termos de magnitude quanto de variação os valores são semelhantes.

\subsection{Análise dos efeitos da estabilização e canais de desempenho na probabilidade de ocorrência do processo de modularização e adaptação}

Uma vez apresentada a porcentagem de ocorrência dos processos de adaptação e modularização para todos os sujeitos do grupo G_3A e G_1, a presente análise buscou descrever se a probabilidade dessas ocorrências muda em função do nível de estabilização alcançado ao final do processo de aquisição, e do nível de estabilidade ao longo dos canais de desempenho das diferentes características investigadas (DCM, CDS e CDC). A TABELA 30 apresenta as tabulações cruzadas 
entre as porcentagens de ocorrência de cada caso. Esses valores aliados aos valores do teste de qui-quadrado servem para se ter um indicativo da generalização da associação.

Com base na informação do DCM (TABELA 30) é possível observar que a frequência de ocorrência dos processos não está associada ao nível de estabilização dos diferentes canais (E_C1, E_C3 e MA). Nota-se que a porcentagem de ocorrência do processo de adaptação para os sujeitos que apresentaram seu desempenho estável durante a fase de estabilização no primeiro canal é próxima à do terceiro (84,84\% para E_C1 e 88,23\% para E_C3). O mesmo ocorre com a porcentagem de ocorrência do processo de modularização. Essa descrição é confirmada pelo teste de qui-quadrado, que não indicou diferença significativa para a associação $\left(\chi^{2}=1,97\right.$; $p=0,581)$.

TABELA 30 - Tabulação cruzada entre a frequência de ocorrência dos processos de modularização e adaptação e os sujeitos com estabilidade no $1^{\circ}$ e $3^{\circ}$ canal de desempenho do DMC.

\begin{tabular}{lccccc}
\hline Processo & E_C1 n(\%) & E_C3 n(\%) & MA n(\%) & MO n(\%) & n total(\%) \\
\hline Adaptação & $28(84,84)$ & $12(88,23)$ & $11(73,3)$ & $12(92,3)$ & $63(82,5)$ \\
Modularização & $5(15,15)$ & $3(11,76)$ & $4(26,7)$ & $1(7,7)$ & $13(17,5)$ \\
\hline Total & 33 & 15 & 15 & 13 & 76 \\
\hline
\end{tabular}

Quando se compara a porcentagem de ocorrência do processo de modularização entre os sujeitos que foram classificados como estáveis no primeiro e terceiro nível da fase de estabilização, nota-se que há uma mudança de 14,7\% quando o sujeito advém do primeiro nível e de $41,14 \%$ quando o sujeito permaneceu no terceiro nível (TABELA 31). Por outro lado, os sujeitos com tendência a mudança ascendente não apresentam nenhuma ocorrência no processo de modularização. Isso indica uma associação entre o nível de consistência e a probabilidade de mudança dos processos ocorrerem. Esses resultados são confirmados com o teste de qui-quadrado, que apresenta efeito de associação entre as duas medidas $\left(\chi^{2}\right.$ $=11,31 ; p=0,003)$. 
TABELA 31 - Tabulação cruzada entre a frequência de ocorrência dos processos de modularização e adaptação e os sujeitos com estabilidade no $1^{\circ}$ e $3^{\circ}$ nível de desempenho e com tendência à mudança ascendente da CDS.

\begin{tabular}{lcccc}
\hline Processo & E_N1 & E_N3 & MA & Total \\
& $\mathrm{n}(\%)$ & $\mathrm{n}(\%)$ & $\mathrm{n}(\%)$ & $\mathrm{n}(\%)$ \\
\hline Adaptação & $29(85,29)$ & $10(58,82)$ & $22(100)$ & $61(83,56)$ \\
Modularização & $5(14,7)$ & $7(41,17)$ & $0(0)$ & $12(16,44)$ \\
\hline Total & 34 & 17 & 22 & 73 \\
\hline
\end{tabular}

Com base na informação do nível de estabilidade da CDC (TABELA 32), pode-se perceber que a porcentagem de ocorrência dos dois processos não apresenta mudança em relação ao nível de estabilidade do sujeito. Em todos os casos, o processo adaptativo ocorre próximo a $80 \%$, com exceção do subgrupo E_N1, mas não ficando muito próximo (66,7\%). Esses resultados indicam não existir associação significativa entre essas variáveis. $O$ teste de qui-quadrado confirmou não haver associação entre essas variáveis $\left(\chi^{2}=2,04 ; p=0,361\right)$.

TABELA 32 - Tabulação cruzada entre a frequência de ocorrência dos processos de modularização e adaptação e os sujeitos com estabilidade no $1^{\circ}$ e $3^{\circ}$ nível de desempenho e com tendência à mudança ascendente da CDC.

\begin{tabular}{lcccc}
\hline Processo & E_N1 & E_N3 & MA & Total \\
& $\mathrm{n}(\%)$ & $\mathrm{n}(\%)$ & $\mathrm{n}(\%)$ & $\mathrm{n}(\%)$ \\
\hline Adaptação & $6(66,7)$ & $51(85,0)$ & $13(86,66)$ & $70(83,33)$ \\
Modularização & $3(33,3)$ & $9(15,0)$ & $2(13,33)$ & $14(16,66)$ \\
\hline Total & 55 & 14 & 15 & 84
\end{tabular}

Com base na informação do nível de estabilização alcançado ao final da fase de estabilização (TABELA 33), pode-se perceber que a porcentagem de ocorrência dos dois processos não apresenta diferenças substanciais em relação aos grupos de estabilização, uma vez que a porcentagem de ocorrência do processo adaptativo 
para o G_1A é próxima à do G_3A, 82,69\% e 84\%, respectivamente. Esses resultados são confirmados pelo teste de qui-quadrado, que não apresenta diferenças significativas $\left(\chi^{2}=0,31 ; p=0,859\right)$.

TABELA 33 - Tabulação cruzada entre a frequência de ocorrência dos processos de modularização e adaptação e os grupos G_1A e G_3A.

\begin{tabular}{lccc}
\hline Processo & G_1A & G_3A & Total \\
& $n(\%)$ & $n(\%)$ & $n(\%)$ \\
\hline Adaptação & $43(82,69)$ & $42(84)$ & $85(83,33)$ \\
Modularização & $9(17,3)$ & $8(16)$ & $17(16,66)$ \\
\hline Total & 52 & 50 & 102 \\
\hline
\end{tabular}

\subsubsection{Modelo de regressão logística}

A análise de regressão logística binária teve como objetivo estimar a chance de mudança na ocorrência dos processos de modularização e adaptação por meio dos níveis de estabilidade alcançados na fase de estabilização. Para isso, foram utilizadas quatro variáveis independentes, categóricas: a) nível de estabilização alcançado ao final do processo de aquisição; b) nível de estabilidade ao longo dos canais do DMC; c) nível de estabilidade ao longo dos canais da CDS; d) nível de estabilidade ao longo dos canais da CDC. Também foram consideradas as interações entre as variáveis independentes.

Com base nas principais estatísticas do modelo de regressão logística (TABELA 34), nota-se que de todas as variáveis, candidatas a preditoras, apenas a consistência no desempenho da sequência apresentou efeito significativo sobre a chance de mudança da ocorrência dos processos de modularização e adaptação. Os valores do -2LL foram menores para o modelo que inclui a variável CDS $\left(\chi^{2}=18,377\right.$; $p<0,000)$. Para essa variável, os valores do teste Wald também indicaram efeito significativo. No entanto, o efeito foi apenas entre o subgrupo com estabilidade no canal 1 e o subgrupo com estabilidade no canal 3. Assim, entende-se que há uma 
probabilidade 4 vezes maior de ocorrer o processo de modularização quando os sujeitos advém do terceiro nível de consistência comparados com os sujeitos do primeiro nível.

TABELA 34 - Principais preditores da chance de mudança da ocorrência dos processos de adaptação e modularização - resultados do modelo de regressão logística.

\begin{tabular}{lccccccc}
\hline Modelos & $(-2 \mathrm{LL})$ & $\mathrm{B}$ & $\begin{array}{c}\text { Erro } \\
\text { padrão }\end{array}$ & $\begin{array}{c}\text { Teste } \\
\text { Wald }\end{array}$ & $\mathrm{p}$ & $\operatorname{Exp}(\mathrm{B})$ & $\mathrm{IC}(95 \%)$ \\
\hline Nulo & 69,807 & & & & & & \\
Final & 51,43 & & & & & & \\
Constante & & $-1,833$ & 0,31 & 34,742 & 0,000 & 0,16 & \\
CDS_Canal 3 & 1,401 & 0,69 & 4,11 & 0,04 & 4,06 & $1,048-15,756$ \\
\hline
\end{tabular}

O valor encontrado na tabela de classificação do modelo de regressão foi de $86,2 \%$, indicando um bom ajustamento para o modelo final. Os valores do $\mathrm{R}^{2}$ de Cox e Snell foram estabelecidos em 0,19 , e o de $R^{2}$ de Nagelkerke 0,34 , indicando que a inclusão da variável independente melhorou o ajustamento do modelo em $19 \%$ e $34 \%$, de acordo com o critério adotado.

Quando observados os valores dos resíduos padronizados, notou-se que apenas dois sujeitos apresentaram valores próximos a 3. A remoção desses casos não acarretou mudança substancial nos modelos e valores preditos. A distância de Cook não indicou casos acima de 1. O teste de Hosmer e Lemeshow indicou pequenas diferenças entre os valores previstos e observados, mas não significativas $\left(\chi^{2}<0,001 ; p=1\right)$.

Com base nos resultados da regressão logística, pode-se entender que foi possível estabelecer um modelo de predição para a ocorrência dos processos de modularização e estabilização, com bons níveis de ajustamento. A variável CDS apresentou efeito significativo na capacidade de predição do modelo. Essa variável potencializou a ocorrência do processo de modularização quando o sujeito situou-se nos níveis superiores de estabilidade, durante a fase de estabilização. 


\subsection{Quantidade de tentativas para aprendizagem da tarefa mais complexa}

No que diz respeito à quantidade de tentativas para aprender a tarefa com o novo componente, $\mathrm{o}$ teste $\mathrm{t}$ de Student indicou diferenças significativas $(t=7,52$; $p<0,0001)$ na comparação entre os sujeitos que mantiveram a estrutura na situação mais complexa e os que reorganizaram. A média da diferença foi de 36 tentativas, com um limite de confiança de 95\%, indicando de 26 a 46 tentativas (FIGURA 17). Com base nesses resultados, entende-se que os sujeitos que mantiveram a estrutura na nova situação apresentaram uma quantidade de tentativas significativamente inferior aos que adaptaram.

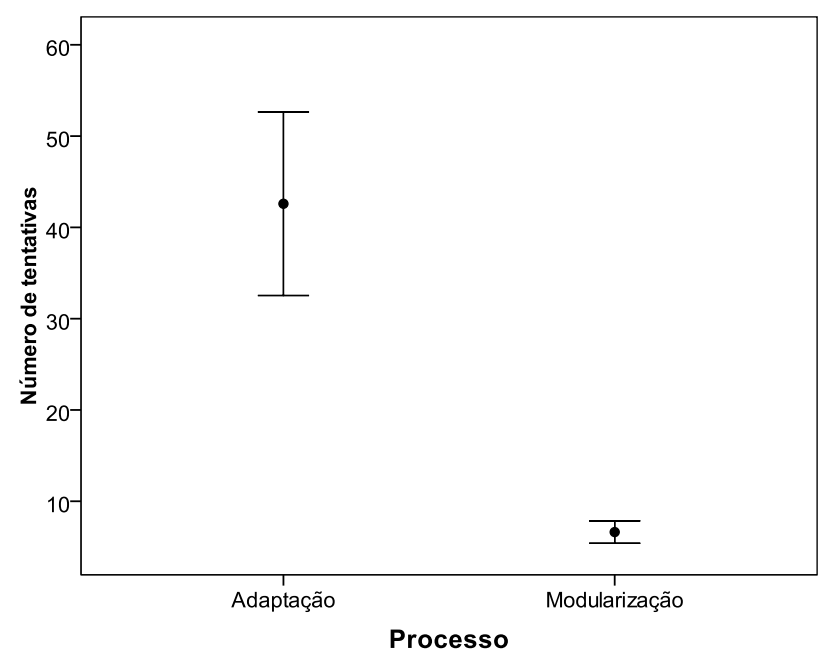

FIGURA 17 -Média e limite de confiança (95\%) da quantidade de tentativas para alcançar o critério da tarefa com o novo componente para os sujeitos que mantiveram a estrutura na nova situação, e os que reorganizaram.

\subsection{Nível de estabilização e quantidade de tentativas para alcançar os critérios}

A quantidade de tentativas para alcancar o critério da fase de estabilização entre os grupos G_1A e G_3A não aparenta ser diferente (FIGURA 16), tanto na fase de estabilização quanto de adaptação: ambos apresentaram diminuição para a 
segunda fase. Já o grupo G_3C utilizou menos tentativas para a alcançar o critério da fase de estabilização do que os outros grupos, no entanto, na fase de adaptação apresentou valores superiores (FIGURA 18). Os resultados da Anova mista indicaram haver efeito significativo para a interação entre grupo e fase (Lambda $\Lambda=$ 0,$\left.98 ; g l=2,14 ; F=38,93 ; p<0,001 ; \eta^{2}=0,34\right)$. O teste a posteriori (Bonferroni) indicou diferenças significativas para todos os grupos entre a fase de estabilização e adaptação, com o grupo G_3C aumentando em média 49 tentativas entre as fases, e os grupos G_1A e G_3A diminuindo em média 15 tentativas, e entre o grupo G_3C e os outros grupos na fase de estabilização, com uma diferença média de 48 tentativas para o G_1A e 43 tentativas para o G_3A.

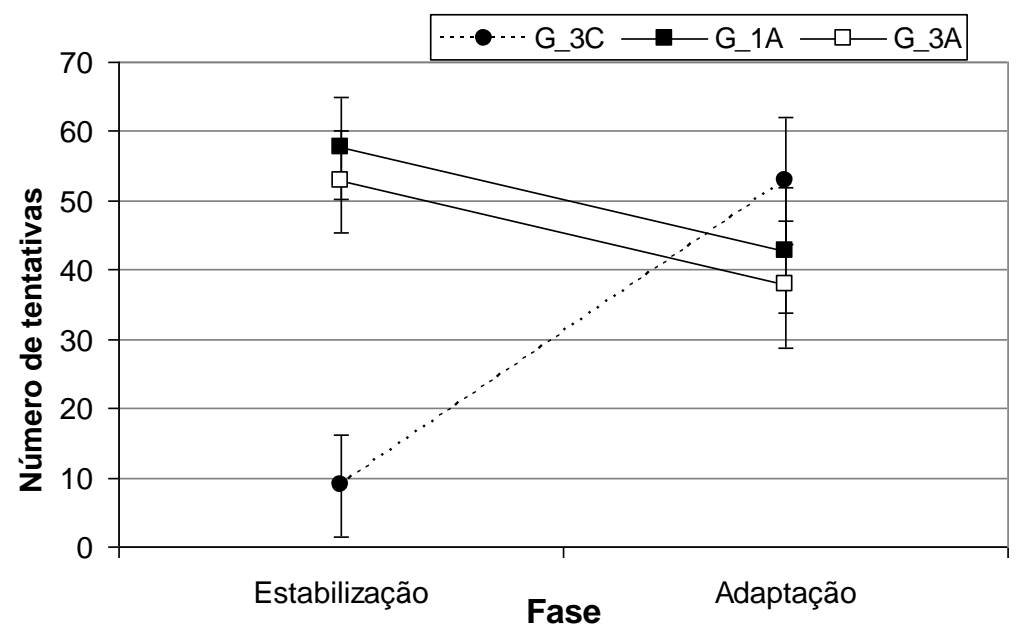

FIGURA 18 - Média e limite de confiança (95\%) da quantidade de tentativas para alcançar o critério da tarefa com o novo componente para os grupos G_3C, G_1A e G_3A nas fases de estabilização e adaptação.

\subsection{Análise da associação entre a quantidade de tentativas para alcance do primeiro e segundo critério de desempenho}

Com base nos valores da TABELA 35 é possível observar que apenas para 0 grupo G_3A há uma correlação fraca, mas significativa, entre a quantidade de tentativas necessárias para alcançar o critério da fase de estabilização e da fase de adaptação. Esses resultados são ilustrados pela FIGURA 19. 
TABELA 35 - Valores da correlação de Pearson, nível de significância e coeficiente de determinação para a quantidade de tentativas da fase de estabilização e adaptação.

\begin{tabular}{cccc}
\hline Grupo & $r$ & $p$ & r2 \\
\hline G_3C & 0,20 & 0,15 & - \\
G_1A & 0,04 & 0,76 & - \\
G_3A & 0,31 & 0,03 & $9,49 \%$ \\
\hline
\end{tabular}

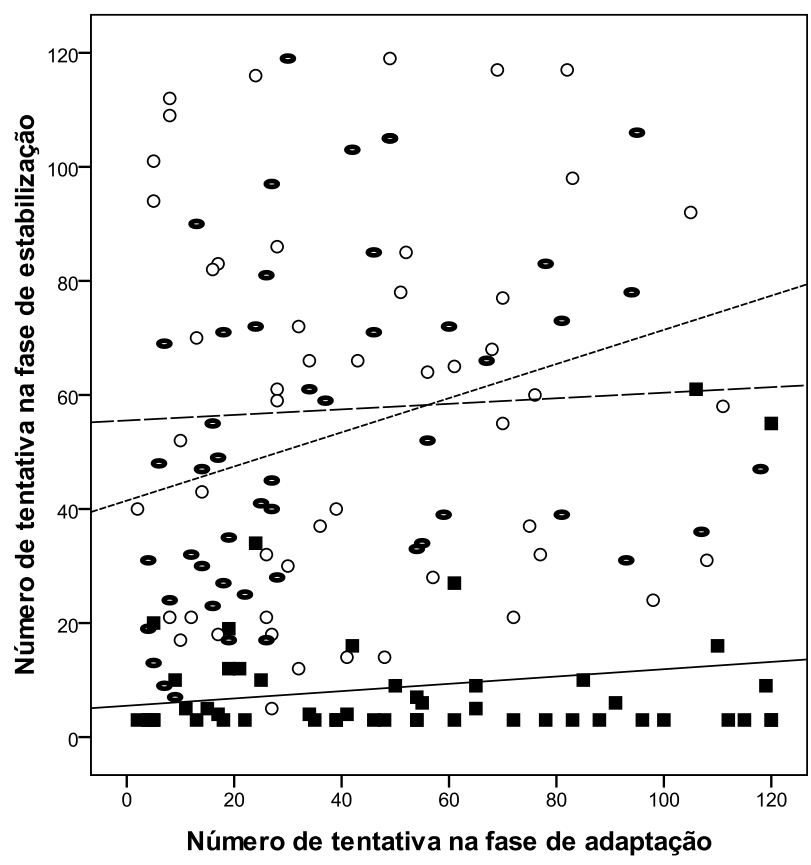

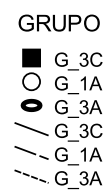

FIGURA 19 - Diagrama de dispersão bivariado da quantidade de tentativas para alcançar o critério das fases de estabilização e adaptação para os diferentes grupos.

Com base nos valores de correlação de Pearson e no diagrama de dispersão, nota-se que os sujeitos que foram mais rápidos na obtenção do critério da fase de estabilização não necessariamente foram os mais rápidos na fase de adaptação. Esses resultados são semelhantes para os diferentes grupos na estabilização. 


\subsection{Análise do tipo de resposta logo após a inserção do novo componente}

Uma forma de observar o efeito do nível de estabilização final no desempenho da tarefa com o novo componente é analisar o comportamento do maior tipo de resposta no primeiro bloco da fase de adaptação. A TABELA 36 apresenta a porcentagem de sujeitos em cada tipo de resposta, descrevendo os que apresentaram respostas antecipatórias em 1, 2, 3 ou 4 componentes, e os que realizaram, com respostas corretas, os 6 componentes. É possível notar que $92 \%$ dos sujeitos do grupo que estabilizou com respostas corretas (G_3C) apresentaram algum nível de respostas corretas no primeiro bloco da fase de adaptação, com a maioria dos sujeitos $(72 \%)$ já realizando toda a nova tarefa com respostas corretas, Esse resultado indica que mesmo após a inserção do novo componente, para a maioria dos sujeitos, a resposta máxima no primeiro bloco manteve-se no mesmo nível: respostas corretas.

TABELA 36 - Porcentagem de sujeitos para cada tipo de resposta no primeiro bloco da fase de adaptação para os três grupos.

\begin{tabular}{lccc}
\hline Resposta & $\begin{array}{c}3 \mathrm{C} \\
(\mathrm{n} \%)\end{array}$ & $\begin{array}{c}1 \mathrm{~A} \\
(\mathrm{n} \%)\end{array}$ & $\begin{array}{c}\text { 3A } \\
(\mathrm{n} \%)\end{array}$ \\
\hline Re\% & 3,9 & 9,6 & 12 \\
& & & \\
\cline { 2 - 4 } Rc\%_6c & 72,2 & 11,5 & 24 \\
$\sum$ Rc\% & 92,2 & 42,3 & 52 \\
& & & \\
\cline { 2 - 4 } Ra\%_1c & & 19,2 & 8 \\
Ra\%_2c & 3,9 & 17,3 & 12 \\
Ra\%_3c & & 3,8 & 6 \\
Ra\%_4c & & 7,7 & 10 \\
$\sum$ Ra\% & 3,9 & 48,1 & 36 \\
\hline
\end{tabular}

No grupo G_1, a maioria dos sujeitos apresentou algum nível de respostas 
antecipatórias $(48,1 \%)$ ou corretas $(42,3)$, porém, os sujeitos que apresentaram respostas antecipatórias, o fizeram no máximo em 2 componentes. Apesar da pequena porcentagem de sujeitos que responde de forma errada $(9,6 \%)$, ela é superior ao grupo G_3C.

Para o grupo G_3A pode-se notar que a maioria dos sujeitos (52\%), no primeiro bloco, responde de forma correta quando o novo componente é inserido, $12 \%$ de forma errada e 36\% de forma antecipatória. Quando comparada a porcentagem de respostas antecipatórias com o grupo G_1A, nota-se que esse grupo apresenta maiores porcentagens para as respostas antecipatórias e menores para as respostas corretas e erradas. Isso pode indicar que esse grupo foi mais afetado pela inserção do novo componente do que o G_1A. No entanto, a série de testes d qui-quadrado, apenas indicou que para Rc\%_6c o G_3C apresenta maior proporção do que G_1A e G_3A $\left(\chi^{2}=46,23\right.$; p<0,0001); e para $\sum R a \%$ o G_3C apresenta menor proporção de sujeitos do que o G_1A e G_3A ( $\chi^{2}=25,73$; $p<0,0001)$. Com base nesses resultados pode-se inferir que o G_3C apresenta maior proporção de sujeitos com respostas corretas e menor com respostas antecipatórias do que os outros grupos.

\section{DISCUSSÃO}

O presente estudo teve como objetivo investigar se os níveis de estabilização modificam a probabilidade de um dos processos envolvidos no aumento de complexidade ocorrer (modularização e adaptativo) quando novos componentes forem inseridos na tarefa já aprendida e também, a influência desses processos na aprendizagem da tarefa com novos componentes.

Para caracterizar o nível de estabilização do desempenho na tarefa inicial buscou-se em diferentes áreas do conhecimento algumas ideias e técnicas para a sua operacionalização. No caso do presente estudo, escolheu-se adotar um indicador já utilizado na literatura de Aprendizagem Motora - critério de estabilização (TANI 1995), e um indicador de outra área de conhecimento (Epidemiologia, Estatística Aplicada) - estabilidade nos canais de desempenho (MAIA et alli, 2007). 
Foram estabelecidas três linhas de análise e discussão. A primeira foi centrada na informação normativa, que descreve o comportamento da maioria dos sujeitos ao longo da fase de estabilização e adaptação. A segunda enfocou a estabilidade interindividual na mudança intraindividual, com o objetivo de estimar o nível de estabilidade ao longo da fase de aquisição e a sua associação com os diferentes canais de desempenho. A terceira se referiu a identificação da ocorrência dos processos de adaptação e modularização, e os efeitos dos níveis de estabilização na probabilidade desses processos ocorrerem e seus efeitos na aprendizagem de tarefas mais complexas.

\subsection{Mudança normativa ao longo das fases}

A caracterização do desempenho ao longo das fases de estabilização e adaptação, ocorreu mediante medidas diferentes daquelas já empregadas em estudos com o mesmo tipo de tarefa. Isso aconteceu devido a algumas particularidades na distribuição dos dados referentes a proporção dos diferentes tipos de respostas encontradas no presente estudo.

Ao observar os valores das análises exploratórias da proporção de ocorrência dos diferentes tipos de respostas, notou-se que mesmo para as técnicas estatísticas mais flexíveis como a modelação linear hierárquica (MAIA, GARGANTA, SEABRA, LOPES, VINAGRE, FREITAS, PRISTA e MEIRA, 2005) ou modelos mistos (UGRINOWITSCH, FELLINGHAM \& RICARD, 2004) ainda havia limitações para a sua utilização. Os resultados exigiram a adição de procedimentos exploratórios com o intuito de entender melhor a estrutura dos dados e adequar as análises inferenciais. A quantidade de casos igual a zero, obtidos nos diferentes blocos e para os diversos tipos de respostas, parece ser o maior limitador. Desde o início até a metade da fase de estabilização, a ocorrência de sujeitos que não realizaram a resposta antecipatória foi muito frequente. O mesmo ocorreu em todos os blocos com respostas omissas, e também nos primeiros blocos para as respostas erradas. Análises semelhantes a essas não foram encontradas na literatura em geral e nem nos trabalhos de referência (CATTUZZO, 2007; TANI, 1995; RESTLE, 1970) para o 
presente estudo.

Há certa dificuldade de elaborar argumentos para os fatos apresentados acima. Isso se deve a preocupação em utilizar uma série de características (sequência, intervalo inter-estímulos, instrução e idade dos sujeitos) semelhantes às empregadas pelos estudos citados acima. Com relação às respostas antecipatórias, essas particularidades foram detectadas mais severamente nos primeiros estudospiloto, mas com a modificação da instrução e a inclusão da demonstração, houve melhora na ocorrência dessas respostas. Possivelmente, explorar mais essas características pode auxiliar no esclarecimento das limitações e possibilitar a utilização dessas medidas como originalmente foram elaboradas. Esses resultados levaram ao desenvolvimento de outras formas de organizar as respostas, a fim de analisar o comportamento dos sujeitos ao longo do processo de estabilização e adaptação.

Uma das soluções adotadas foi a elaboração de uma estratégia que em si, apresentasse indicativos da presença dos diferentes tipos de respostas numa medida denominada de DCM (Desempenho Coletivo Máximo). A outra estratégia foi classificar a freqüência de Ra em 3 categorias de níveis distintos de ocorrência, discriminando ainda a frequência de ocorrência dos componentes CDC (Consistência de Desempenho dos Componentes) da frequência de ocorrência da sequência CDS.

O fato de haver mudança nas fases de estabilização e adaptação para as diferentes facetas do desempenho foi uma condição esperada, uma vez que para os diferentes grupos foram elaborados critérios desafiadores e possíveis de serem atingidos. No entanto, houve algumas particularidades na forma de como essa mudança ocorreu.

Para o DCM, a constatação de a mudança ocorrer apenas entre os blocos não adjacentes na fase de estabilização e em alguns blocos da fase de adaptação, trouxe a evidência de que somente após várias tentativas o melhor desempenho aumenta ainda mais. Por exemplo, após o sujeito atingir um desempenho máximo no primeiro bloco, ele consegue no máximo repetí-lo no segundo. Um DCM superior somente é alcançado no terceiro bloco, e assim sucessivamente. Esse comportamento é generalizável para os 3 grupos e difere apenas na pontuação do 
DCM alcançado ao final da fase de estabilização, uma vez que na fase de adaptação todos grupos alcançaram o mesmo critério.

Esse fato pode indicar que, independentemente do nível de estabilização alcançado, os sujeitos apresentam uma mudança normativa semelhante, e necessitam de uma série de tentativas para alcançar os novos níveis de desempenho. Essa ideia pode pressupor que o desempenho possa mudar em forma de degraus ou "patamares", e para atingir patamares superiores é necessária uma série de tentativas. É possível pensar que esse fato esteja associado ao uso do desempenho máximo como medida. No entanto, a CDC e CDS apresentam indicativos parcialmente convergentes aos do DCM. Pode-se tentar visualizar isso a partir do seguinte exemplo: houve aumento na proporção de sujeitos com alta consistência de Ra ao final da fase estabilização, porém o nível de consistência com maior proporção de sujeitos repete-se em dois terços dos blocos para 3 das 4 análises realizadas.

Se focar o olhar na análise do sentido da mudança do DCM, estritamente na categoria com maior proporção de sujeitos, as evidências não auxiliam na sustentação da ideia de que o desempenho muda em termos de patamares para os grupos que se estabilizaram nas respostas antecipatórias. Uma vez que para a maior parte dos contrastes entre blocos, a maioria dos sujeitos tende a mudança ascendente no DCM para o G_1A e G_3A. No entanto, para ambos os grupos sempre há uma quantidade de sujeitos (18 a $40 \%$ ) que consegue apenas manter 0 desempenho de um bloco para o outro. A maioria dos sujeitos do grupo G_3C apresenta um comportamento de manutenção.

Em síntese, os resultados encontrados auxiliam na sustentação de que há mudança no desempenho com a prática, mas é preciso pensar em como analisar a forma da mudança. A partir de seus resultados TANI (1995) e CATTUZZO (2007) descrevem que a mudança no desempenho ocorre de forma gradual. Cabe assim, pensar em como testar mais efetivamente tais questões. Se essa diferenciação na forma de descrever a mudança está atrelada à natureza e particularidades da informação ou ao tipo de medida deve ser considerada. 


\subsection{Análise da estabilidade interindividual na mudança intraindividual}

A segunda linha de análises enfocou a estabilidade interindividual na mudança intraindividual, com o objetivo de estimar individualmente o nível de estabilidade ao longo da fase de aquisição e a sua associação com os diferentes canais de desempenho. A partir desses resultados, foram estabelecidos os subgrupos de sujeitos com diferentes tipos de estabilidade em determinados canais para testar os seus efeitos na probabilidade de ocorrência dos processos de modularização e adaptação.

Os resultados das análises gerais da estabilidade interindividual na mudança intraindividual apresentaram uma clara heterogeneidade nas trajetórias das diferentes facetas dos sujeitos, para alcançar os critérios de estabilização da primeira fase. Independentemente das medidas e grupos analisados, a estabilidade foi fraca. Esses resultados indicam que a discussão da previsibilidade do desempenho nessa tarefa necessita de cuidado. Principalmente as discussões que definem o sentido e a magnitude das mudanças em termos médios. Vale ressaltar que uma das características importantes para estabelecer as predições no comportamento é a presença de bons níveis de estabilidade (MAIA et alli, 2007). No entanto, a análise da proporção de sujeitos por nível de estabilidade indicou que, independentemente da característica do desempenho, a maioria dos sujeitos apresenta estabilidade boa, ou seja, é possível predizer o comportamento de determinados subgrupos, mas para outros a descrição e predição do comportamento ao longo da prática constitui um desfafio.

Deve-se ressaltar que mesmo para os sujeitos com estabilidade boa não se poderia pensar em comportamentos semelhantes, pois podem diferenciar-se em termos de permanência nos diferentes canais modais. De acordo com essas considerações, só faz sentido atribuir valor a ideia de estabilidade nos canais quando houver possibilidade de elaborar as previsões das trajetórias ao longo da prática e distinguir os canais modais. Somente com a atribuição nos canais modais dos sujeitos com estabilidade boa e excelente, é que se pode estabelecer uma ordem e atribuir um valor aos seus comportamentos. 
Para os sujeitos com estabilidade fraca ficou claro que há tendência a mudança ascendente e oscilação, ou seja, há sujeitos que saem de um canal inferior no início da prática e ao longo das tentativas ascendem a canais superiores, e sujeitos que não apresentam nenhum indicativo de tendência, configurando-se assim um comportamento "errático". Apenas para a medida do DCM observou-se sujeitos também com tendência a mudanças descendentes.

Os resultados da permanência dos sujeitos nos canais de estabilidade excelente e boa para o DCM e a CDS indicaram que a maioria deles permanece nos canais inferiores, em contrapartida, para o CDC a maioria dos sujeitos permaneceu no canal superior. Outro aspecto que requer atenção é não haver uma proporcionalidade na distribuição dos sujeitos de acordo com o nível de estabilidade e os canais de desempenho. Com isso, pode-se inferir que apresentar Ra sem considerar a distribuição ao longo das tentativas pode influenciar na caracterização dos sujeitos em mais ou menos consistêntes. Entende-se assim que alguns sujeitos teriam altos níveis de consistência em $\mathrm{Ra}$ nos componentes, mas não necessariamente teriam consistência no desempenho da sequência completa em Ra.

No seu conjunto, os resultados da estabilidade nos canais de desempenho impõem desafios na elaboração de hipóteses explicativas sobre a diversidade das trajetórias ao longo da estabilização. Uma vez que, ao focalizar o comportamento dos sujeitos, não foi possível observar níveis de estabilidade elevados, mas sim a ocorrência de subgrupos de sujeitos com maior ou menor semelhança na trajetória ao longo do processo. DEADRICK e MADIGAN (1990) apresentam evidências empíricas do desempenho longitudinal de atletas profissionais que auxiliam a fortalecer $o$ argumento de que as diferenças na mudança intra-individual, poderiam ser o "sinal" mais visível de que na mesma tarefa os sujeitos apresentam diferentes níveis de estabilidade. Se tal resultado ocorre, sugere-se a hipótese dos sujeitos apresentarem diferentes padrões de mudança intra-individual do desempenho ao longo da prática.

Se o entendimento da mudança e da obtenção da estabilização nas diferentes facetas do desempenho tem papel central na investigação da aprendizagem motora em tarefas seriadas de rastreamento luminoso (TANI, 1995), 
então a inclusão da identificação direta da mudança ocorrida em cada sujeito ao longo da prática torna-se uma aspecto central. Cabe ressaltar que, há algum tempo é chamada a atenção para a ideia de que a mudança no desempenho é um fenômeno de natureza intra-individual, uma propriedade intrínseca de cada unidade individual de observação (MAIA et alli, 2007; NESSELROADE, 1991).

Para se dar a devida atenção aos aspectos da mudança intra-individual e das diferenças inter-individuais, é necessário encaminhar as análises para além dos valores normativos, explorando a diversidade das trajetórias intra-individuais. Essencialmente, deve-se atentar para a história do desempenho de cada sujeito, e assim analisar as semelhanças e diferenças para então discutir o seu significado. A combinação dessas análises possibilita discutir os aspectos da aprendizagem motora, tanto a partir de uma abordagem centrada na variável quanto no sujeito. Trata-se de um território aberto à exploração e interpretação substantiva.

Um outro aspecto que merece destaque, devido ao desempenho nesse tipo de tarefa ser composto por 4 tipos de resposta complementarmente (TANI, 1995), se refere à exploração da associação entre elas ao longo da prática, tentando identificar a presença de invariância configuracional e métrica. A importância desse tipo de análise reside no fato de possibilitar entender como individualmente a mudança numa faceta se relaciona com as outras. Por exemplo, em termos médios há sugestão de que o aumento de respostas corretas ocorre associado à diminuição de respostas erradas e omissas (TANI, 1995), mas ainda não se sabe se em termos individuais com qual frequência isso ocorre.

\subsection{Análises sobre os processos envolvidos no aumento de complexidade de habilidades motoras}

A terceira linha de análises centrou-se na identificação da ocorrência dos processos de adaptação e modularização, efeitos dos níveis de estabilização na probabilidade desses processos ocorrerem e o seus efeitos na aprendizagem da tarefa mais complexa.

Os resultados encontrados sobre a analise da manutenção da estrutura de 
respostas antecipatórias quando houve a inserção do novo componente possibilitaram obter indicativos claros da ocorrência do processo adaptativo. Houve uma frequência elevada de sujeitos que deixaram de responder no nível antecipatório; indicativo de que a inserção do novo componente pode ter gerado altos níveis de perturbação na maioria dos sujeitos. Por outro lado, a quantidade de sujeitos que realizaram de 1 a 5 componentes com respostas antecipatórias, possibilita argumentar que a inserção de um mesmo componente pode gerar níveis diferentes de perturbação nos sujeitos, exigindo uma adaptação estrutural em graus variados, hipotése inicialmente apresentada por MANOEL e BASSO (2005).

Os resultados referentes a identificação de sujeitos respondendo antecipatoriamente aos 5 componentes inicialmente estabilizados é a condição essencial para continuar a investigar a ocorrência do processo de modularização. A utilização imediata da estrutura antiga de respostas antecipatórias na nova tarefa é um dos indicativos mais relevantes para a argumentação da ocorrência do processo de modularização. Essa ideia torna-se mais concreta quando é adicionada a evidência da semelhança dos parâmetros da estrutura em termos de magnitude e variação entre as tentativas de antes e após a inserção do novo componente.

Com esses resultados pode-se argumentar a favor da ocorrência dos dois processos no aumento de complexidade em aprendizagem motora. O que os distingue, até o momento, é a frequência de ocorrência: 16\% para a modularização e 84\% para a adaptação. Esses resultados corroboram as ideias e resultados de MANOEL e BASSO (2005), ao argumentarem que tais processos podem ser vistos como etapas de um processo de aumento de complexidade em aprendizagem motora. No entanto, a ocorrência de um ou outro processo não estaria necessariamente atrelada somente ao local da inserção do novo componente, como sugere o estudo de MANOEL et alli (2002). Se no estudo de BASSO (2002) houve a ocorrência dos dois processos e só a localização da inserção dos novos componentes não foi suficiente para a distinção dos processos, o presente estudo pode indicar que não é necessário manipular as características dos novos componentes para a ocorrência dos dois processos. $O$ presente estudo apresentou a ocorrência de ambos processos, mas com a inserção de um mesmo componente. 
Assim, um mesmo componente pode gerar diferentes níveis de perturbação nos sujeitos.

Esse resultado pode ser descrito como esperado quando se recorre às ideias e evidências que os estudos em processo adaptativo têm apresentado (UGRINOWITSCH, 2003; TANI, 1995), nos quais se atrelam os diferentes níveis de perturbação aos níveis de estabilização que o sujeito se encontra no momento da modificação da tarefa. Essas ideias combinadas com a concepção de que apenas programas estáveis, destinados a níveis inferiores de controle pelo sistema nervoso central tornariam-se unidades modulares em tarefas mais complexas fez com que se buscasse elaborar diferentes formas de mensurar o nível de estabilização alcançado pelo programa na tarefa mais simples.

Especificamente investigou-se o efeito do nível de estabilização alcançado ao final do processo e ao longo dos canais de desempenho da tarefa mais simples, expresso por diferentes medidas, na probabilidade de um dos processos ocorrer. Os resultados indicaram que apenas a estabilidade nos canais de desempenho da CDS esteve associdada a tais ideias, mais especificamente o modelo de regressão indicou que os sujeitos com estabilidade em canais de consistência superiores têm 4 vezes mais probabilidade de se utilizarem do processo de modularização do que os sujeitos com estabilidade em canais de consistência inferiores.

Esses resultados denotam que uma condição que contribui favoravelmente para a ocorrência do processo de modularização em situações onde a inserção do novo componente, teoricamente, acarreta em um maior nível de perturbação - de acordo com os princípios de pre-programação e programação on-line (BURTON, 1987) - está associada a presença da estabilidade acima de 10\% de ocorrência em pelo menos metade dos componentes da sequência com respostas antecipatórias.

Pode-se argumentar que há indicativos de que o nível de estabilização alcançado ao final da fase de aquisição (uma ou três tentativas em Ra) não influencia na probabilidade de ocorrência de um dos processos frente a inserção de novos componentes. $\mathrm{O}$ aumento de uma para três sequências em Ra não gerou maiores níveis de estabilização no programa formado inicialmente. E assim não permitiu ao programa condição suficiente de tornar-se uma unidade modular quando em tarefas 
mais complexas.

Por outro lado, permanecer em canais de desempenho elevados ao longo da fase de estabilização, considerando a execução da sequência com respostas antecipatórias, aumentaria a probabilidade de ocorrência do programa inicialmente formado tornar-se uma unidade modular nas situações mais complexas.

Essas ideias possibilitam uma reflexão mais direta quando se nota diferentes resultados na associação entre os níveis de CDS e CDC com a probabilidade de ocorrência de um dos processos. Se o importante fosse em atingir maiores níveis de resposta antecipatória nessa tarefa, então a associação entre a ocorrência de um dos processos aconteceria para ambas as medidas. Entretanto, o fato de apenas terse efeito significativo para a CDS possibilita pensar que é necessário diferenciar o nível de consistência do desempenho com Ra. A ideia é que a probabilidade de ocorrência estaria atrelada ao domínio da sequência, e não apenas ao aumento da frequência do desempenho em Ra. Reforçando as ideias de RESTLE (1970), em que a aprendizagem desse tipo de tarefa centra-se na integração da sequência de respostas que são organizadas de forma siginificativa. E assim, apenas a observação da frequência de $\mathrm{Ra}$, sem discriminar a distribuição ao longo das tentativas, não seria o melhor indicador visível da formação de estrutura.

Essas ideias podem ser associadas ao processo descrito por HOLLAND (1997), de que um bloco constituinte que fosse utilizado consistentemente com sucesso nas situações vividas, seria um bom candidato à utilização nas novas situações. Significa que os sujeitos que vivenciaram com sucesso a sequência com Ra na situação mais simples têm mais probabilidade de utilizar-se dela como um bloco constituinte na tarefa mais complexa, do que em relação aos sujeitos que realizaram com maior sucesso blocos constituintes com menos componentes. Cabe questionar se os sujeitos com domínio de uma estrutura menor da sequência também não teriam a sua manutenção na fase mais complexa. No entanto, pelo fato de esses "blocos constituintes" não se referirem a estrutura total, o presente estudo o considerou como reorganização. Essa especulação traz à tona a ideia de que a formação do programa para a tarefa mais simples também ocorreu por meio da integração de programas, o que não é totalmente estranho na literatura. É só 
observar os vários trabalhos sobre a formação de chunkings para a aprendizagem de sequências de ações motoras (SIMON, 1974, SAKAI, KITAGUCHI \& HIKOSAKA, 2003), ou até mesmo ao observar os trabalhos de RESTLE (1970), quando eram intencionalmente introduzidas determinadas organizações de estímulos dentro de uma sequência maior.

Os resultados da quantidade de prática para aprender a nova tarefa indicaram uma vantagem para os sujeitos que conseguiram utilizar o programa formado inicialmente na nova situação. Apesar de exitirem uma série de estudos sobre a unidade modular, como citados na revisão de literatura, apenas o estudo de BASSO (2002) se preocupou com essa característica. Na comparação dos resultados do presente estudo com os resultados do referido estudo, nota-se divergência, pois no estudo desse autor os sujeitos que reorganizaram o programa formado inicialmente é que obtiveram melhores desempenhos na nova tarefa. Cabe lembrar que no estudo de BASSO (2002) a medida de desempenho não era específica como no presente estudo e assim a quantidade de tentativas não foi utilizada, mas sim, o desempenho na própria tarefa com um número específico de tentativas.

Uma possível hipótese para o processo modular alcançar a meta da nova tarefa com menor quantidade de tentativas poderia advir da ideia de que o sujeito com maior consistência em mais da metade da sequência dos componentes teria menor grau de incerteza no momento de inserção do novo componente. Sujeitos que ao longo da fase de estabilização realizaram por mais vezes uma maior proporção da sequência em respostas antecipatórias, independentemente de ter alcançado o critério de uma ou três vezes a sequência em Ra, teriam menor incerteza na realização da tarefa inicial. Consequentemente, ao ser inserido o novo componente, uma menor quantidade de tentativas seria suficiente para alcançar o novo objetivo.

Os resultados da quantidade de prática necessária para a obtenção dos critérios nas duas fases entre os sujeitos dos grupos G_3A e G_1A indicaram não haver diferença entre os mesmos. $O$ aumento de frequência de sequências em $\mathrm{Ra}$ não aumentou o desafio. Isso se torna mais interessante, ao se considerar o fato de o G_3C também apresentar quantidade semelhante de tentativas para a obtenção do 
critério da tarefa mais complexa e menor quantidade para a obteção do primeiro critério. Estariam os três grupos na mesma condição no início da fase de adaptação? Se atentar para o número de tentativas para a obtenção do critério pode-se argumentar que sim, pois é utilizada a mesma quantidade de tentativas pelos três grupos. No entanto, o fato de o grupo G_3C ser mais rápido que os outros grupos na obtenção do primeiro critério, o torna o grupo com menor quantidade total de tentativas para obter ambos os critérios. Vale resssaltar que sujeitos mais rápidos para alcançar o primeiro critério não o foram para atingir o segundo.

Se o número de tentativas para alcançar o segundo critério foi semelhante entre os grupos, o mesmo não ocorreu com o DCM, pois após a inserção do novo componente houve uma diferenciação entre os grupos. Nota-se que para o grupo estabilizado com respostas corretas, a maioria dos sujeitos consegue manter-se no mesmo nível para toda a nova sequência, após uma pequena quantidade de prática, ao contrário dos grupos que estabilizaram em respostas antecipatórias em que, ao inserir o novo componente, alguns sujeitos conseguriam apenas responder alguns componentes com Ra, e outros ainda, apenas com alguns componentes com Rc. Esses resultados vão ao encontro dos apresentados por TANI (1995), indicando a existência de uma hierarquia para os diferentes tipos de respostas.

\section{CONCLUSÕES}

A interpretação e a generalização dos resultados do presente estudo ficam delimitadas às seguintes especificações: a) utilização de uma tarefa laboratorial de rastreamento de um padrão luminoso seriado de 5 e 6 estímulos; b) quantidade máxima de prática de 120 tentativas por fase do experimento; c) amostra de crianças de 10 a 13 anos de idade; d) análise de resultados dos aspectos temporais do movimento; e) processo de aprendizagem em uma única sessão.

Apesar do esforço empreendido para minimizar o efeito de variáveis intervenientes à coleta, algumas limitações devem ser consideradas: a) queda de motivação - alguns sujeitos abandonaram a tarefa no meio do experimento, devido à quantidade de prática; b) dificuldade no entendimento e execução da tarefa - muitas 
crianças não conseguiram atingir os critérios estabelecidos para terminar a tarefa.

Considerando os aspectos apresentados acima, pode-se concluir que:

Os níveis de estabilização alcançados no final do processo de aquisição não modificaram a probabilidade dos processos de modularização e adaptativo ocorrerem quando novos componentes foram inseridos.

Houve efeito dos níveis de estabilidade individual nos canais de desempenho da aquisição na probabilidade de um dos processos envolvidos no aumento de complexidade ocorrer, quando novos componentes foram inseridos na tarefa.

Os sujeitos com estabilidade em canais superiores da consistência da sequência em respostas antecipatórias apresentaram quatro vezes mais probabilidade de utilizarem o processo de modularização do que sujeitos com estabilidade nos canais inferiores.

Os sujeitos que utilizaram o processo de modularização apresentaram uma menor quantidade de tentativas para aprender a tarefa mais complexa.

Ao final desse estudo alguns desafios para futuras investigações podem ser destacados: a) a busca de técnicas que permitam analisar, tentativa por tentativa, o comportamento do programa formado inicialmente e o formado com os novos componentes; b) a realização de análises para além dos valores normativos, explorando a diversidade das trajetórias intra-individuais e a sua importância para o estudo da aprendizagem motora; b) a investigação do padrão de mudança intraindividual na relação entre os 4 tipos de respostas ao longo da prática. 


\section{REFERÊNCIAS}

ADAMS, J.A. A closed-loop theory of motor learning. Journal of Motor Behavior, Washington, v.3, p.111-50, 1971.

BASSO, L. Modularização e processo adaptativo em aprendizagem motora. 2002. 139 f. Dissertação (Mestrado em Educação Física) - Escola de Educação Física e Esporte, Universidade de São Paulo, São Paulo, 2002.

BENDA, R.N. Variabilidade e processo adaptativo na aquisição de habilidades Motoras. 2001. 314 f. Tese (Doutorado em Educação Física) - Escola de Educação Física e Esporte, Universidade de São Paulo, São Paulo, 2001.

BENDA, R.N.; CORRÊA, U.C.; LUSTOSA DE OLIVEIRA, D.; TANI, G. Variabilidade e processo adaptativo na aprendizagem de uma tarefa de controle da força manual. In: BARREIROS, J.; MELO, F.; SARDINHA, E.B. (Eds.). Percepção \& Acção III. Lisboa: Edições FMH, 2000.

BENDA, R.N.; TANI, G. Variabilidade e processo adaptativo na aquisição de habilidades motoras. In: TANI, G. (Org.). Comportamento motor: aprendizagem e desenvolvimento. Rio de Janeiro: Guanabara Koogan, 2005.

BERNSTEIN, I.H. Applied multivariate analysis. New York: Springer-Verlag, 1988.

BISHOP, A; HARRISON, A. A demonstration of modular units in motor programming? Journal of Human Movement Studies, London, v.3, p.99-109, 1977.

BRUNER, J.S. (1973) Organization of early skilled action. Child Development, v.44, p.1-11.

BRUNER, J.S. The growth of skill. In: CONNOLLY, K.J. (Ed.). Mechanisms of motor skill development. London: Academic Press, 1970. 
BURTON, A. W. The effect of number of movement components on response time in children. Journal of Human Movement Studies, London, v.13, n.2, p.231-247, 1987.

CATTUZZO, M.T. O ciclo instabilidade-estabilidade-instabilidade no processo adaptativo em aprendizagem motora. 2007. 247 f. Tese (Doutorado em Educação Física) - Escola de Educação Física e Esporte, Universidade de São Paulo, São Paulo, 2007.

$\mathrm{CHOSHI}$, K. Aprendizagem motora como um problema mal-definido. Revista Paulista de Educação Física, São Paulo, suplemento 3, p.16-23, 2000.

CONNOLLY, K.J. Factors influencing the learning of manual skills by young children. In: HINDE, R.; STEVENSON-HINDE, J. (Eds.). Constraints on learning. London: Academic Press, 1973.

CONNOLLY, K.J. Skill development: problems and plans. In: CONNOLLY, K.J. (Ed.). Mechanisms of motor skill development. London: Academic Press, 1970.

CONNOLLY, K.J. The nature of motor skill development. Journal of Human Movement Studies, London, v.3, p.128-143, 1977.

CORRÊA, U.C. A prática constante-variada e a aquisição de habilidades motoras: efeitos da quantidade e do tipo de prática variada. 2007. 109 f. Tese (Livre-Docência) - Escola de Educação Física e Esporte, Universidade de São Paulo, São Paulo, 2007.

CORRÊA, U.C. Estrutura de prática e processo adaptativo na aquisição de habilidades motoras. 2001. 220 f. Tese (Doutorado em Educação Física) - Escola de Educação Física e Esporte, Universidade de São Paulo, São Paulo, 2001.

CORRÊA, U.C.; BENDA, R.N.; TANI, G. Estrutura de prática e processo adaptativo 
na aprendizagem do arremesso de dardo de salão. Revista Brasileira de Ciências do Esporte, São Paulo, v. 22, n. 2, p.69-84, 2001.

CORRÊA, U.C.; GONÇALVES, L.A.; BARROS, J.A.C.; MASSIGLI, M. Prática constante-aleatória e aprendizagem motora: efeitos da quantidade de prática constante e da manipulação de exigências motoras da tarefa. Brazilian Journal of Motor Behavior, v.1, p.41-52, 2006.

DEADRICK, D.L.; MADIGAN, R.M. Dynamic criteria revisited: A longitudinal study of performance stability and predictive validity. Personnel Psychology, v.43, p.717$744,1990$.

ELLIOTT, J.; CONNOLLY, K.J. Hierarchical structure in skill development. In: CONNOLLY, K.J.; BRUNER, J.S. (Eds.). The growth of competence. London, Academic Press, 1974.

FISCHMAN, M. G. Programming time as a function of number of movement parts and change in movement direction. Journal of Motor Behaviour, Washingtont, v.16, n.4, p.405-423, 1984.

FITTS, P.M.; POSNER, M.I. Human performance. Belmont: California, 1967.

FOULKES, M.A.; DAVIS, C.E. An index of tracking for longitudinal data. Biometrics, Oxford, v.37,p.439-46, 1981.

GENTILE, A.M. A working model of skill acquisition with application to teaching. Quest, Champaing, v.17, p.3-23, 1972.

GIMENEZ, R. Combinação de padrões fundamentais de movimento em indivíduos normais e portadores da Síndrome de Down. 2001. 129 f. Dissertação (Mestrado em Educação Física) - Escola de Educação Física e Esporte, Universidade de São Paulo, São Paulo, 2001. 
GIMENEZ, R.; MANOEL, E.J.; BASSO, L. Modularidade de programas de ação em indivíduos normais e portadores da síndrome de Down. Psicologia: Reflexão e Crítica, Porto Alegre, v.19, n.1, p.60-65, 2006.

GIMENEZ, R.; MANOEL, E.J.; LUSTOSA DE OLIVEIRA, D.; BASSO, L. Combinação de padrões fundamentais de movimento: crianças, adultos e portadores de síndrome de down. Revista Paulista de Educação Física, São Paulo, v.18, p.101-116, 2004.

HAIR JR, J.F.; ANDERSON, R.E.; TATHAM, R.L.; BLACK, W.C. Análise multivariada de dados. 5 ed. Porto Alegre: Bookman, 2005.

HAKEN, H. Synergetics of movement coordination. Human Movement Science, Amsterdan, v.10, p.113-116, 1991.

HOLLAND, J.H. A ordem oculta: como a adaptação gera a complexidade. Lisboa: Gradiva,1997.

JEANNEROD, M. The cognitive neuroscience of action. London: Blackwell, 1996.

KOESTLER, A. O fantasma da máquina. Rio de Janeiro: Zahar, 1969.

LANDIS, J.; KOCH, G. The measurement of observer agreement for categorical data. Biometrics, Oxford, v.33, p.159-174, 1977.

LASHLEY, K.S. The problem of serial order in behavior. In: JEFFRESS, L.A. (Ed.). Cerebral Mechanisms in Behavior. New York: Wiley, 1951.

MAIA J.A.R.; LEFEVRE, J.; BEUNEN, G.; CLAESSENS, A. Tracking of physical fitness during adolescence. A panel study in boys. Medicine and Science in Sports and Exercise, Indianapolis, v.33, n.5, p.761-771, 2001.

MAIA, J.A.R.; SEABRA, A.; LOPES, V.P.; SILVA, R.G. A importância do estudo do 
tracking (estabilidade e previsão) em delineamentos longitudinais: um estudo aplicado à epidemiologia da actividade física e à performance desportivo-motora. Revista Portuguesa de Ciências do Desporto, v.2, n.4, p.41-54, 2002.

MAIA, J.A.R.; GARGANTA, R.; LEFEVRE, J.; BEUNEN, G.; CLAESSENS, A.; SEABRA, A. O tracking da actividade física: um estudo em adolescentes do sexo masculino. Revista Brasileira de Ciência e Movimento, Taguatinga, v.10, n.4, p.2734, 2002.

MAIA, J.A.R.; GARGANTA, R.; SEABRA, A.; LOPES, V.; SILVA, S.P.; MEIRA JÚNIOR, C.M. Explorando a noção e significado de tracking. Um percurso didáctico para investigadores. Psicologia, Lisboa, v.21, n.5, p.1-23, 2007.

MAIA, J.A.R.; GARGANTA, R.; SEABRA, A.; LOPES, V.P.; VINAGRE, J.; FREITAS, D.L.; PRISTA, A.; MEIRA, C. Dados longitudinais e modelação hierárquica. Um tutorial para investigadores das Ciências do Desporto. Revista Brasileira de Cineantropometria e Desempenho Humano, Florianópolis, v.7, n.2, p.94-108, 2005.

MANOEL, E.J. Desenvolvimento motor: padrões em mudança, complexidade crescente. Revista Paulista de Educação Física, São Paulo, Suplemento 3, p.35$54,2000$.

Modularização, organização hierárquica e variabilidade na aquisição de habilidades motoras. 1998. 84 f. Tese (Livre Docência) - Escola de Educação Física Esporte, Universidade de São Paulo, São Paulo, 1998.

Adaptive control and variability in the development of skilled actions. 1993. 353 f. Tese (Doutorado em Psicologia) - Departamento de Psicologia, Universidade de Sheffield, Sheffield, Inglaterra, 1993.

Desenvolvimento do comportamento motor humano: uma abordagem 
sistêmica. 1989. 321 f. Dissertação (Mestrado em Educação Física) - Escola de Educação Física e Esporte, Universidade de São Paulo, São Paulo, 1989.

MANOEL, E.J.; BASSO, L. Modularidade, hierarquia e adaptação no comportamento motor. In: TANI, G. (Org.). Comportamento motor: aprendizagem e desenvolvimento. Rio de Janeiro: Guanabara Koogan, 2005.

MANOEL, E.J.; BASSO, L.; CORRÊA, U.C.; TANI, G. Modularity and hierarchical organization of action programs in human acquisition of graphic skills. Neuroscience Letters, Clare, v.335, p.83-86, 2002.

MANOEL, E.J.; CONNOLLY, K. Variability and stability in the development of skilled actions. In: CONNOLLY, K.; FORSSBERG, H. (Eds.). Neurophisiology and Neuropsychology of motor development. London: MacKeith Press \& Cambridge University Press, 1997.

MANOEL, E.J.; CONNOLLY, K. Variability and the development of skilled actions. International Journal of Psychophysiology, Amsterdam, v.2, n.19, p.129-147, 1995.

MARINOVIC, W. Efeito da modificação da tarefa no movimento de rebatida de forehand de mesa-tenistas habilidosos. 2003. 133 f. Dissertação (Mestrado em Educação Física) - Escola de Educação Física e Esporte, Universidade de São Paulo, São Paulo, 2003.

MARTENIUK, R.G.; ROMANOW, S.K. Human movement organization and learning as revealed by variability of movement, use of kinematic information and Fourier analysis. In: MAGILL, R.A. (Ed.). Memory and control of action. Amsterdam: NorthHolland, 1983.

McGRAW, M. The neuromuscular maturation of the human infant. New York: Columbia University Press, 1945. 
MEIRA JÚNIOR, C.M. Conhecimento de resultados no processo adaptativo em aprendizagem motora. 2005. 320 f. Tese (Doutorado em Educação Física) - Escola de Educação Física e Esporte, Universidade de São Paulo, São Paulo, 2005.

MORTIMER, J.T., FINCH, M.D., KUMKA, D. Persistence and change in development: the multidimensional self-concept. In: BALTES, P.B. (Ed.). Life-span development and behavior. New York: Academic Press, 1982.

MOSS, S.; HOGG, J. The development and integration of integration of fine motor sequences in 12- to 18- month old children: A test of the modular theory of motor skill acquisition. Genetic Psychology Monographs, Worcester, n.107, p.145-187, 1983.

NESSELROADE, J.R. Interindividual differences in intraindividual change. In: COLLINS, L.M.; HORN, J.L. (Eds.). Best methods for the analysis of change: Recent advances, unanswered questions, future directions. Washington: American Psychological Association, 1991.

NEWELL, K. M. Coordination, control, and skill. In: GOODMAN, D.; WILBERG, R.B.; FRANKS, I.M. (Eds.). Differing perspectives in motor learning, memory, and control. Amsterdam: North-Holland, 1985.

PARK, J.H.; SHEA, C.H. Sequence learning: response structure and effector transfer. The Quarterly Journal of Experimental Psychology, Philadelphia, v.58, n.3, p.387419, 2005.

PAROLI, R. Efeito da estrutura de prática na aquisição de uma habilidade motora. 2004. 278 f. Dissertação (Mestrado em Educação Física) - Escola de Educação Física e Esporte, Universidade de São Paulo, São Paulo, 2004.

PINHEIRO, J.P. Estrutura de prática na aquisição de uma tarefa de timing coincidente com desaceleração do estímulo visual. Relatório Final de Iniciação Científica, FAPESP, São Paulo, 2006. 
RESTLE, F. Theory of serial patterns learning: structural trees. Psychological Review, Washington, v.77, n.6, p.481-495, 1970.

ROSENBAUM, D.A.; COHEN, R.G.; JAX, S.A.; WEISS, D.J.; VAN DER WEL, R. The problem of serial order in behavior: Lashley's legacy. Human Movement Science, Amsterdan, v.26, n.4, p.525-54, 2007.

SAKAI, K.; KITAGUCHI, K.; HIKOSAKA, O. Chunking during human visuomotor sequence learning. Experimental Brain Research, v.152, p. 229-242, 2003.

SIEGEL, S.; CASTELLAN JR, N.J. Estatística não-parmétrica para as ciências do comportamento. $2^{\mathrm{a}}$ ed. Porto Alegre: Bookman, 2006.

SIMON, H.A. How Big is a Chunk? Science, v.183, p.482-488, 1974.

SCHMIDT, R.A. A schema theory of discrete motor skill learning. Psychological Review, Washington, v.82, n.4, p.225-60, 1975.

SCHMIDT, R.A.; WRISBERG, C.A. Aprendizagem e performance motora: uma abordagem da aprendizagem baseada no problema. 2 ed. Porto Alegre: Artmed, 2001.

SCHNEIDERMAN, E.; KOWALSKI, C.J. Analysis of longitudinal data in craniofacial research: Some strategies. Critical Reviews in Oral Biology and Medicine, v.5, p.187-202, 1994.

STEVENS, J.P. Applied multivariate statistic for the social sciences. $4^{\text {th }}$ ed. Mahwah: Lawrence Erlbaum, 2002.

SUMMERS, J.J. Has ecological psychology delivered what it promised? In: PIEK, J.P. (Ed.). Motor behavior and human skill: a multidisciplinary approach. Champaign: Human Kinetics, 1998. 
TANI, G. Comportamento motor: aprendizagem e desenvolvimento. Rio de Janeiro: Guanabara Koogan, 2005.

TANI, G. Hierarchical organization of an action programme in the acquisition of a graphic skill. Relatório Final (Atividades de Pós-Doutorado) - Departamento de Psicologia, Universidade de Sheffield, Sheffield - Inglaterra, 1995.

TANI, G. Variabilidade de resposta e processo adaptativo em aprendizagem motora. 1989. 78 f. Tese (Livre Docência) - Escola de Educação Física e Esporte, Universidade de São Paulo, São Paulo, 1989.

TANI, G. O processo adaptativo na aprendizagem motora e suas implicações na organização do processo ensino-aprendizagem em educação física. Resumo da tese de doutorado, 1982.

TANI, G.; BASTOS, F.C.; CASTRO, I.J.; JESUS, J.F.; SACAY, R.C.; PASSOS, S.C.E. Variabilidade de resposta e processo adaptativo em aprendizagem motora. Revista Paulista de Educação Física, São Paulo, v.6, n.1, p.16-25, 1992.

TANI, G.; MANOEL, E.J.; KOKUBUN, E.; PROENÇA, J.E. Educação física escolar: fundamentos para uma abordagem desenvolvimentista. São Paulo: EPU/EDUSP, 1988.

TANI, G.; MEIRA JUNIOR, C.M.; GOMES, F.R.F. Freqüência, precisão e localização temporal de conhecimento de resultados e o processo adaptativo na aquisição de uma habilidade motora de controle de força manual. Revista Portuguesa de Ciências do Desporto, Porto, v.5, n.1, p.59-68, 2005.

TANNER, J.M. Fetus into Man: physical growth from conception to maturity. Cambridge: Harvard University Press, 1990.

UGRINOWITSCH, C.; FELLINGHAM, G.W.; RICARD, M.D. Limitations of ordinary 
least squares models in analyzing repeated measures data. Medicine and Science in Sports and Exercise, New York, v.36, n.12, p. 2144-2148, 2004.

UGRINOWITSCH, H. Efeito do nível de estabilização do desempenho e do tipo de perturbação no processo adaptativo em aprendizagem motora. 2003. $365 \mathrm{f}$. Tese (Doutorado em Educação Física) - Escola de Educação Física e Esporte, Universidade de São Paulo, São Paulo, 2003.

UGRINOWITSCH, H.; TANI, G. Efeitos do tipo de perturbação e do nível de estabilização no processo adaptativo em aprendizagem motora. In: TANI, G. (Org.). Comportamento motor: aprendizagem e desenvolvimento. Rio de Janeiro: Guanabara Koogan, 2005.

VIVIANI, P. Do units of motor action really exist? In: HEUER, H.; FROMM, C. (Eds.). Generation and modulation of action patterns. Berlin: Springer, 1986.

VON HOFSTEN, C. The study of goal directed actions. In KALVERBOER, A.; GUEZE, R. (Eds.). Motor development in early and late childhood: longitudinal approaches. Cambridge: Cambridge University Press, 1993.

WADDINGTON, C.H. Strategy of the Genes: a discussion of some aspects of theoretical biology. London: Allen and Unwin, 1957. 
ANEXO I - Termo de consentimento

\author{
ESCOLA DE EDUCAÇÃO FISICA E ESPORTE \\ DA \\ UNIVERSIDADE DE SÃO PAULO \\ TERMO DE CONSENTIMENTO LIVRE E ESCLARECIDO
}

(Instruções para preenchimento no verso)

\title{
I - DADOS DE IDENTIFICAÇÃO DO SUJEITO DA PESQUISA OU RESPONSÁVEL LEGAL
}

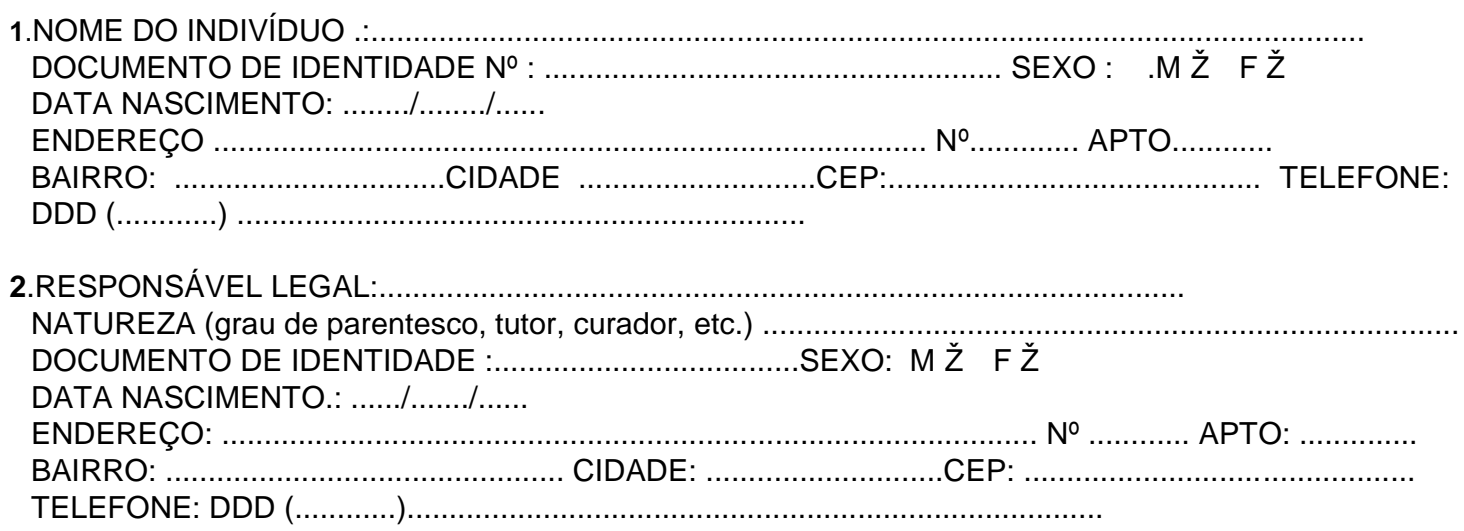

\section{II - DADOS SOBRE A PESQUISA CIENTÍFICA}

1. Este projeto intitula-se "Aumento de complexidade na aprendizagem motora: relação entre os níveis de estabilização e a organização da resposta quando inserido novos componentes numa tarefa de rastreamento luminoso seriado".

2. PESQUISADOR RESPONSÁVEL: Prof. Dr. Go Tani

3. CARGO/FUNÇÃO: Professor Titular

4. AVALIAÇÃO DO RISCO DA PESQUISA:

$\begin{array}{llll}\text { RISCO MíNIMO } & \mathbf{x} & \text { RISCO MÉDIO } & \check{Z} \\ \text { RISCO BAIXO } & \check{Z} & \text { RISCO MAIOR } & \check{Z}\end{array}$

(probabilidade de que o indivíduo sofra algum dano como conseqüência imediata ou tardia do estudo)

5. DURAÇÃO DA PESQUISA: outubro de 2009 a Fevereiro de 2010.

\section{III - EXPLICAÇÕES DO PESQUISADOR AO INDIVÍDUO OU SEU REPRESENTANTE LEGAL SOBRE A PESQUISA, CONSIGNANDO:}

1. Esse estudo está sendo desenvolvido pelo Laboratório de Comportamento Motor da Escola de Educação Física e Esporte da USP. Com ele pretendemos investigar a reposta motora numa tarefa de rastreamento de um sinal luminoso.

2. Para investigar o problema, a criança apertará botões em consonância com o acendimento de luzes (diodos) durante aproximadamente 10 minutos. O equipamento irá captar momento em que os toques ocorrem em relação ao acendimento das luzes.

3. O experimento não será invasivo e não modificará o desenvolvimento das atividades regulares da criança. Como a tarefa apenas envolve o toque em botões em resposta aos estímulos luminosos, entende-se que o envolvimento tenha riscos mínimos.

4. No caso de ocorrer um acidente com a criança durante a pesquisa será oferecido assistência no Hospital Universitário da Universidade de São Paulo. 
ANEXO I - Termo de consentimento (cont.).

\section{IV - ESCLARECIMENTOS DADOS PELO PESQUISADOR SOBRE GARANTIAS DO SUJEITO DA PESQUISA:}

1. Você tem direito a fazer perguntas a qualquer momento sobre os objetivos do experimento, o procedimento experimental, riscos envolvidos e benefício relacionado à pesquisa, de modo que suas dúvidas sobre o experimento sejam esclarecidas pelo pesquisador.

2. A participação nesse estudo é voluntária e você tem o direito de interromper a participação da criança a qualquer momento sem prejuízo.

3. A identidade da criança não será revelada em qualquer momento, bem como os dados pessoais, a qual será usada apenas para os fins desse estudo.

\section{V - INFORMAÇÕES DE NOMES, ENDEREÇOS E TELEFONES DOS RESPONSÁVEIS PELO ACOMPANHAMENTO DA PESQUISA, PARA CONTATO EM CASO DE INTERCORRÊNCIAS CLÍNICAS E REAÇÕES ADVERSAS.}

Para questões associadas com este experimento, por favor, entre em contato com Prof. Dr. Go Tani-, pesquisador responsável pelo estudo ou Prof. Luciano Basso -, Gerente da pesquisa - pelo telefone (0XX11) 30913135.

O Laboratório de Comportamento Motor fica na escola de Educação Física e Esporte, Universidade de São Paulo (USP), na avenida Prof. Dr. Mello Moraes, 65 - Butantã, São Paulo, SP. CEP: 05508-030.

\section{OBSERVAÇÕES COMPLEMENTARES:}

Não há.

\section{VII - CONSENTIMENTO PÓS-ESCLARECIDO}

Declaro que, após convenientemente esclarecido pelo pesquisador e ter entendido o que me foi explicado, consinto a criança acima citada, pela qual sou responsável legal, em participar do presente Projeto de Pesquisa.

São Paulo, de de 2009. 


\section{ANEXO II - Valores dos testes de normalidade para os diferentes tipos de proporção de respostas.}

\begin{tabular}{|r|c|c|c|c|c|c|}
\hline \multirow{2}{*}{ GRUPO } & \multicolumn{3}{|c|}{ Kolmogorov-Smirnov } & \multicolumn{3}{c|}{ Shapiro-Wilk } \\
\cline { 2 - 7 } G_3C Rstatística & $\mathrm{gl}$ & $\mathrm{p}$ & Estatística & $\mathrm{gl}$ & $\mathrm{p}$ \\
Re_B1 & 0,440 & 50 & 0,000 & 0,536 & 50 & 0,000 \\
Re_B2 & 0,413 & 50 & 0,000 & 0,575 & 50 & 0,000 \\
Re_B3 & 0,394 & 50 & 0,000 & 0,529 & 50 & 0,000 \\
Re_B4 & 0,332 & 25 & 0,000 & 0,694 & 25 & 0,000 \\
Re_B5 & 0,261 & 22 & 0,000 & 0,700 & 22 & 0,000 \\
Re_B6 & 0,230 & 11 & 0,108 & 0,755 & 11 & 0,002 \\
Rc_B1 & 0,354 & 50 & 0,000 & 0,673 & 50 & 0,000 \\
Rc_B2 & 0,369 & 50 & 0,000 & 0,691 & 50 & 0,000 \\
Rc_B3 & 0,364 & 50 & 0,000 & 0,715 & 50 & 0,000 \\
Rc_B4 & 0,322 & 25 & 0,000 & 0,787 & 25 & 0,000 \\
Rc_B5 & 0,279 & 22 & 0,000 & 0,812 & 22 & 0,001 \\
Rc_B6 & 0,136 & 11 & 0,200 & 0,976 & 11 & 0,940 \\
Ra_B1 & 0,536 & 50 & 0,000 & 0,125 & 50 & 0,000 \\
Ra_B2 & 0,501 & 50 & 0,000 & 0,142 & 50 & 0,000 \\
Ra_B3 & 0,521 & 50 & 0,000 & 0,275 & 50 & 0,000 \\
Ra_B4 & 0,508 & 25 & 0,000 & 0,236 & 25 & 0,000 \\
Ra_B5 & 0,374 & 22 & 0,000 & 0,586 & 22 & 0,000 \\
Ra_B6 & 0,255 & 11 & 0,045 & 0,782 & 11 & 0,005 \\
Ro_B1 & 0,341 & 50 & 0,000 & 0,468 & 50 & 0,000 \\
Ro_B2 & 0,369 & 50 & 0,000 & 0,507 & 50 & 0,000 \\
Ro_B3 & 0,412 & 50 & 0,000 & 0,581 & 50 & 0,000 \\
Ro_B4 & 0,313 & 25 & 0,000 & 0,727 & 25 & 0,000 \\
Ro_B5 & 0,299 & 22 & 0,000 & 0,631 & 22 & 0,000 \\
Ro_B6 & 0,244 & 11 & 0,066 & 0,807 & 11 & 0,012 \\
\hline
\end{tabular}


ANEXO II - Valores dos testes de normalidade para os diferentes tipos de proporção de respostas (cont.).

\begin{tabular}{|r|c|c|c|c|c|c|}
\hline \multirow{2}{*}{ GRUPO } & \multicolumn{2}{|c|}{ Kolmogorov-Smirnov } & \multicolumn{3}{c|}{ Shapiro-Wilk } \\
\cline { 2 - 7 } Gs_1A A Re_B1 & 0,161 & 52 & 0,002 & 0,876 & 52 & 0,000 \\
Re_B2 & 0,149 & 52 & 0,005 & 0,868 & 52 & 0,000 \\
Re_B3 & 0,128 & 52 & 0,032 & 0,914 & 52 & 0,001 \\
Re_B4 & 0,155 & 52 & 0,003 & 0,884 & 52 & 0,000 \\
Re_B5 & 0,173 & 52 & 0,000 & 0,835 & 52 & 0,000 \\
Re_B6 & 0,110 & 50 & 0,185 & 0,936 & 50 & 0,009 \\
Rc_B1 & 0,101 & 52 & 0,200 & 0,956 & 52 & 0,050 \\
Rc_B2 & 0,145 & 52 & 0,008 & 0,948 & 52 & 0,024 \\
Rc_B3 & 0,082 & 52 & 0,200 & 0,971 & 52 & 0,223 \\
Rc_B4 & 0,071 & 52 & 0,200 & 0,977 & 52 & 0,390 \\
Rc_B5 & 0,064 & 52 & 0,200 & 0,988 & 52 & 0,876 \\
Rc_B6 & 0,070 & 50 & 0,200 & 0,975 & 50 & 0,368 \\
Ra_B1 & 0,440 & 52 & 0,000 & 0,514 & 52 & 0,000 \\
Ra_B2 & 0,297 & 52 & 0,000 & 0,592 & 52 & 0,000 \\
Ra_B3 & 0,211 & 52 & 0,000 & 0,800 & 52 & 0,000 \\
Ra_B4 & 0,176 & 52 & 0,000 & 0,878 & 52 & 0,000 \\
Ra_B5 & 0,136 & 52 & 0,017 & 0,882 & 52 & 0,000 \\
Ra_B6 & 0,128 & 50 & 0,040 & 0,903 & 50 & 0,001 \\
Ro_B1 & 0,200 & 52 & 0,000 & 0,773 & 52 & 0,000 \\
Ro_B2 & 0,228 & 52 & 0,000 & 0,670 & 52 & 0,000 \\
Ro_B3 & 0,169 & 52 & 0,001 & 0,898 & 52 & 0,000 \\
Ro_B4 & 0,176 & 52 & 0,000 & 0,855 & 52 & 0,000 \\
Ro_B5 & 0,159 & 52 & 0,002 & 0,877 & 52 & 0,000 \\
Ro_B6 & 0,212 & 50 & 0,000 & 0,762 & 50 & 0,000 \\
\hline
\end{tabular}


ANEXO II - Valores dos testes de normalidade para os diferentes tipos de proporção de respostas (cont.).

\begin{tabular}{|r|c|c|c|c|c|c|}
\hline \multirow{2}{*}{ GRUPO } & \multicolumn{2}{|c|}{ Kolmogorov-Smirnov } & \multicolumn{3}{c|}{ Shapiro-Wilk } \\
\cline { 2 - 7 } Estatística & $\mathrm{gl}$ & $\mathrm{p}$ & Estatística & $\mathrm{gl}$ & $\mathrm{p}$ \\
\hline Re_B1 & 0,193 & 50 & 0,000 & 0,821 & 50 & 0,000 \\
Re_B2 & 0,184 & 50 & 0,000 & 0,829 & 50 & 0,000 \\
Re_B3 & 0,161 & 50 & 0,002 & 0,863 & 50 & 0,000 \\
Re_B4 & 0,184 & 50 & 0,000 & 0,848 & 50 & 0,000 \\
Re_B5 & 0,149 & 50 & 0,007 & 0,892 & 50 & 0,000 \\
Re_B6 & 0,177 & 49 & 0,001 & 0,842 & 49 & 0,000 \\
Rc_B1 & 0,101 & 50 & 0,200 & 0,943 & 50 & 0,018 \\
Rc_B2 & 0,096 & 50 & 0,200 & 0,967 & 50 & 0,172 \\
Rc_B3 & 0,129 & 50 & 0,038 & 0,946 & 50 & 0,024 \\
Rc_B4 & 0,073 & 50 & 0,200 & 0,977 & 50 & 0,437 \\
Rc_B5 & 0,090 & 50 & 0,200 & 0,955 & 50 & 0,056 \\
Rc_B6 & 0,082 & 49 & 0,200 & 0,977 & 49 & 0,433 \\
Ra_B1 & 0,340 & 50 & 0,000 & 0,548 & 50 & 0,000 \\
Ra_B2 & 0,234 & 50 & 0,000 & 0,740 & 50 & 0,000 \\
Ra_B3 & 0,198 & 50 & 0,000 & 0,816 & 50 & 0,000 \\
Ra_B4 & 0,116 & 50 & 0,089 & 0,920 & 50 & 0,002 \\
Ra_B5 & 0,104 & 50 & 0,200 & 0,933 & 50 & 0,007 \\
Ra_B6 & 0,065 & 49 & 0,200 & 0,978 & 49 & 0,470 \\
Ro_B1 & 0,157 & 50 & 0,004 & 0,879 & 50 & 0,000 \\
Ro_B2 & 0,222 & 50 & 0,000 & 0,810 & 50 & 0,000 \\
Ro_B3 & 0,214 & 50 & 0,000 & 0,758 & 50 & 0,000 \\
Ro_B4 & 0,226 & 50 & 0,000 & 0,768 & 50 & 0,000 \\
Ro_B5 & 0,204 & 50 & 0,000 & 0,797 & 50 & 0,000 \\
Ro_B6 & 0,239 & 49 & 0,000 & 0,744 & 49 & 0,000 \\
\hline
\end{tabular}


ANEXO III - Tabulação cruzada entre blocos adjacentes do DCM nas fases de estabilização e adaptação para o G_3C.

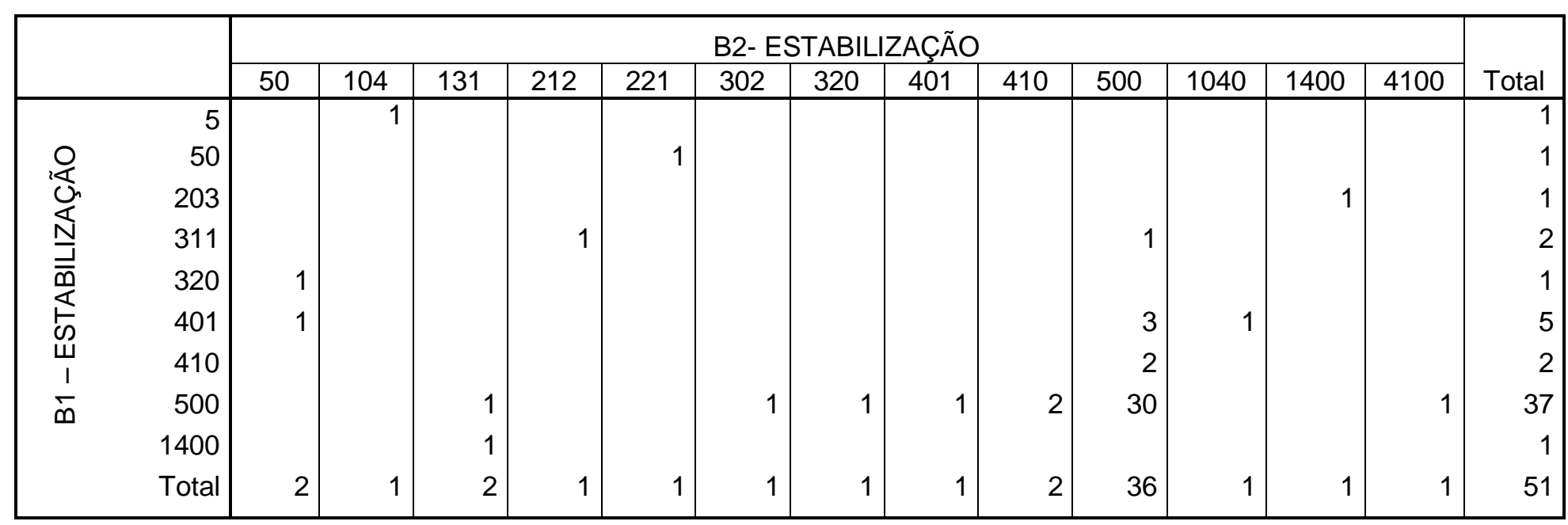


ANEXO III - Tabulação cruzada entre blocos adjacentes do DCM nas fases de estabilização e adaptação para o G_3C (cont.).

\begin{tabular}{|c|c|c|c|c|c|c|c|c|c|c|c|c|c|c|c|}
\hline & \multicolumn{13}{|c|}{ B3 - ESTABILIZAÇÃO } & \multirow[b]{2}{*}{ Total } \\
\hline & & 50 & 122 & 131 & 140 & 203 & 302 & 311 & 401 & 410 & 500 & 2030 & 2300 & 4100 & \\
\hline & 50 & & & & & 1 & & & & 1 & & & & & 2 \\
\hline & 104 & & & & & 1 & & & & & & & & & 1 \\
\hline & 131 & & & & 1 & & & & & & & 1 & & & 2 \\
\hline 0 & 212 & & & & & & & & 1 & & & & & & 1 \\
\hline | & 221 & & & & & & & & & & 1 & & & & 1 \\
\hline$\stackrel{N}{\beth}$ & 302 & & & & & & 1 & & & & & & & & 1 \\
\hline$\frac{\overline{\mathbf{m}}}{\alpha}$ & 320 & & & & & & & & & & 1 & & & & 1 \\
\hline es & 401 & & & & & & & & & & 1 & & & & 1 \\
\hline ш & 410 & & 1 & & & & & & & & 1 & & & & 2 \\
\hline$\widetilde{\infty}$ & 500 & 1 & & 1 & & & 1 & 1 & & & 30 & & 1 & 1 & 36 \\
\hline & 1040 & & & & & & & & & & 1 & & & & 1 \\
\hline & 1400 & & & & & & & 1 & & & & & & & 1 \\
\hline & 4100 & & & & & & & & & & & & & 1 & 1 \\
\hline To & & 1 & 1 & 1 & 1 & 2 & 2 & 2 & 1 & 1 & 35 & 1 & 1 & 2 & 51 \\
\hline
\end{tabular}


ANEXO III - Tabulação cruzada entre blocos adjacentes do DCM nas fases de estabilização e adaptação para o G_3C (cont.).

\begin{tabular}{|c|c|c|c|c|c|c|c|c|}
\hline & \multicolumn{6}{|c|}{ B4 - ESTABILIZAÇÃO } & \multirow[b]{2}{*}{ Total } \\
\hline & & 140 & 311 & 401 & 500 & 1022 & 3200 & \\
\hline \multirow{11}{*}{ 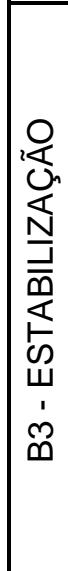 } & 50 & 1 & & & & & & 1 \\
\hline & 122 & & & & 1 & & & 1 \\
\hline & 131 & & & & 1 & & & 1 \\
\hline & 140 & & & & 1 & & & 1 \\
\hline & 203 & & & & 2 & & & 2 \\
\hline & 302 & & & 1 & 1 & & & 2 \\
\hline & 311 & & & & 1 & 1 & & 2 \\
\hline & 401 & & & 1 & & & & 1 \\
\hline & 410 & & & & 1 & & & 1 \\
\hline & 500 & & 1 & 1 & 10 & & & 12 \\
\hline & 2030 & & & & & & 1 & 1 \\
\hline Tot & & 1 & 1 & 3 & 18 & 1 & 1 & 25 \\
\hline
\end{tabular}

\begin{tabular}{|c|c|c|c|c|c|c|c|c|c|c|c|}
\hline & \multicolumn{9}{|c|}{ B5 - ESTABILIZAÇÃO } & \multirow[b]{2}{*}{ Total } \\
\hline & & 311 & 320 & 410 & 500 & 1040 & 1130 & 1400 & 2210 & 3110 & \\
\hline & 140 & & & & & & & & & 1 & 1 \\
\hline \multirow{5}{*}{ B4 - ESTABILIZAÇÁO } & 311 & & & & & & 1 & & & & 1 \\
\hline & 401 & & & & 1 & 1 & & & 1 & & 3 \\
\hline & 500 & 1 & 1 & 1 & 11 & 1 & & & & & 15 \\
\hline & 1022 & & & & & & & 1 & & & 1 \\
\hline & 3200 & & & & & & & 1 & & & 1 \\
\hline Total & & 1 & 1 & 1 & 12 & 2 & 1 & 2 & 1 & 1 & 22 \\
\hline
\end{tabular}


ANEXO III - Tabulação cruzada entre blocos adjacentes do DCM nas fases de estabilização e adaptação para o G_3C (cont.).

\begin{tabular}{|c|c|c|c|c|c|c|c|c|c|}
\hline & \multicolumn{7}{|c|}{ B6 - ESTABILIZAÇÃO } & \multirow[b]{2}{*}{ Total } \\
\hline & & 500 & 1040 & 1211 & 1400 & 2300 & 3200 & 4100 & \\
\hline & $\begin{array}{l}311 \\
320\end{array}$ & 1 & & 1 & & & & & $\begin{array}{l}1 \\
1\end{array}$ \\
\hline 选。 & 410 & 1 & & & & & & & \\
\hline న & 500 & 2 & & & & & & & \\
\hline $\overrightarrow{\bar{m}}$ & 1040 & & 1 & & & & & 1 & 2 \\
\hline $\mathbb{E}$ & 1130 & & & & & 1 & & & 1 \\
\hline 山 & 1400 & & & & 1 & & & & 1 \\
\hline L & 2210 & & & & & & 1 & & 1 \\
\hline & 3110 & & & & & 1 & & & 1 \\
\hline Total & & 4 & 1 & 1 & 1 & 2 & 1 & 1 & 11 \\
\hline
\end{tabular}

\begin{tabular}{|c|c|c|c|c|c|c|c|c|c|c|c|c|c|c|c|c|c|c|c|}
\hline & \multicolumn{17}{|c|}{ B2 - ADAPTAÇÃO } & \multirow[b]{2}{*}{ Total } \\
\hline & & 114 & 231 & 321 & 40 & & 420 & 600 & 1050 & 1302 & 1311 & 1320 & 1401 & 2211 & 2301 & 2400 & 4200 & 6000 & \\
\hline & 114 & 1 & & & & & & & & & & & & & & & & & 1 \\
\hline 更 & 312 & & & & & & & 1 & & & & & & & & & & & 1 \\
\hline$\frac{0}{s}$ & 411 & & & & & & & 1 & & & & & & & & 1 & & & 2 \\
\hline & $\begin{array}{r}600 \\
2022\end{array}$ & & & & & & 1 & 28 & 1 & 1 & 1 & 1 & 1 & 1 & & 1 & 1 & & $\begin{array}{r}37 \\
1\end{array}$ \\
\hline & 2130 & & & & & & & & & & & & & & 1 & & & & 1 \\
\hline Tot & & 1 & 1 & & & & 2 & 34 & 1 & 1 & 1 & 1 & 1 & 1 & 1 & 2 & 1 & 1 & 51 \\
\hline
\end{tabular}


ANEXO III - Tabulação cruzada entre blocos adjacentes do DCM nas fases de estabilização e adaptação para o G_3C (cont.).

\begin{tabular}{|c|c|c|c|c|c|c|c|c|c|c|c|c|c|c|c|c|c|c|c|c|c|}
\hline & \multicolumn{19}{|c|}{ B3- ADAPTAÇÃO } & \multirow[b]{2}{*}{ Total } \\
\hline & & 303 & 321 & 402 & 411 & 501 & 600 & 1050 & 1230 & 1302 & 1401 & 1500 & 2211 & 2301 & 2310 & 2400 & 3120 & 3300 & 4200 & 5100 & \\
\hline & 114 & & & & 1 & & & & & & & & & & & & & & & & 1 \\
\hline & 231 & & & & & & & & & & & & 1 & & & & & & & & 1 \\
\hline & 321 & & & & & 1 & & & & & & & & & & & & & & & 1 \\
\hline & 402 & 1 & & & & & & & & & & & & & & & & & & & 1 \\
\hline & 420 & & & & & & 2 & & & & & & & & & & & & & & 2 \\
\hline ড্র & 1050 & & & & & & & 1 & & & & & & & & & & & & & 1 \\
\hline$\frac{\hbar}{2}$ & 1302 & & & & & & & & & & & & & 1 & & & & & & & 1 \\
\hline 是 & 1311 & & & & & & & & & & & & & & & 1 & & & & & 1 \\
\hline$\stackrel{\sim}{\sim}$ & 1320 & & & & & & 1 & & & & & & & & & & & & & & 1 \\
\hline & 1401 & & & & & & 1 & & & & & & & & & & & & & & 1 \\
\hline & 2211 & & & & & & & & & & & & & & & & 1 & & & & 1 \\
\hline & 2400 & & & & & & & & & & & & & & & & & 1 & 1 & & 2 \\
\hline & 4200 & & & & & & & & & & & & & & & & & & 1 & & 1 \\
\hline Total & & 1 & 1 & 1 & 1 & 2 & 21 & 1 & 1 & 1 & 1 & 4 & 1 & 1 & 1 & 3 & 1 & 1 & 4 & 3 & 50 \\
\hline
\end{tabular}


ANEXO III - Tabulação cruzada entre blocos adjacentes do DCM nas fases de estabilização e adaptação para o G_3C (cont.).

\begin{tabular}{|c|c|c|c|c|c|c|c|c|c|c|c|c|c|c|c|c|c|c|c|c|c|c|c|}
\hline & \multicolumn{22}{|c|}{ B4 - ADAPTAÇÃO } & \multirow[b]{2}{*}{ Tota } \\
\hline & 60 & 231 & 321 & 501 & 600 & 1050 & 1212 & 1311 & 1320 & 1401 & 1410 & 1500 & 2040 & 2400 & 3012 & 3300 & 4020 & 4101 & 4110 & 4200 & 5100 & 6000 & \\
\hline 303 & & & 1 & & & & & & & & & & & & & & & & & & & & 1 \\
\hline $\begin{array}{l}321 \\
402\end{array}$ & & & & 1 & 1 & & & & & & & & & & & & & & & & & & $\begin{array}{l}1 \\
1\end{array}$ \\
\hline 411 & 1 & & & & & & & & & & & & & & & & & & & & & & 1 \\
\hline 501 & & 1 & & & & 1 & & & & & & & & & & & & & & & & & 2 \\
\hline 600 & 1 & & 1 & & 5 & & 1 & 1 & 1 & & 1 & 3 & 2 & 1 & 1 & 1 & & & & 1 & 1 & & 21 \\
\hline 这 1050 & & & & & 1 & & & & & & & & & & & & & & & & & & 1 \\
\hline 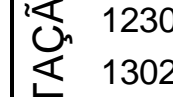 & & & & & & & & & & 1 & & & & 1 & & & & & & & & & $\begin{array}{l}1 \\
1\end{array}$ \\
\hline$\frac{-b}{4} \quad 1401$ & & & & & & & & & & & & & & & & & & & & 1 & & & 1 \\
\hline 安 1500 & & & & & 2 & & & & & & & & & 1 & 1 & & & & & & & & 4 \\
\hline $\begin{array}{ll}1 & 2211 \\
\infty & 2301\end{array}$ & & & & & & & & & & & & & & & & & & 1 & 1 & & & & $\begin{array}{l}1 \\
1\end{array}$ \\
\hline 2310 & & & & & & & & & & & & & & & & & & & & 1 & & & 1 \\
\hline 2400 & & & & & & & & & & & & & & 1 & & 1 & & & & & 1 & & 3 \\
\hline 3120 & & & & & 1 & & & & & & & & & & & & & & & & & & 1 \\
\hline 3300 & & & & & & & & & & & & & & & & & & & & & & 1 & 1 \\
\hline 4200 & & & & & & & & & & & & & & 1 & & & & & & & 2 & 1 & 4 \\
\hline 5100 & & & & & & & & & & & & & & & & & 1 & & & 1 & 1 & & 3 \\
\hline Total & 2 & 1 & 2 & 1 & 10 & 1 & 1 & 1 & 1 & 1 & 1 & 3 & 2 & 5 & 2 & 2 & 1 & 1 & 1 & 4 & 5 & 2 & 50 \\
\hline
\end{tabular}


ANEXO III - Tabulação cruzada entre blocos adjacentes do DCM nas fases de estabilização e adaptação para o G_3C (cont.).

\begin{tabular}{|c|c|c|c|c|c|c|c|c|c|c|c|c|c|c|c|c|c|c|c|c|c|c|}
\hline & \multicolumn{20}{|c|}{ B5 - ADAPTAÇÃO } & \multirow[b]{2}{*}{ Total } \\
\hline & & 330 & 411 & 600 & 1050 & 1113 & 1140 & 1320 & 1500 & 2121 & 2301 & 2400 & 3030 & 3201 & 3300 & 4020 & 4101 & 4200 & 5010 & 5100 & 6000 & \\
\hline & 60 & & & & & & & & & & & & & & & & & & & 1 & 1 & 2 \\
\hline & 321 & & & & & & & & & & 1 & & & & & & 1 & & & & & 2 \\
\hline & 501 & & & & & & & & & & & & & & & & & & & & 1 & 1 \\
\hline & 600 & & 1 & 3 & & 1 & & 1 & & & 1 & 1 & & & & & & & & 1 & 1 & 10 \\
\hline & 1212 & & & & & & & & & & & & & & & & & 1 & & & & 1 \\
\hline & 1311 & & & & & & & & & & & & & 1 & & & & & & & & 1 \\
\hline 운 & 1320 & & & 1 & & & & & & & & & & & & & & & & & & 1 \\
\hline 岕 & 1401 & & & & & & & & & & & & & & & & & 1 & & & & 1 \\
\hline$\frac{0}{\alpha}$ & 1410 & & & & & & & & & & & & & & & & & 1 & & & & 1 \\
\hline 足 & 1500 & & & 1 & & & & & & & & & & & & & & 1 & & & 1 & 3 \\
\hline & 2400 & & & & & & & & 1 & 1 & & 1 & & & 1 & & & & & 1 & & 5 \\
\hline & 3012 & & & & & & & & & & & & & & & & & & 1 & 1 & & 2 \\
\hline & 3300 & & & & & & & & & & & & & & & & & & & 2 & & 2 \\
\hline & 4020 & & & 1 & & & & & & & & & & & & & & & & & & 1 \\
\hline & 4101 & & & & & & & & & 1 & & & & & & & & & & & & 1 \\
\hline & 4110 & & & & & & & & & & & & & & & 1 & & & & & & 1 \\
\hline & 4200 & & & & & & & & & & & & & & & & & & 1 & 2 & 1 & 4 \\
\hline & 5100 & & & & & & 1 & & & & & & & & 1 & & & 1 & & 2 & & 5 \\
\hline Total & & 1 & 1 & 6 & 1 & 1 & 1 & 1 & 1 & 2 & 2 & 2 & 1 & 1 & 2 & 1 & 1 & 6 & 2 & 10 & 5 & 48 \\
\hline
\end{tabular}


ANEXO III - Tabulação cruzada entre blocos adjacentes do DCM nas fases de estabilização e adaptação para o G_3C (cont.).

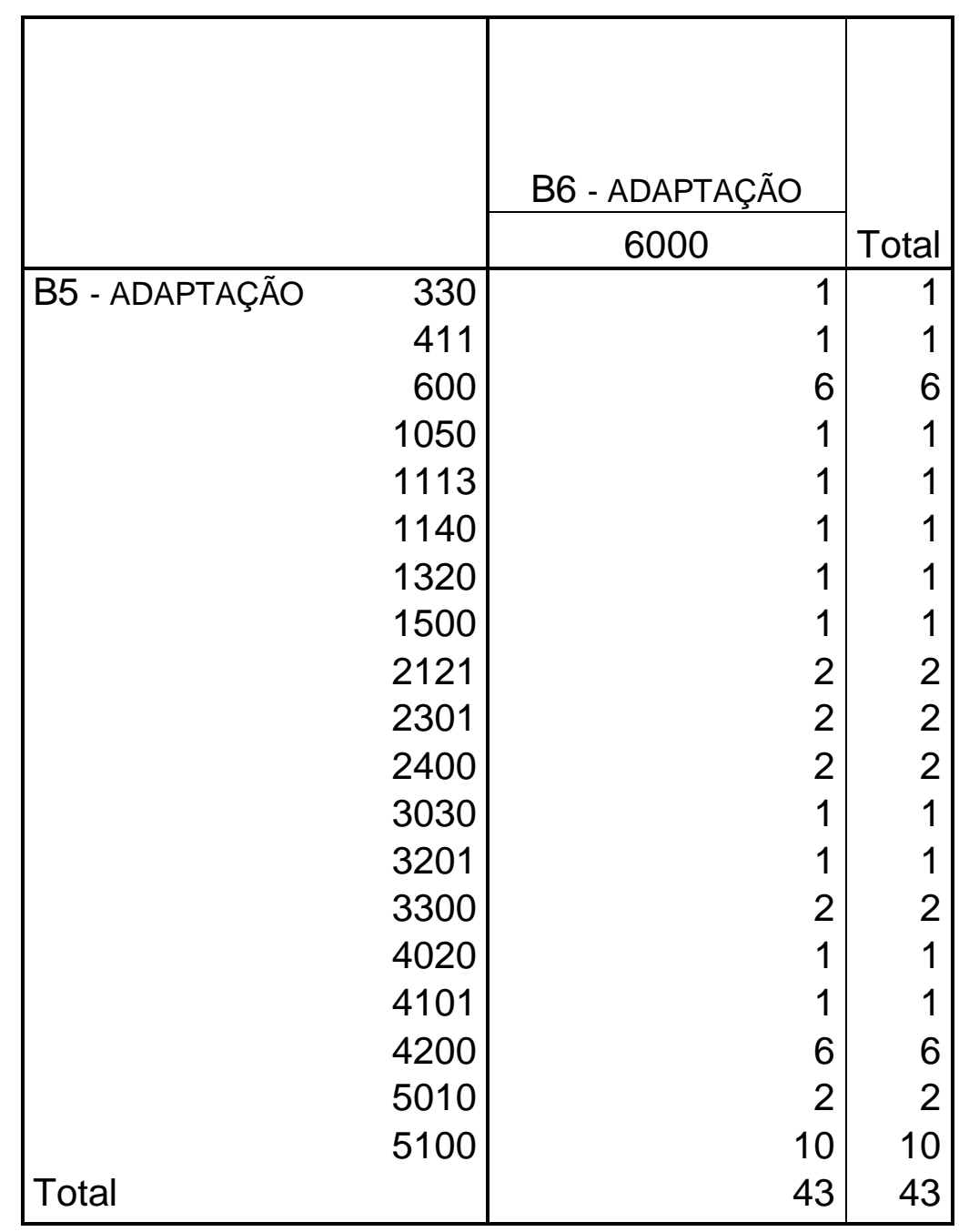


ANEXO III - Tabulação cruzada entre blocos adjacentes do DCM nas fases de estabilização e adaptação para o G_1A (cont.).

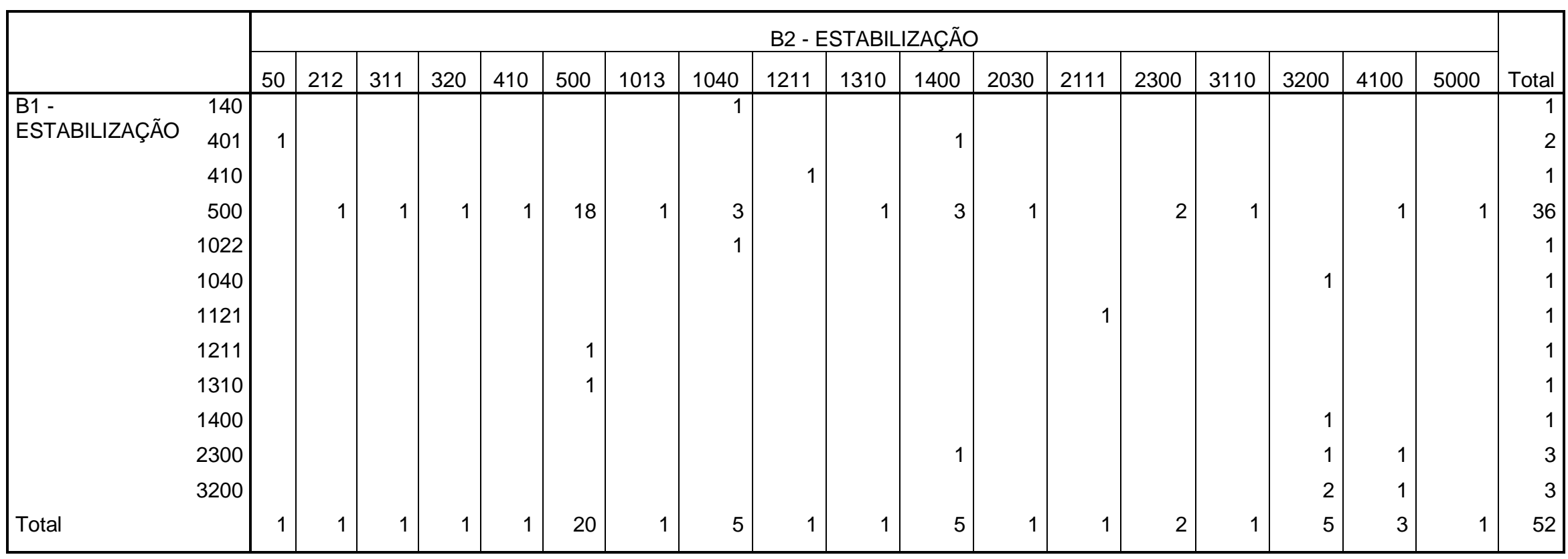


ANEXO III - Tabulação cruzada entre blocos adjacentes do DCM nas fases de estabilização e adaptação para o G_1A (cont.).

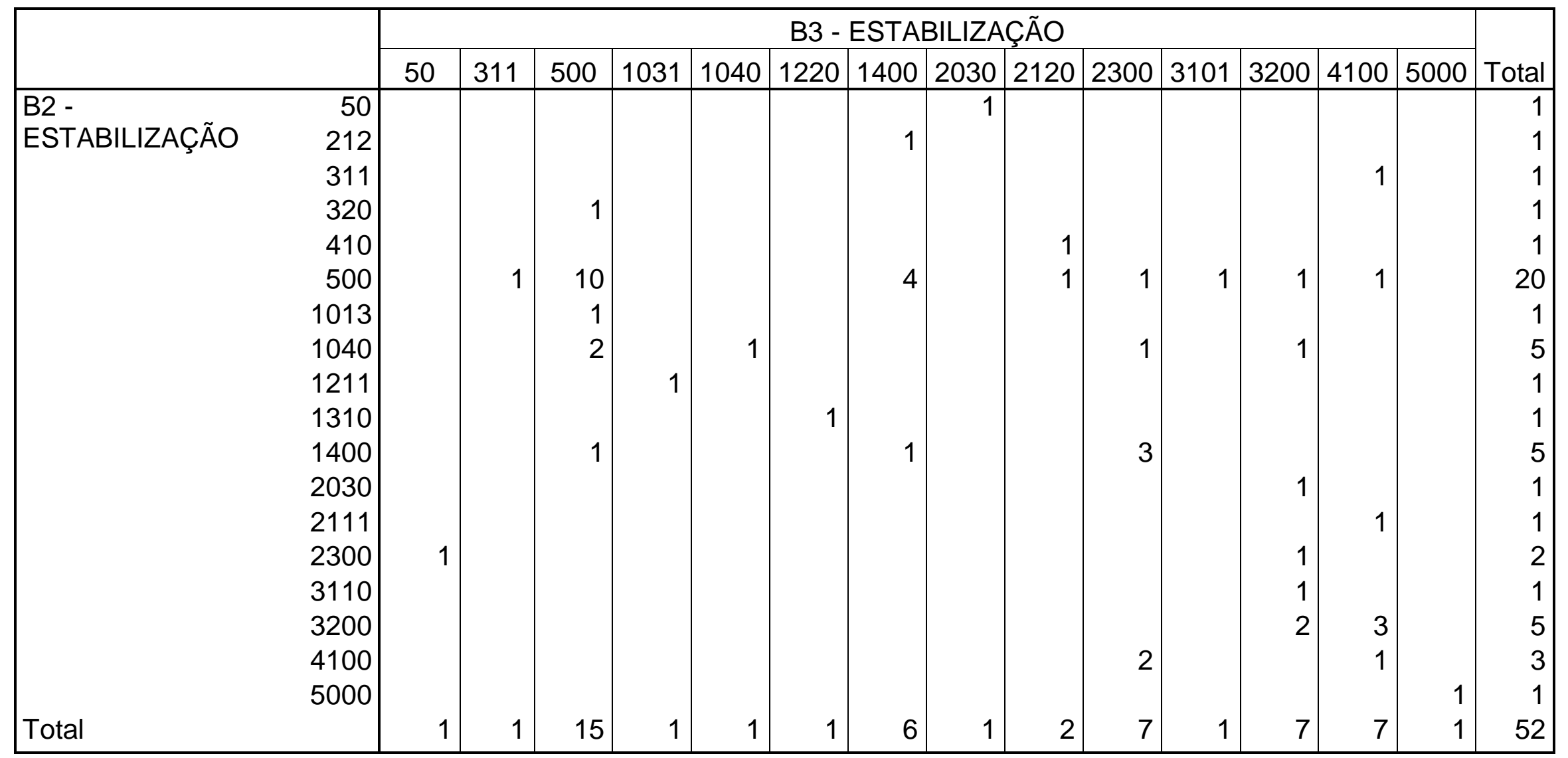


ANEXO III - Tabulação cruzada entre blocos adjacentes do DCM nas fases de estabilização e adaptação para o G_1A (cont.).

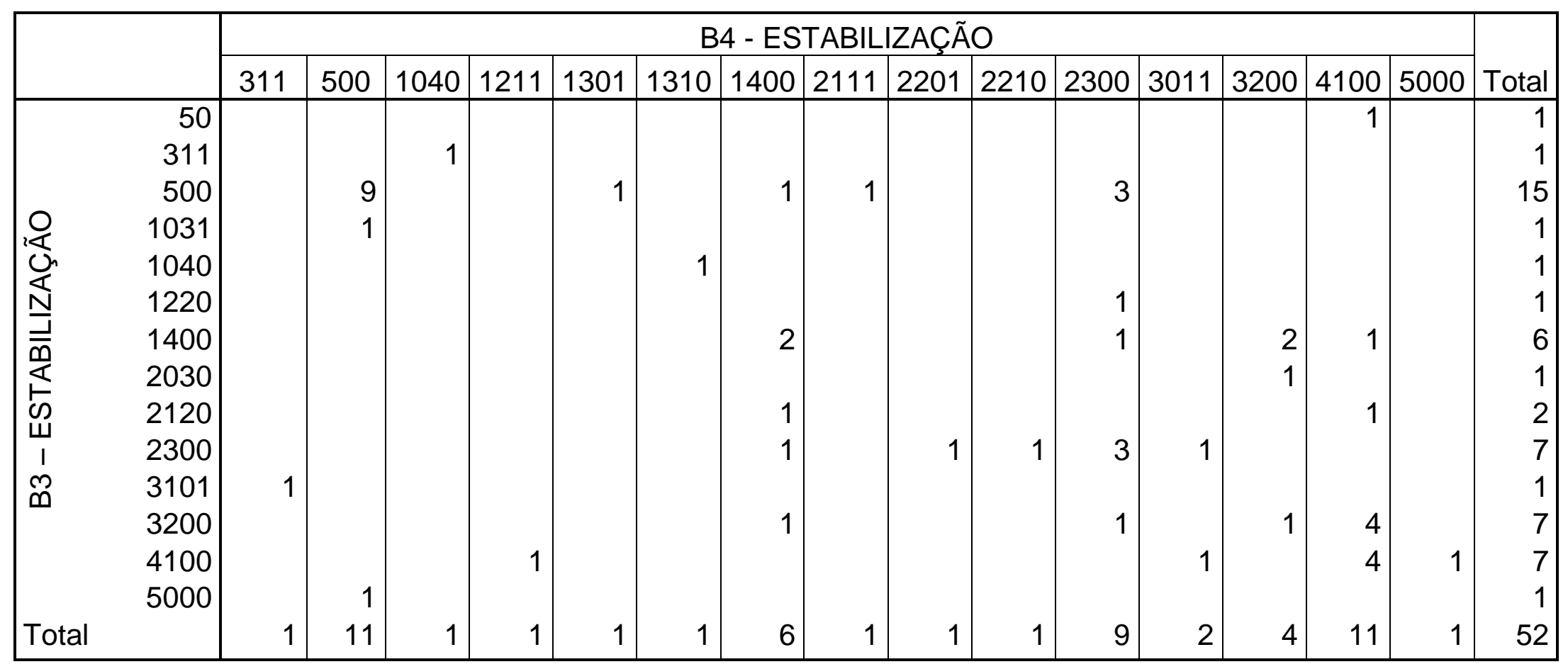


ANEXO III - Tabulação cruzada entre blocos adjacentes do DCM nas fases de estabilização e adaptação para o G_1A (cont.).

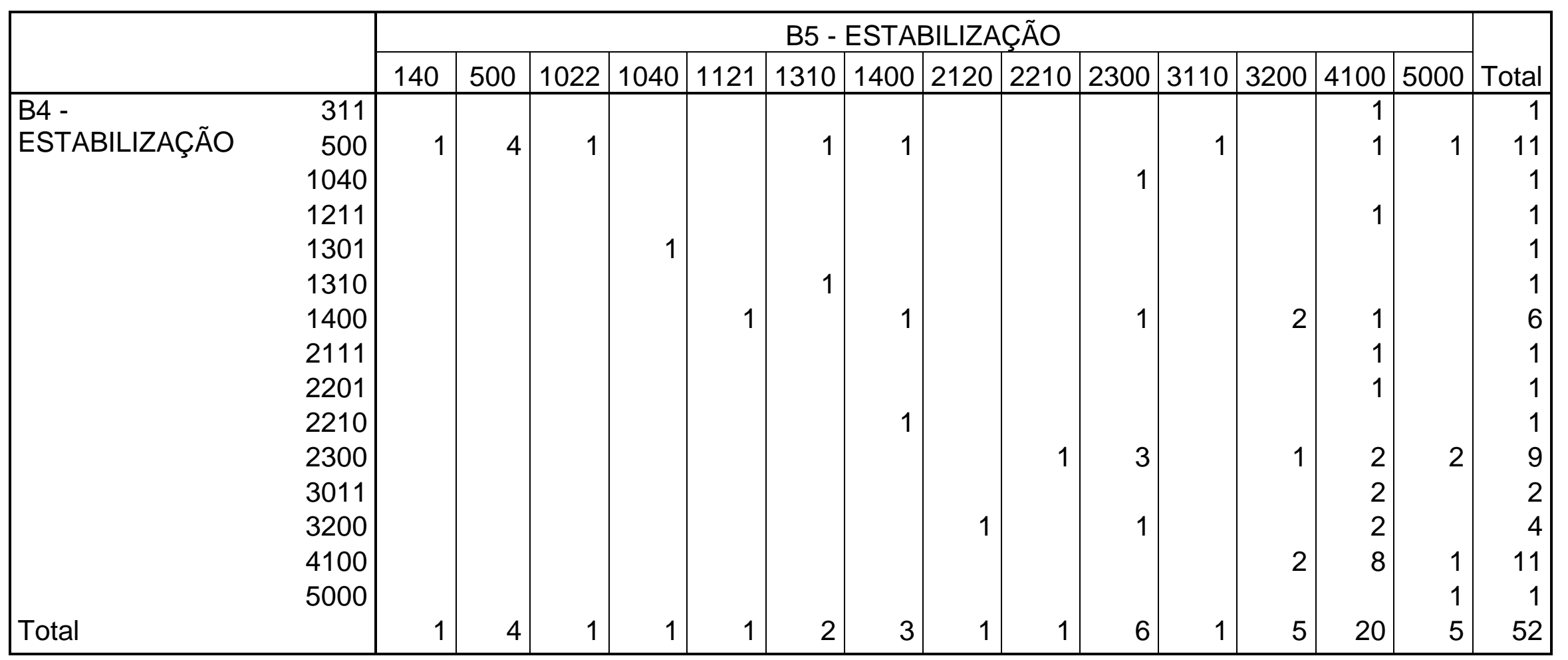


ANEXO III - Tabulação cruzada entre blocos adjacentes do DCM nas fases de estabilização e adaptação para o G_1A (cont.).

\begin{tabular}{|c|c|c|c|}
\hline & & B6 - ESTABILIZAÇÃO & \\
\hline & & 5000 & Total \\
\hline & 140 & & 1 \\
\hline & 500 & & 4 \\
\hline & 1022 & & 1 \\
\hline 10 & 1040 & & 1 \\
\hline 0 & 1121 & & 1 \\
\hline$\underline{N}$ & 1310 & & 2 \\
\hline $\overrightarrow{\bar{m}}$ & 1400 & & 3 \\
\hline 岩 & 2120 & & 1 \\
\hline s & 2210 & & 1 \\
\hline , & 2300 & & 6 \\
\hline$\stackrel{\llcorner}{\infty}$ & 3110 & & 1 \\
\hline & 3200 & & 5 \\
\hline & 4100 & & 20 \\
\hline & 5000 & & 3 \\
\hline & & & 50 \\
\hline
\end{tabular}


ANEXO III - Tabulação cruzada entre blocos adjacentes do DCM nas fases de estabilização e adaptação para o G_1A (cont.).

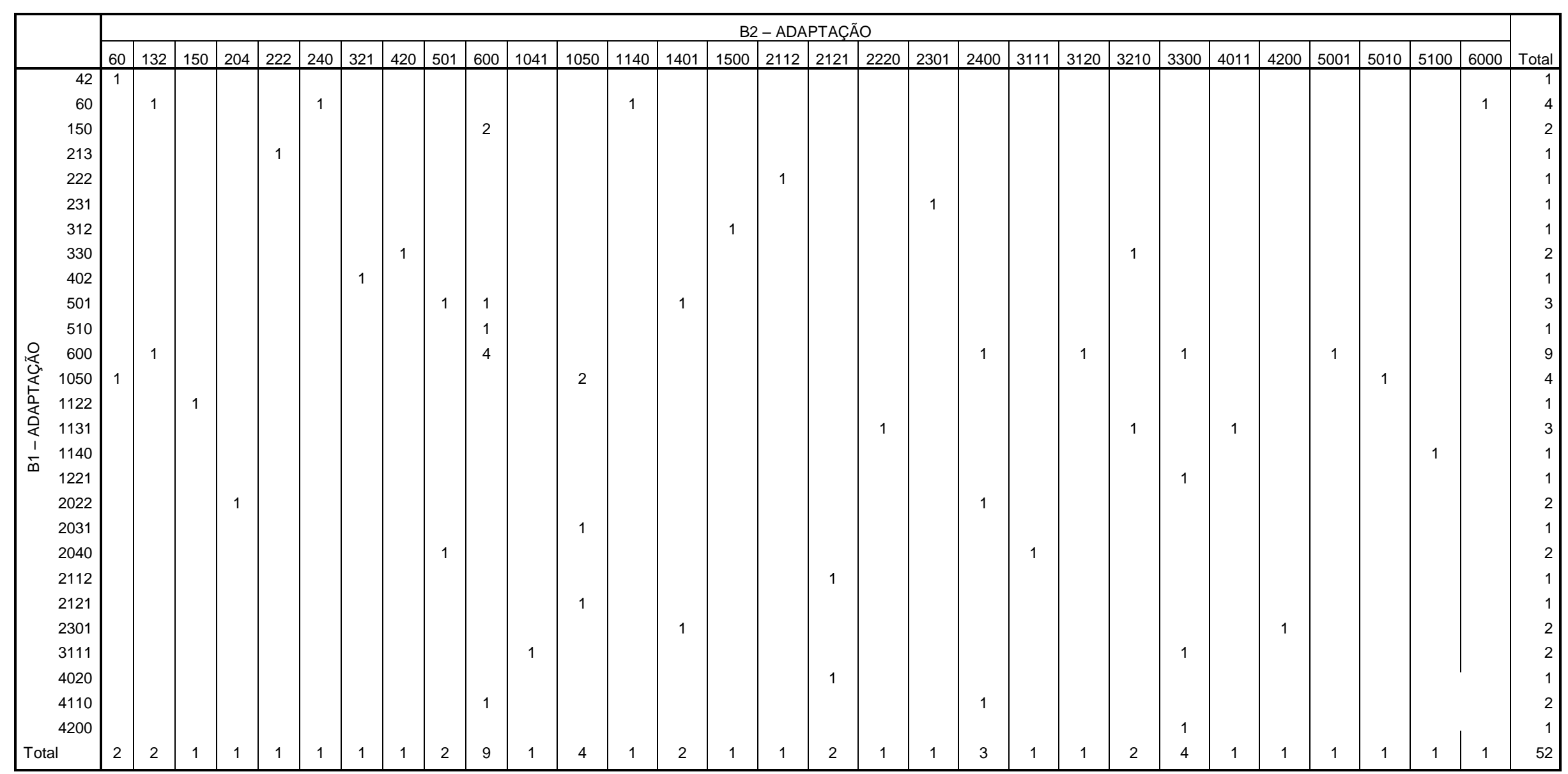


ANEXO III - Tabulação cruzada entre blocos adjacentes do DCM nas fases de estabilização e adaptação para o G_1A (cont.).

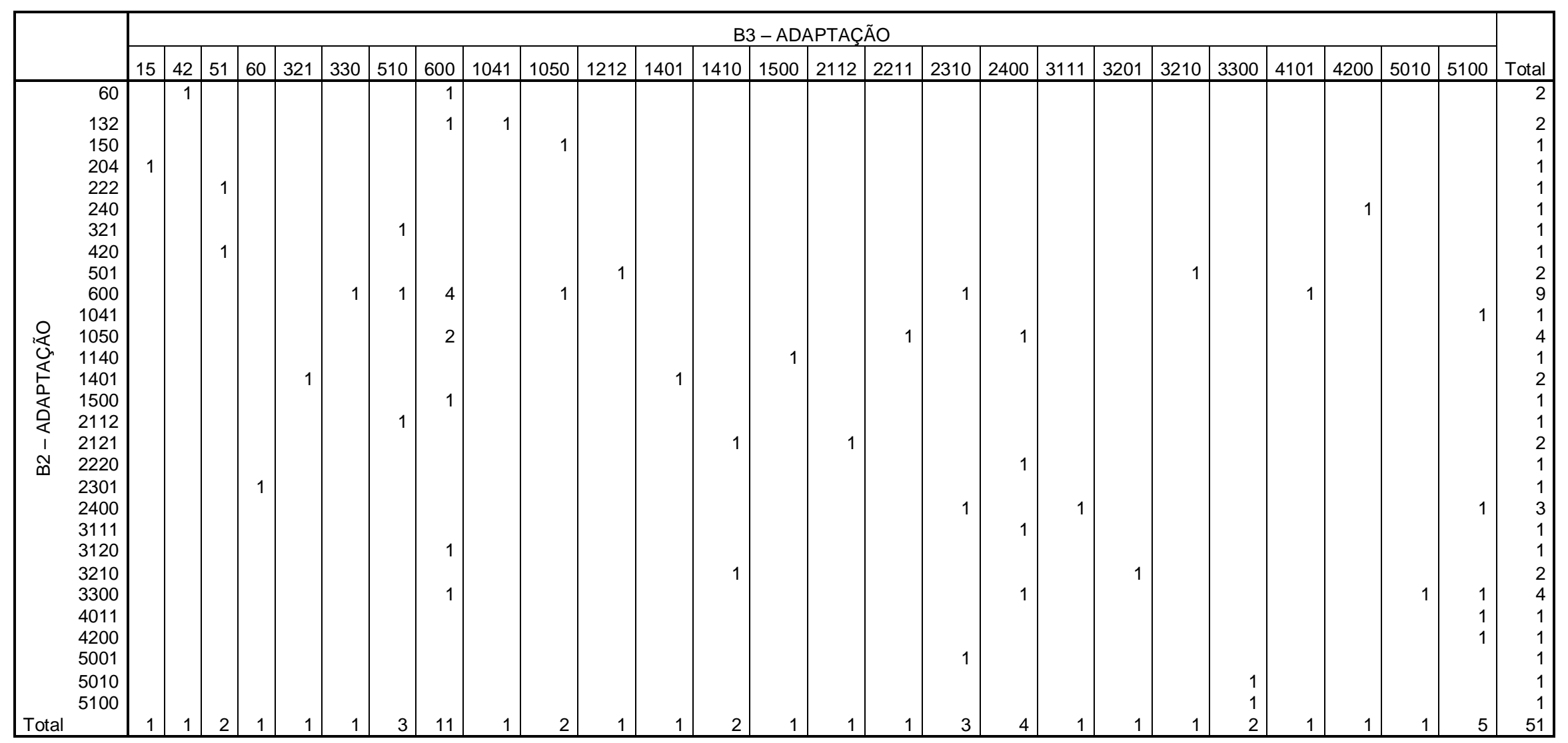


ANEXO III - Tabulação cruzada entre blocos adjacentes do DCM nas fases de estabilização e adaptação para o G_1A (cont.).

\begin{tabular}{|c|c|c|c|c|c|c|c|c|c|c|c|c|c|c|c|c|c|c|c|c|c|c|c|}
\hline & \multicolumn{21}{|c|}{ B4 - ADAPTAÇÃO } & \multirow[b]{2}{*}{ Total } \\
\hline & & 6 & \begin{tabular}{|l|}
51 \\
\end{tabular} & 60 & 312 & 321 & 420 & 501 & 600 & 1230 & 1410 & \begin{tabular}{|l|}
1500 \\
\end{tabular} & 2013 & 2040 & 2400 & 3030 & 3210 & 3300 & \begin{tabular}{|l|}
4020 \\
\end{tabular} & \begin{tabular}{|l|l|}
4110 \\
\end{tabular} & \begin{tabular}{|l|}
4200 \\
\end{tabular} & 5100 & \\
\hline & $\begin{array}{l}15 \\
42\end{array}$ & & 1 & & & 1 & & & & & & & & & & & & & & & & & $\begin{array}{l}1 \\
1\end{array}$ \\
\hline & 51 & & & & 1 & & & & 1 & & & & & & & & & & & & & & 2 \\
\hline & 60 & & & 1 & & & & & & & & & & & & & & & & & & & 1 \\
\hline & 321 & & & & & & & & & & & & & & 1 & & & & & & & & 1 \\
\hline & 330 & & & 1 & & & & & & & & & & & & & & & & & & & 1 \\
\hline & 510 & 1 & & & & & & & 1 & & & & 1 & & & & & & & & & & 3 \\
\hline & 600 & & & & & & 1 & 1 & 3 & 1 & & 1 & & & & & & 1 & & & & 3 & 11 \\
\hline & 1041 & & & & & & & & 1 & & & & & & & & & & & & & & 1 \\
\hline & 1050 & & & & & & & & 1 & & & & & & & 1 & & & & & & & 2 \\
\hline & 1212 & & & & & & & & & & 1 & & & & & & & & & & & & 1 \\
\hline 选 & 1401 & & & & & & & & & & & & & & & & & & & & 1 & & 1 \\
\hline$\stackrel{5}{5}$ & 1410 & & & & & & & & 1 & & & & & & & & & 1 & & & & & 2 \\
\hline 岩 & 1500 & & & & & & & 1 & & & & & & & & & & & & & & & 1 \\
\hline$\underset{1}{1}$ & 2112 & & & & & & & & 1 & & & & & & & & & & & & & & 1 \\
\hline $\mathscr{m}$ & 2211 & & & & & & & & & & & & & & & & & & & & 1 & & 1 \\
\hline & 2310 & & & & & & & & 1 & & & & & & & & & & & & & 2 & 3 \\
\hline & 2400 & & & & & & & & & & & & & 1 & & & & & & & & 3 & 4 \\
\hline & 3111 & & & & & & & & & & & 1 & & & & & & & & & & & 1 \\
\hline & 3201 & & & & & & & & & & & & & & & & & 1 & & & & & 1 \\
\hline & 3210 & & & & & & & & & & & & & & 1 & & & & & & & & 1 \\
\hline & 3300 & & & & & & & & & & & & & & & & 1 & & & & & 1 & 2 \\
\hline & 4101 & & & & & & & & & & & & & & & & & & & & 1 & & 1 \\
\hline & 4200 & & & & & & & & & & & & & & & & & & & & 1 & & 1 \\
\hline & 5010 & & & & & & & & & & & 1 & & & & & & & & & & & 1 \\
\hline & 5100 & & & & & & & & & & & & & 1 & 1 & & & & 1 & 1 & & 1 & 5 \\
\hline Total & & 1 & 1 & 2 & 1 & 1 & 1 & 2 & 10 & 1 & 1 & 3 & 1 & 2 & 3 & 1 & 1 & 3 & 1 & 1 & 4 & 10 & 51 \\
\hline
\end{tabular}


ANEXO III - Tabulação cruzada entre blocos adjacentes do DCM nas fases de estabilização e adaptação para o G_1A (cont.).

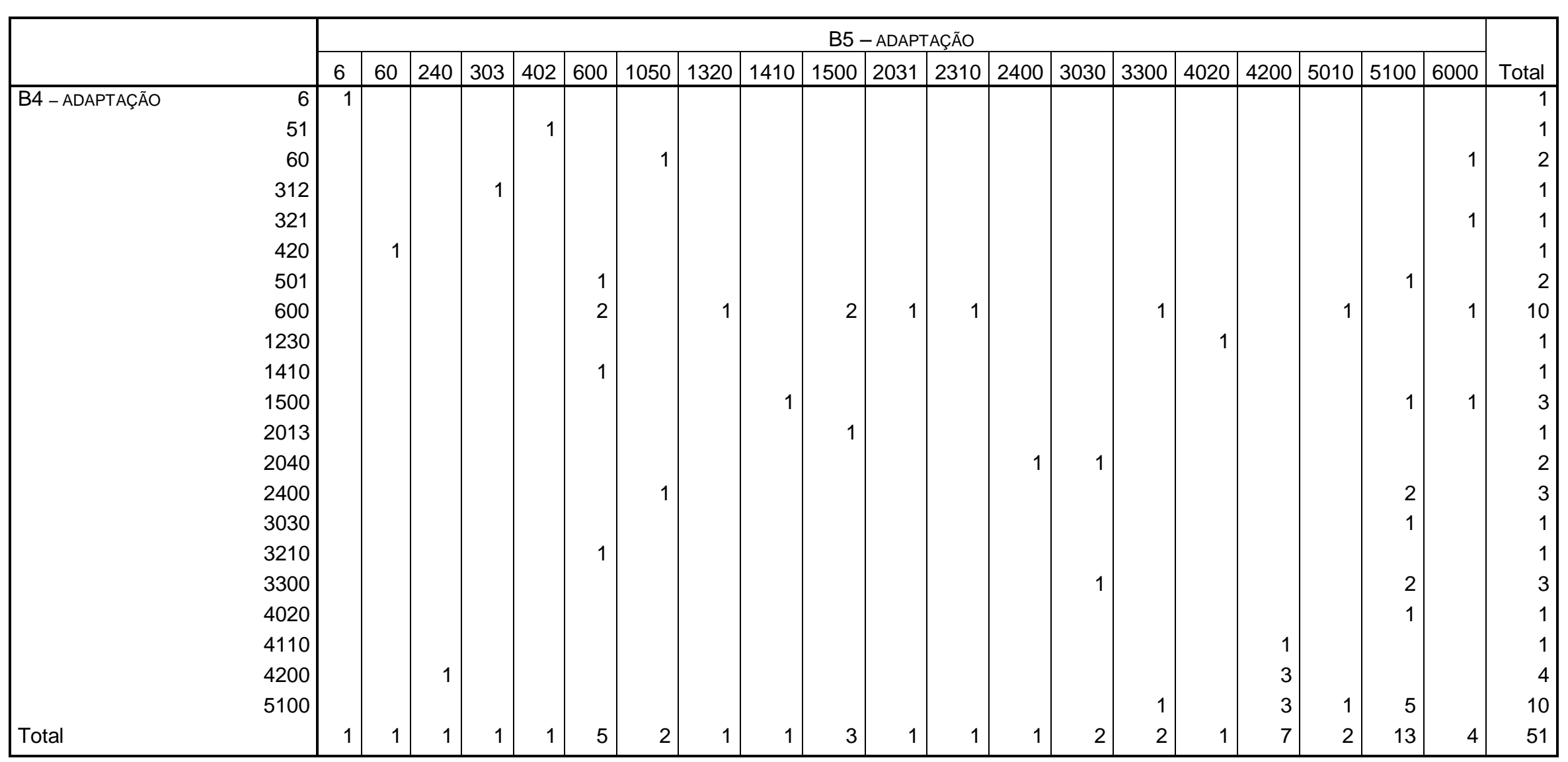


ANEXO III - Tabulação cruzada entre blocos adjacentes do DCM nas fases de estabilização e adaptação para o G_1A (cont.).

\begin{tabular}{|c|c|c|}
\hline & B6 - ADAPTAÇÃO & \multirow[b]{2}{*}{ Total } \\
\hline & 6000 & \\
\hline 6 & 1 & 1 \\
\hline 60 & 1 & 1 \\
\hline 240 & 1 & 1 \\
\hline 303 & 1 & 1 \\
\hline 402 & 1 & 1 \\
\hline 600 & 5 & 5 \\
\hline 1050 & 2 & 2 \\
\hline i 1320 & 1 & 1 \\
\hline 总 1410 & 1 & 1 \\
\hline 离 1500 & 3 & 3 \\
\hline 2031 & 1 & 1 \\
\hline$\stackrel{\text { L }}{\infty} \quad 2310$ & 1 & 1 \\
\hline 2400 & 1 & 1 \\
\hline 3030 & 2 & 2 \\
\hline 3300 & 2 & 2 \\
\hline 4020 & 1 & 1 \\
\hline 4200 & 7 & 7 \\
\hline 5010 & 2 & 2 \\
\hline 5100 & 13 & 13 \\
\hline Total & 47 & 47 \\
\hline
\end{tabular}


ANEXO III - Tabulação cruzada entre blocos adjacentes do DCM nas fases de estabilização e adaptação para o G_3A (cont.).

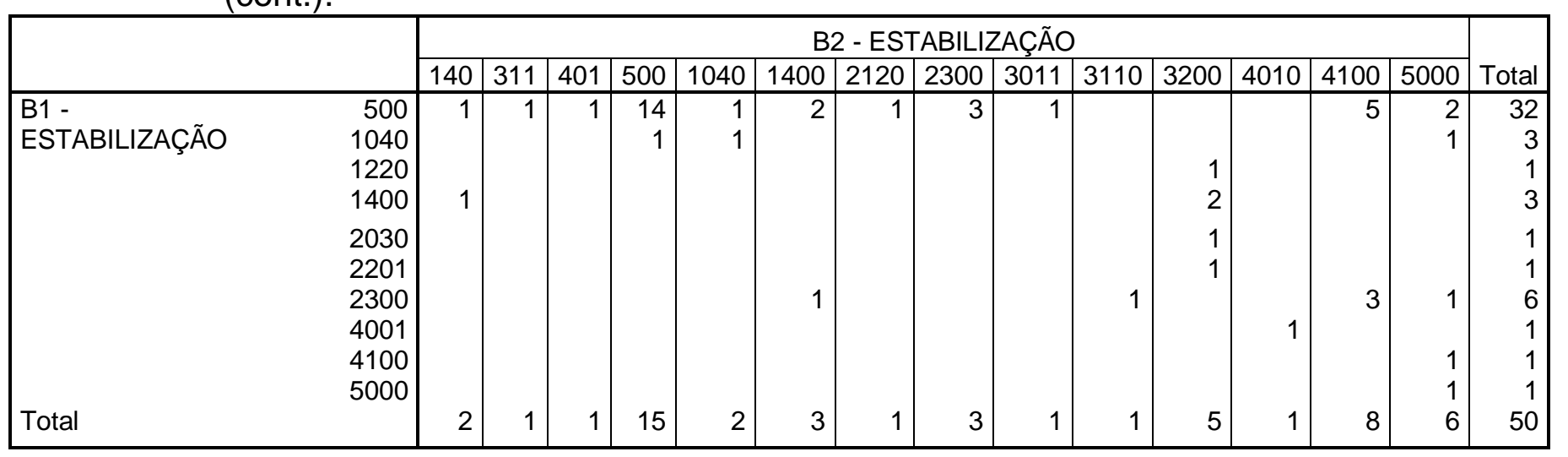

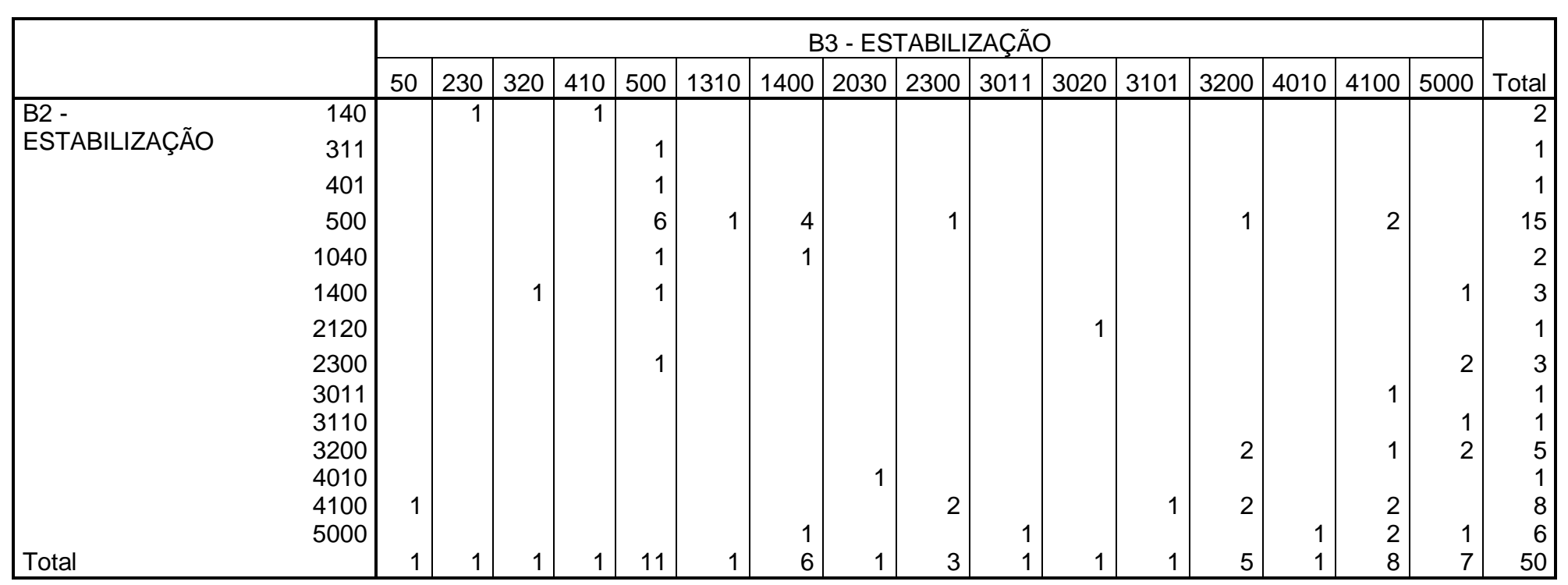


ANEXO III - Tabulação cruzada entre blocos adjacentes do DCM nas fases de estabilização e adaptação para o G_3A (cont.).

\begin{tabular}{|c|c|c|c|c|c|c|c|c|c|c|c|c|c|c|c|}
\hline & \multicolumn{13}{|c|}{ B4 - ESTABILIZAÇÃO } & \multirow[b]{2}{*}{ Tota } \\
\hline & & 500 & 1040 & 1130 & 1400 & 2030 & 2120 & 230 & & 3020 & 3200 & 4010 & 4100 & 5000 & \\
\hline \multirow{16}{*}{\begin{tabular}{|l} 
B3 - \\
ESTABILIZAÇÃO
\end{tabular}} & 50 & & & & & & & & & & & & 1 & & 1 \\
\hline & 230 & & & & & & & & & & 1 & & & & 1 \\
\hline & 320 & & & & & & & & & & & & 1 & & 1 \\
\hline & 410 & 1 & & & & & & & & & & & & & 1 \\
\hline & 500 & 3 & & 1 & & & 1 & & & 1 & & & 2 & 3 & 11 \\
\hline & 1310 & & & & & & & & & & & & 1 & & 1 \\
\hline & 1400 & & & & 1 & & & & & & 4 & & 1 & & 6 \\
\hline & 2030 & & & & & . & & & & & & & & & 1 \\
\hline & 2300 & & 1 & & & & & & & & 1 & & 1 & & 3 \\
\hline & 3011 & & & & & & & & & & & & 1 & & 1 \\
\hline & 3020 & & & & & & & & 1 & & & & & & 1 \\
\hline & 3101 & & & & & & & & & & & & & 1 & 1 \\
\hline & 3200 & & & & & & & & & & & & 3 & 2 & 5 \\
\hline & 4010 & & & & & & & & & 1 & & & & & 1 \\
\hline & 4100 & & & & & & & & 1 & & 1 & 1 & 2 & 3 & 8 \\
\hline & 5000 & & & & & & 1 & & 1 & 1 & & & 2 & 2 & 7 \\
\hline Total & & 4 & 1 & 1 & 1 & . & 2 & & 3 & 3 & 7 & 1 & 15 & 11 & 50 \\
\hline
\end{tabular}


ANEXO III - Tabulação cruzada entre blocos adjacentes do DCM nas fases de estabilização e adaptação para o G_3A (cont.).

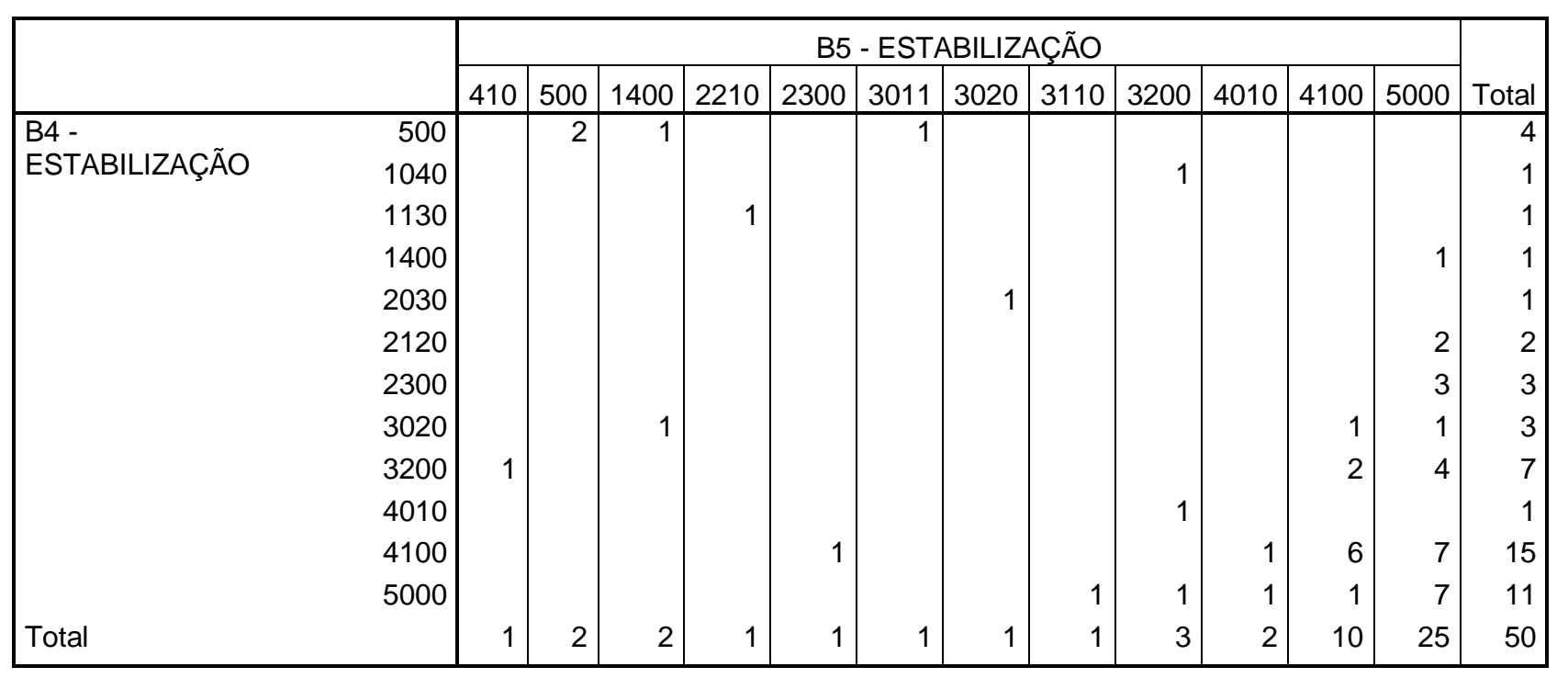


ANEXO III - Tabulação cruzada entre blocos adjacentes do DCM nas fases de estabilização e adaptação para o G_3A (cont.).

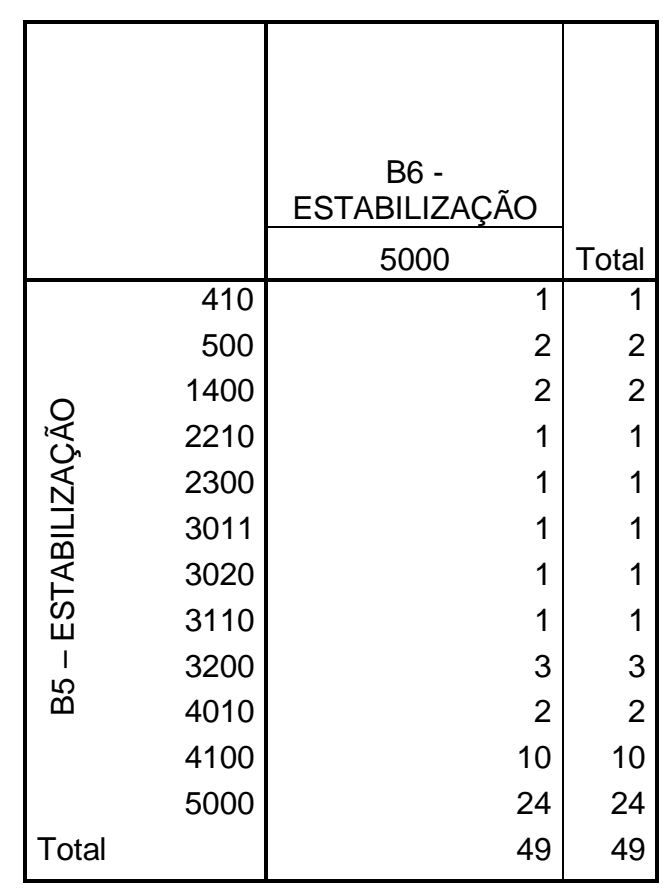


ANEXO III - Tabulação cruzada entre blocos adjacentes do DCM nas fases de estabilização e adaptação para o G_3A (cont.).

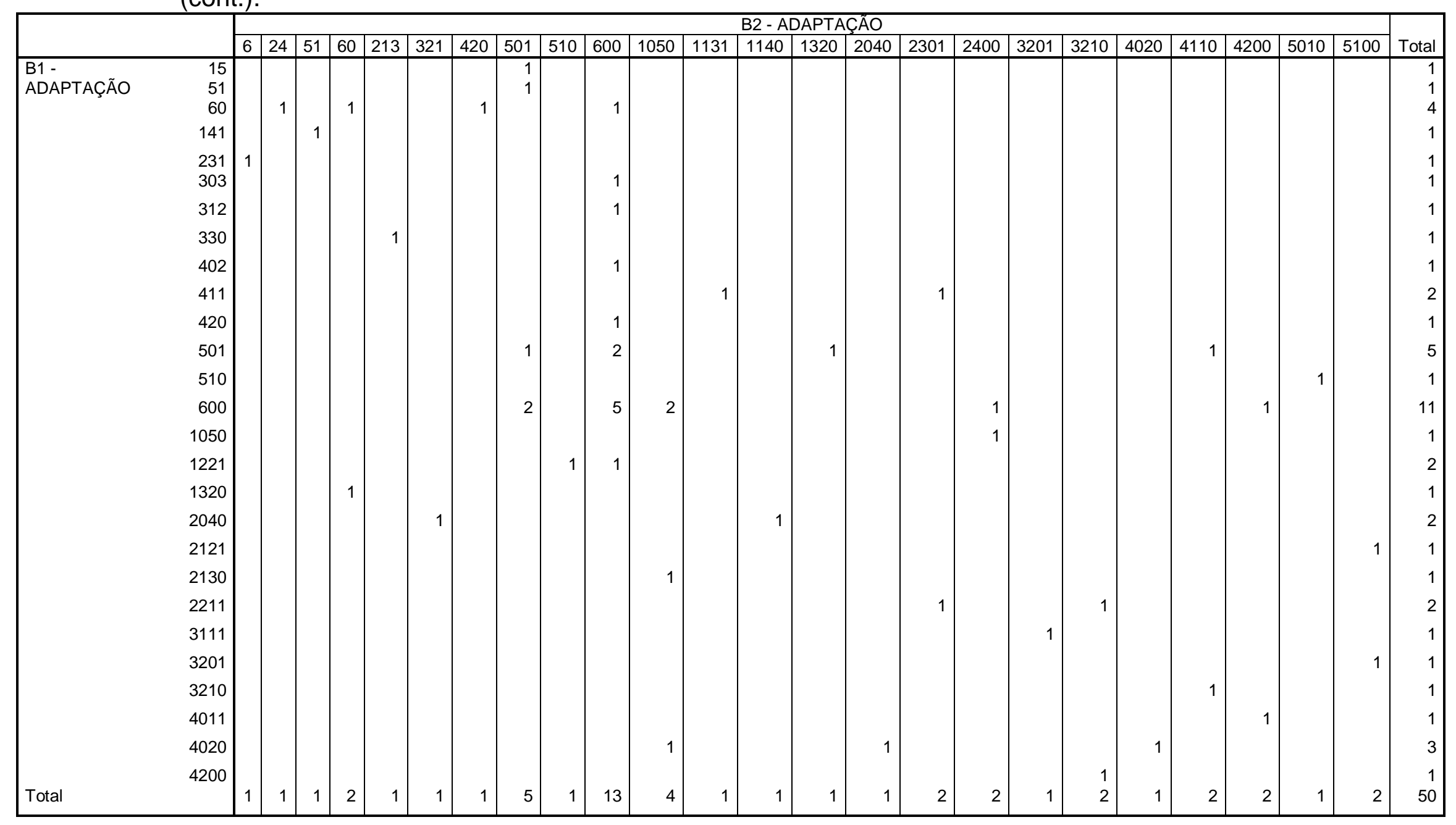


ANEXO III - Tabulação cruzada entre blocos adjacentes do DCM nas fases de estabilização e adaptação para o G_3A (cont.).

\begin{tabular}{|c|c|c|c|c|c|c|c|c|c|c|c|c|c|c|c|c|c|c|c|c|c|c|c|c|}
\hline & & & & & & & & & & & & B3 - & ADAP & TAÇÃ & & & & & & & & & & \\
\hline & & 51 & 222 & 312 & 411 & 501 & 510 & 600 & 1032 & 1041 & 1050 & 1230 & 2040 & 2130 & 2211 & 2220 & 2400 & 3030 & 3210 & 3300 & 4200 & 5001 & 5100 & Total \\
\hline $\begin{array}{l}\text { B2 - } \\
\text { ADAPTACÃO }\end{array}$ & 6 & & 1 & & & & & & & & & & & & & & & & & & & & & \\
\hline ADAPIAÇAO & $\begin{array}{l}24 \\
51\end{array}$ & & & & 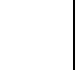 & 1 & & 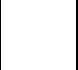 & & & & & & & & & & & & & & & & 1 \\
\hline & 60 & & & & 1 & & & & & & & & & 1 & & & & & 1 & & & & & $\begin{array}{l}1 \\
2\end{array}$ \\
\hline & 213 & & & & & & & 1 & & & & & & & & & & & & & & & & 1 \\
\hline & 321 & & & & & & & & & & & & & & & & & & & & 1 & & & 1 \\
\hline & 420 & & & & & & & & & 1 & & & & & & & & & & & & & & 1 \\
\hline & 501 & & & 1 & & & & 2 & & 1 & & & & & & & & & & & & 1 & & 5 \\
\hline & 510 & & & & & & & & & & & & 1 & & & & & & & & & & & 1 \\
\hline & 600 & & & & & 1 & 1 & 8 & & & & & & & & & 1 & & & & 1 & & 1 & 13 \\
\hline & 1050 & & & & & & & & 1 & & & & & & & & 2 & & & 1 & & & & 4 \\
\hline & 1131 & & & & & & & 1 & & & & & & & & & & & & & & & & 1 \\
\hline & 1140 & & & & & & & & & & & 1 & & & & & & & & & & & & 1 \\
\hline & 1320 & & & & & & & & & & & & & & & 1 & & & & & & & & 1 \\
\hline & 2040 & & & & & & & & & & 1 & & & & & & & & & & & & & 1 \\
\hline & 2301 & 1 & & & & & & 1 & & & & & & & & & & & & & & & & 2 \\
\hline & 2400 & & & & & & & & & & & & & & & & & 1 & & 1 & & & & 2 \\
\hline & 3201 & & & & & & & & & & & & & & & & & & & 1 & & & & 1 \\
\hline & 3210 & & & & & & & & & & & & & & 1 & & & & & & 1 & & & 2 \\
\hline & 4020 & & & & & & & & & & & & & & & 1 & & & & & & & & 1 \\
\hline & 4110 & & & & & & & & & & 1 & & & & & & & & & & 1 & & & 2 \\
\hline & 4200 & & & & & & & & & & & & & & & & & & & 1 & 1 & & & 2 \\
\hline & 5010 & & & & & & & & & & & & & & & & & & & & 1 & & & 1 \\
\hline & 5100 & & & & & & & & & & & & & & & & & & & & & & 2 & 2 \\
\hline Total & & 1 & 1 & 1 & 1 & 2 & 1 & 13 & 1 & 2 & 2 & 1 & 1 & 1 & 1 & 2 & 3 & 1 & 1 & 4 & 6 & 1 & 3 & 50 \\
\hline
\end{tabular}


ANEXO III - Tabulação cruzada entre blocos adjacentes do DCM nas fases de estabilização e adaptação para o G_3A (cont.).

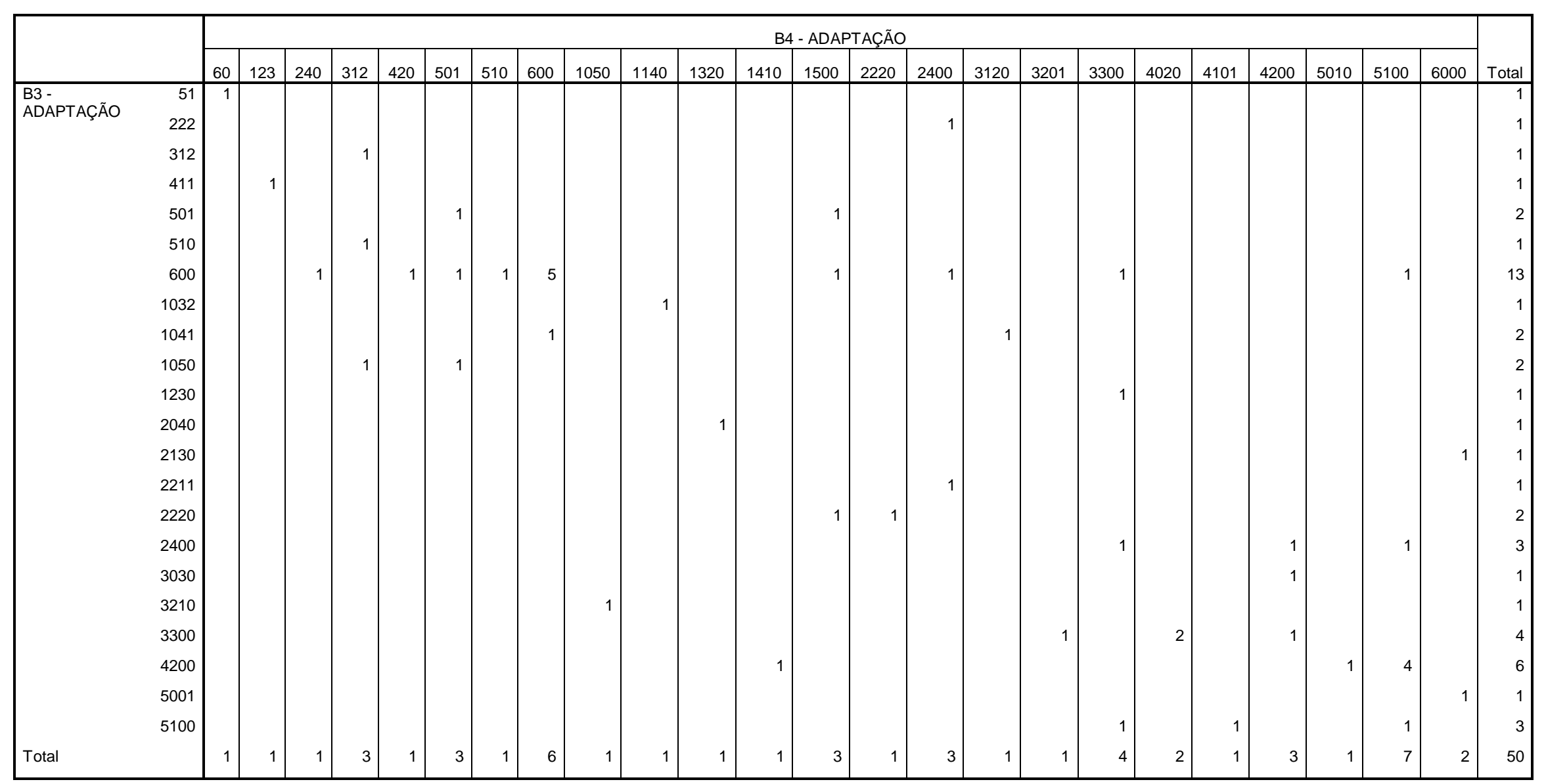


ANEXO III - Tabulação cruzada entre blocos adjacentes do DCM nas fases de estabilização e adaptação para o G_3A (cont.).

\begin{tabular}{|c|c|c|c|c|c|c|c|c|c|c|c|c|c|c|c|c|c|c|c|c|c|}
\hline & \multicolumn{20}{|c|}{ B5 - ADAPTAÇÃO } & \multirow[b]{2}{*}{ Total } \\
\hline & 60 & 123 & 600 & 1050 & 1311 & 1500 & 2040 & 2220 & 2301 & 2310 & 2400 & 3120 & 3210 & 3300 & 4020 & 4110 & 4200 & 5010 & 5100 & 6000 & \\
\hline \multirow[t]{23}{*}{ B4 - ADAPTAÇĀO } & & & & & & & & & 1 & & & & & & & & & & & & \\
\hline & & & & & & & & & & 1 & & & & & & & & & & & 1 \\
\hline & & & & & & & & & & & & & & 1 & & & & & & & 1 \\
\hline & & 1 & & & & & 1 & & 1 & & & & & & & & & & & & 3 \\
\hline & & & 1 & & & & & & & & & & & & & & & & & & 1 \\
\hline & & & 2 & & & & & 1 & & & & & & & & & & & & & 3 \\
\hline & & & & & & & & & & & 1 & & & & & & & & & & 1 \\
\hline & & & 1 & & & 2 & & & & & & 1 & & & & & 1 & 1 & & & $\epsilon$ \\
\hline & 1 & & & & & & & & & & & & & & & & & & & & 1 \\
\hline & & & & & & & & & & & & & & & 1 & & & & & & 1 \\
\hline & & & & 1 & & & & & & & & & & & & & & & & & 1 \\
\hline & & & & & & & & & & & & & & & & & & & 1 & & 1 \\
\hline & & & 1 & & & & & & & & 1 & & & & & & & & & 1 & 3 \\
\hline & & & & & & 1 & & & & & & & & & & & & & & & 1 \\
\hline & & & & & & & & & & & & & & & & & & & 2 & 1 & 3 \\
\hline & & & & & & 1 & & & & & & & & & & & & & & & 1 \\
\hline & & & & & & & & & & & & & & & & & 1 & & & & 1 \\
\hline & & & & & & & & & & & & & & & & 1 & & & 3 & & 2 \\
\hline & & & & & 1 & & & & & & 1 & & & & & & & & & & 2 \\
\hline & & & & & & & & & & & & & & & & 1 & & & & & 1 \\
\hline & & & & & & & & & & & & & & 1 & & & 1 & & 1 & & 3 \\
\hline & & & & & & & & & 1 & & & & & & & & & & & & 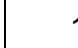 \\
\hline & & & & & & & & & & & 1 & 1 & 2 & 1 & & & 1 & & 1 & & 7 \\
\hline Total & 1 & 1 & 5 & 1 & 1 & 4 & 1 & 1 & 3 & 1 & 4 & 2 & 2 & 3 & 1 & 2 & 4 & 1 & 8 & 2 & $4 \varepsilon$ \\
\hline
\end{tabular}


ANEXO III - Tabulação cruzada entre blocos adjacentes do DCM nas fases de estabilização e adaptação para o G_3A (cont.).

\begin{tabular}{|c|c|c|c|c|}
\hline & & \multicolumn{2}{|l|}{ B6 - ADAPTAÇÃO } & \multirow[b]{2}{*}{ Total } \\
\hline & & 6000 & & \\
\hline \multirow{19}{*}{ B5 - ADAPTAÇÃO } & 60 & & 1 & 1 \\
\hline & 123 & & 1 & 1 \\
\hline & 600 & & 5 & 5 \\
\hline & 1050 & & 1 & 1 \\
\hline & 1311 & & 1 & 1 \\
\hline & 1500 & & 4 & 4 \\
\hline & 2040 & & 1 & 1 \\
\hline & 2220 & & 1 & 1 \\
\hline & 2301 & & 3 & 3 \\
\hline & 2310 & & 1 & 1 \\
\hline & 2400 & & 4 & 4 \\
\hline & 3120 & & 2 & 2 \\
\hline & 3210 & & 2 & 2 \\
\hline & 3300 & & 3 & 3 \\
\hline & 4020 & & 1 & 1 \\
\hline & 4110 & & 2 & 2 \\
\hline & 4200 & & 4 & 4 \\
\hline & 5010 & & 1 & 1 \\
\hline & 5100 & & 8 & 8 \\
\hline Total & & & 46 & 46 \\
\hline
\end{tabular}

